Portland State University

PDXScholar

Fall 11-21-2013

\title{
Facilitating Master's Student Success: A Quantitative Examination of Student Perspectives on Advising
}

Sarah Brooks Drummond Hays

Portland State University

Follow this and additional works at: https://pdxscholar.library.pdx.edu/open_access_etds

Part of the Higher Education Commons, and the Student Counseling and Personnel Services

Commons

Let us know how access to this document benefits you.

\section{Recommended Citation}

Drummond Hays, Sarah Brooks, "Facilitating Master's Student Success: A Quantitative Examination of Student Perspectives on Advising" (2013). Dissertations and Theses. Paper 1518.

https://doi.org/10.15760/etd.1502

This Dissertation is brought to you for free and open access. It has been accepted for inclusion in Dissertations and Theses by an authorized administrator of PDXScholar. Please contact us if we can make this document more accessible: pdxscholar@pdx.edu. 
Facilitating Master's Student Success:

A Quantitative Examination of Student Perspectives on Advising

by

Sarah Brooks Drummond Hays

A dissertation submitted in partial fulfillment of the requirements for the degree of

Doctor of Education

in

Educational Leadership: Postsecondary Education

Dissertation Committee:

Christine Cress, Chair

Janine Allen

Karen Haley

DeLys Ostlund

Portland State University

2013 


\begin{abstract}
Faculty advising is crucial for student success, but little is known about the specific relationship between advising and master's students' success. Given that master's student enrollment is growing and diversifying, examining the relationships between advising and success is imperative for institutional efficiency and educational excellence. This quantitative study investigated nearly 1,000 master's students' experiences with two primary types of advising — administrative and mentoring. The study looked for correlations with multiple proxies of student success (e.g., graduation, retention, institutional commitment, and GPA). As well, other potentially influential individual, educational, and organizational variables (e.g., background characteristics, peer culture, and department climate) were examined for their effect on the relationship between advising and success. Results indicate that student satisfaction with advising is correlated with success. In particular, student satisfaction with administrative advising, which communicates accurate policies and helps students form educational plans, increased student success. Student satisfaction with mentoring advising, which emphasizes individualized professional support (e.g., feedback on thesis writing) was also shown to facilitate master's student success. Recommendations highlight the importance of creating degree maps and electronic degree tracking as a form of administrative advising support for students and the importance of having nurturing multiple faculty-student contacts within the department to build collegial rapport and mentoring relationships.
\end{abstract}




\section{Acknowledgements}

I am very grateful to a number of people for making this dissertation possible including my adviser and mentor, Christine Cress, for believing in me, giving me countless opportunities to research, consult, present, and teach, and helping me become the researcher I am today; my master's adviser and mentor, Janine Allen, and her research partner, Cathleen Smith, for inspiring my research and giving me my first graduate assistantship, without which I would not have begun this journey; DeLys Ostlund for making this study possible, creating a job for me, and serving on my committee in multiple capacities; Karen Haley for supporting me through this process and sharing a passion for graduate student development; Moti Hara for teaching me quantitative analysis and changing my life; Vicki Wise for providing me with opportunities to intern and learn about assessment and for serving on my proposal committee; Margaret Everett for providing me with great opportunities to apply my knowledge at the Office of Graduate Studies; my cohort for sharing this experience; Brett McFarlane for sharing a passion for advising and student success; Tommy Van Cleave for traveling these five years with me; Maureen Reed for guiding me in this process; Daveena Tauber for helping me get unstuck and find my way; my parents for their love and support; my brother for always believing in me and talking stats; my running partner, Debbie Hall, for helping me figure it all out on the road; my dear friend, Karey Gold, for supporting me through this process; and most of all my daughters and my husband for supporting me in my work and always believing in me. 


\section{Table of Contents}

Abstract___ i

Acknowledgements___ ii

List of Tables _ vi

List of Figures__ Xiv

Chapter 1: Introduction ___ 1

The Problem __ 1

Graduate Students \& Master's Degree Students___ 2

Graduate Student Success __ 5

Advising and Master's Student Success ___ 7

Administrative Advising___ 9

Mentoring Advising _ 10

Student Success__ 13

Culture and Climate __ 14

Peer Culture _— 14

Department Culture__ 15

Department Climate __ 16

Student and Educational Characteristics__ 16

Inquiry _ 17

Chapter Summary ___ 18

Chapter 2: Review of Related Literature __ 20

Advising __ 21

Learning Paradigm Model __ 23

Administrative Advising__ 25

Informational Advising _ 25

Organizational Advising ___ 27

Mentoring Advising __ 30

Relational Advising _ 32

Educational Advising __ 36 
FACILITATING MASTER'S STUDENT SUCCESS iv

Master's Students' Characteristics __ 39

Demographically Diverse Students___ 39

Educational Characteristics___ 43

Climate and Culture __ 46

Peer Culture _ـ 46

Department Culture___ 47

Department Climate __ 49

Master's Student Success ___ 51

Graduation__ 51

Retention__ 52

Student commitment to progress _ 52

Grade Point Average__ 53

Chapter 2 Summary _ـ 53

Chapter 3: Methods__ 54

Research Questions _ 55

Study Design _ 56

Participants _ 56

Instrument _ 57

Graduate Advising __ 58

Master's Student Success Variables ___ 59

Student Characteristics _ 60

Peer Culture _ 61

Department culture __ 62

Department climate __ 62

Data Collection __ 63

Data Analysis __ 64

Logistic Regression___ 65

Factor Analysis __ 65

Linear Regression ___ 66

Limitations _ 67

Chapter 3 Summary _ 69 
FACILITATING MASTER'S STUDENT SUCCESS V V

Chapter 4: Results__ 70

Descriptive Statistics___ 71

Student and Educational Characteristics__ 71

Advising and Mentoring ___ 72

Multivariate analysis: Student characteristics and advising satisfaction $\_81$

Advising Satisfaction _ـ 84

Student Success___ 87

Culture \& Climate _ 89

Factor Analysis __ 92

Exploratory Factor Analysis ___ 93

Confirmatory Factor Analysis___ 97

Advising satisfaction and master's student enrollment and graduation ___ 99

Advising Satisfaction and Institutional Commitment___ 116

Advising satisfaction and Program Commitment____ 134

Advising Satisfaction and Degree Commitment____ 152

Chapter 5: Implications___ 172

Recommendations__ 175

Create interactive, online degree maps and education plans __ 176

Transparent adviser matching process ___ 177

Offer group advising or multiple orientations ___ 177

Multiple faculty___ 178

Mentors _ 179

Future Research _ 180

Conclusion _ـ 181

References__ 183

Appendix A: Graduate Student Advising Survey: Master's Student Version ___ 196

Appendix B: Advising Survey Letters __ 205

First Follow-Up Email __ 206

Second Follow-up Email___ 207

Appendix C: Results of regression analyses with student characteristics predicting student satisfaction with advising 209 


\section{List of Tables}

Table 1: Graduate Advising Variables 59

Table 2: Student Success Variables 60

Table 3: Student Characteristics 60

Table 4: Peer Culture 61

Table 5: Department Culture __ 62

Table 6: Department Climate ___ 62

Table 7: Student Demographics Gender ___ 71

Table 8: Student Demographics Race/Ethnicity ___ 71

Table 9: Student Demographics Age __ 71

Table 10: Enrollment 2012-2013

Table 11: Student Meetings with Adviser

Table 12: Methods of Contact with Adviser___ 74

Table 13: Mentor

Table 14: Primary Source of Information

Table 15: Advising Responses __ 78

Table 16: Results of regression analyses with student characteristics predicting student satisfaction with advising variables (Full tables available in Appendix C) _ 86

Table 17: Student Success Responses___ 89

Table 18: Peer Culture Responses __ 90

Table 19: Department Culture Responses___ 91

Table 20: Department Climate Responses ___ 91 
Table 21: Total Variance Explained 93

Table 22: Exploratory Factor Analysis with five factors in a rotated factor matrix ${ }^{\mathrm{a}}$ 96

Table 23: Exploratory Factor Analysis with three factors in a rotated factor matrix ${ }^{\mathrm{a}} \_97$

Table 24: CFA Standardized Regression Weights 98

Table 25: Results of regression analysis of student satisfaction with accurate information predicting student graduate GPA 100

Table 26: Results of regression analysis with student satisfaction with policies and procedures predicting student graduate GPA 101

Table 27: Results of regression analysis with student satisfaction with adviser help with educational plan predicting student graduate GPA 102

Table 28: Results of regression analysis with student satisfaction with adviser accessibility predicting student graduate GPA 103

Table 29: Results of regression analysis with student satisfaction with adviser time predicting student graduate GPA 104

Table 30: Results of regression analysis with student satisfaction with how advisers are assigned predicting student graduate GPA 105

Table 31: Results of regression analysis with student satisfaction with adviser wish predicting student graduate GPA 106

Table 32: Results of regression analysis with student satisfaction good feedback with predicting student graduate GPA

Table 33: Results of regression analysis with student satisfaction with faculty collaboration with predicting student graduate GPA 
Table 34: Results of regression analysis with student satisfaction with faculty networking with predicting student graduate GPA 108

Table 35: Results of regression analysis of student satisfaction with referral to academic support with predicting student graduate GPA 110

Table 36: Results of regression analysis with student satisfaction with referral to nonacademic support with predicting student graduate GPA

Table 37: Results of regression analysis with student satisfaction with help identifying funding with predicting student graduate GPA

Table 38: Results of regression analysis with student satisfaction with encouraging students to make progress on their thesis with predicting student graduate GPA

Table 39: Results of regression analysis with student satisfaction with their adviser knowing them as an individual with predicting student graduate GPA

Table 40: Results of regression analysis with student satisfaction with their adviser caring about their academic progress with predicting student graduate GPA 115

Table 41: Results of regression analysis with student satisfaction with accurate information predicting student institutional commitment

Table 42: Results of regression analysis with student satisfaction with policies and procedures predicting student institutional commitment

Table 43: Results of regression analysis with student satisfaction with help creating an educational plan predicting student institutional commitment

Table 44: Results of regression analysis with student satisfaction with adviser accessibility predicting student institutional commitment 
Table 45: Results of regression analysis with student satisfaction with adviser time predicting student institutional commitment

Table 46: Results of regression analysis with student satisfaction with adviser assigned predicting student institutional commitment

Table 47: Results of regression analysis with student satisfaction with adviser wish predicting student institutional commitment

Table 48: Results of regression analysis with student satisfaction good feedback with predicting student institutional commitment

Table 49: Results of regression analysis with student satisfaction with faculty collaboration with predicting student institutional commitment 126

Table 50: Results of regression analysis with student satisfaction with faculty networking with predicting student institutional commitment

Table 51: Results of regression analysis with student satisfaction with referral to academic support with predicting student institutional commitment

Table 52: Results of regression analysis with student satisfaction with referral to nonacademic support with predicting student institutional commitment

Table 53: Results of regression analysis with student satisfaction with help identifying funding with predicting student institutional commitment 130

Table 54: Results of regression analysis with student satisfaction with encouraging students to make progress on their thesis with predicting student institutional commitment 
Table 55: Results of regression analysis with student satisfaction with knowing you as an individual with predicting student institutional commitment 132

Table 56: Results of regression analysis with student satisfaction with caring about your academic progress with predicting student institutional commitment

Table 57: Results of regression analysis with student satisfaction with accurate information predicting student program commitment

Table 58: Results of regression analysis with student satisfaction with policies and procedures predicting student program commitment

Table 59: Results of regression analysis with student satisfaction with help creating an educational plan predicting student program commitment 137

Table 60: Results of regression analysis with student satisfaction with adviser accessibility predicting student program commitment

Table 61: Results of regression analysis with student satisfaction with adviser time predicting student program commitment

Table 62: Results of regression analysis with student satisfaction with adviser assigned predicting student program commitment 140

Table 63: Results of regression analysis with student satisfaction with adviser wish predicting student program commitment 141

Table 64: Results of regression analysis with student satisfaction good feedback with predicting student program commitment 142

Table 65: Results of regression analysis with student satisfaction with faculty collaboration with predicting student program commitment 143 
Table 66: Results of regression analysis with student satisfaction with faculty networking with predicting student program commitment 144

Table 67: Results of regression analysis with student satisfaction with referral to academic support with predicting student program commitment 145

Table 68: Results of regression analysis with student satisfaction with referral to nonacademic support with predicting student program commitment

Table 69: Results of regression analysis with student satisfaction with help identifying funding with predicting student program commitment

Table 70: Results of regression analysis with student satisfaction with encouraging students to make progress on their thesis with predicting student program commitment

Table 71: Results of regression analysis with student satisfaction with knowing you as an individual with predicting student program commitment 150

Table 72: Results of regression analysis with student satisfaction with caring about your academic progress with predicting student program commitment 151

Table 73: Results of regression analysis with student satisfaction with accurate information predicting student degree commitment 152

Table 74: Results of regression analysis with student satisfaction with policies and procedures predicting student degree commitment

Table 75: Results of regression analysis with student satisfaction with help creating an educational plan predicting student degree commitment 
Table 76: Results of regression analysis with student satisfaction with adviser accessibility predicting student degree commitment

Table 77: Results of regression analysis with student satisfaction with adviser time predicting student degree commitment

Table 78: Results of regression analysis with student satisfaction with adviser assigned predicting student degree commitment

Table 79: Results of regression analysis with student satisfaction with adviser wish predicting student degree commitment

Table 80: Results of regression analysis with student satisfaction good feedback with predicting student degree commitment

Table 81: Results of regression analysis with student satisfaction with faculty collaboration with predicting student degree commitment 161

Table 82: Results of regression analysis with student satisfaction with faculty networking with predicting student degree commitment 162

Table 83: Results of regression analysis with student satisfaction with referral to academic support with predicting student degree commitment

Table 84: Results of regression analysis with student satisfaction with referral to nonacademic support with predicting student degree commitment

Table 85: Results of regression analysis with student satisfaction with help identifying funding with predicting student degree commitment 165

Table 86: Results of regression analysis with student satisfaction with encouraging students to make progress on their thesis with predicting student degree commitment 166 
Table 87: Results of regression analysis with student satisfaction with knowing you as an individual with predicting student degree commitment 167

Table 88: Results of regression analysis with student satisfaction with caring about your academic progress with predicting student degree commitment 168

Table 89: Results of regression analysis with student satisfaction with advising predicting GPA, institutional commitment, program commitment, and degree commitment summary 


\section{List of Figures}

Figure 1: Scree Plot 


\section{Chapter 1: Introduction}

\section{The Problem}

Graduate education matters. It provides the advanced skills, knowledge, and dispositions necessary for graduates to compete and problem solve in the global economy (Gardner \& Mendoza, 2010; Wendler, Bridgeman, et al. 2012). It produces the professionals and scholars of tomorrow. Furthermore, graduate degrees now form the necessary credential for numerous professions, replacing the bachelor's degree (Glazer, 1986; Wendler et al., 2010). Graduate degrees can aid in professional placement and advancement, and may lead to higher salaries (Stewart, 2010).

The increasingly important role that the master's degree plays in preparing professionals to address complex economic and social concerns of our country has led larger numbers of students to graduate programs of study. However, very little research exists to help guide graduate school faculty and administrators to facilitate the success of the diverse and growing numbers of students who are pursuing master's degrees. Indeed, students enrolled in master's degree programs seem to have been invisible to education researchers and overshadowed by research on undergraduates and doctoral students. Thus, those concerned with helping master's degree students- hereafter referred to as master's students - complete their programs in a timely manner are left attempting to extrapolate research findings on undergraduate and doctoral students to inform practices to serve master's students. To address this gap in the literature needed to inform practice, 
it is important for educational researchers to examine the experiences of master's students and how they relate to student success.

\section{Graduate Students \& Master’s Degree Students}

While all graduate populations are increasing and diversifying, the population of master's students is growing most rapidly (Snyder, Dillow, \& Hoffman, 2009; Wendler et al., 2010). Of the half million students who earned master's degrees in 2010 , racial and ethnic diversity increased by $47 \%$ compared to a decade ago (American Council on Education, 2008). Over half a million students $(693,025)$ earned master's degrees in 2009-2010 (Snyder \& Dillow, 2012). Master's students make up 75\% of graduate student enrollment and 90\% of graduate degrees awarded (Council of Graduate Schools, 2009). According to Glazer-Raymo (2005), “three times as many institutions award master's degrees as doctorates" (p. vii). Despite this increasing and diversifying presence on university campuses, little is known about master's student experiences (Conrad, Duren, \& Haworth, 1998). Because there is a lack of research specifically on master's students, the literature review for this dissertation draws from research collected on doctoral students and sometimes mixed studies that include both master's and doctoral students together in order to define changes in graduate education enrollment and degree attainment. When graduate degree numbers are reported, these numbers may include all post-baccalaureate students including master's degree, certificate, and doctoral students. When possible, master's students' data will be isolated and reported.

Generally, the overall increase in graduate enrollment has been by non-traditional students including women and racial and ethnic minorities (Stewart, 2010). Students 
attending graduate school are more diverse than ever (Allum, Bell, \& Sowell, 2012; Austin, 2002; Glazer-Raymo, 2005; National Center for Education Statistics, 2010; Snyder \& Dillow, 2011). This diversity extends beyond gender and race (Council of Graduate Schools, 2009) to include students who are older, may be married or in a domestic partnership, may have children, and/or may attend school part-time (Gardner \& Gopaul, 2012; Gardner, 2008a). The factors that contribute to the relative success or failure of students in graduate school may vary substantially for diverse students. Historically, methods of supporting student success have been based upon research of traditional-aged students in undergraduate programs (Astin, 1984; Kuh, Kinzie, Schuh, Whitt, \& Associates, 2005; Pascarella \& Terenzini, 2005; \& Tinto, 1993). Yet, traditional students are not the only ones being served by our higher education institutions today. Therefore, there is a need for research on student success that takes into account the diversity of the students pursuing degrees today.

While researchers delve into undergraduate student success (Astin, 1984, Kuh, Kinzie, Schuh, Whitt, \& Associates, 2005, Pascarella \& Terenzini, 2005, \& Tinto, 1993), and others have brought research on doctoral advising to the forefront (Barnes, Williams, \& Stassen 2011; Golde, 1998, 2000, 2005; Gardner, 2008; Gardner \& Mendoza, 2010) master's students have rarely been studied by educational researchers (Girves \& Wemmerus, 1998). Existing national data collected on master's students does not track time-to-degree nor does it track how many students leave without completing their degree. While the National Center for Education Statistics (2010) tracks how many students enroll in master's programs and how many students earn master's degrees each 
year, there is no national effort to track master's students from enrollment to the end of their master's degree efforts, whether they depart without a degree or graduate. The lack of research on the master's student experience may be due to a number of factors including the positive growth in enrollment over the last decade, the diversity of the master's degree in both subject matter and degree requirements, and expectations that master's students can transfer their undergraduate knowledge about how to be successful to their graduate programs. The overall increase in graduate enrollment may send the message to administrators and researchers alike that all is well with master's education and that it is not a critical area for research. However, the number of students who depart before completing their degrees is not known.

Another potential reason for the lack of aggregate research into master's degree students could be the diversity of the degrees awarded. In 2004, there were master's degrees conferred in 29 fields and 426 subfields according to NCES (Glazer-Raymo, 2005). The number of fields and subfields within master's degrees continues to grow, making it more difficult to compare master's student experiences across disciplines. Additionally, master's programs vary in purpose, length, and capstone experiences (e.g., comprehensive exams, culminating projects, and theses) (Glazer-Raymo, 2005). In fact, the master's degree has three very different objectives: it serves first as a professional credential and/or terminal degree in some disciplines; second, as a pathway to the doctorate in others; and third as a "consolation prize" for students who on the pathway to the doctorate fail or opt out (Glazer-Raymo, 2005, p. 1). The multiple purposes for 
pursuing the degree along with the diversity in programs makes comparisons more challenging.

Therefore, due to gaps in research on master's students, gaps in national data collection, as well as the various pathways to the master's degrees, much has yet to be discovered about facilitating success for master's students. In order to develop a greater understanding of master's student success and begin to identify possible factors which might lead to that success, it is necessary and important to extrapolate from the bodies of research available. These studies focus on undergraduates, doctoral students, and graduate students as a post-baccalaureate population and may not distinguish master's students as a unique population.

\section{Graduate Student Success}

Obviously, graduate student degree completion is the goal of faculty, staff, and students. Students who persist in their programs continue to progress toward degree completion and professional success, which benefits them, their programs, and their communities. In contrast, if students depart before completing their degrees they may experience regret, disappointment, or a sense of loss (Golde, 2000). In addition, there may be negative impacts in the form of financial and time investment loss for students, faculty, and institutions (Gardner, 2008a; Lovitts, 2001). Students have invested funds, time, and energy into their programs of study. Faculty members have invested time into training and advising students. And institutions have devoted faculty and financial resources toward graduate student development. The possible return on investment is not garnered if students leave before completing their degrees. Therefore, considering the 
need for skilled labor (Stewart, 2010) and faced with the potential loss when students depart graduate programs, it is clear that helping students finish their graduate degree is an important goal. In order to help students graduate, it would be helpful to know why some students depart without completing their degrees.

Research on graduate student departure focuses almost exclusively on doctoral students, but this research also has implications for master's students. Studies of doctoral student departure (Golde, 1998; Lovitts, 2001; Nettles \& Millet, 2006; Tinto, 1993) reveal the multiple factors that may be at work when students do not succeed. These factors include academic ability (Lovitts, 2001; Nettles \& Millet, 2006); financial reasons including funding (Golde, 1998; Lovitts, 2001; Nettles \& Millet, 2006; Tinto, 1993); personal circumstances or external responsibilities to work and family (Golde, 1998; Lovitts, 2001; Nettles \& Millet, 2006; Sallee, 2010); peer and faculty relationships (Golde, 1998; Nettles \& Millet, 2006); and the doctoral student experience, including expectations and coursework, adviser and committee challenges, dissertation-related issues, and department characteristics (Nettles \& Millet, 2006). Finally, students leave for a variety of reasons including the program, discipline, or if the career outcome is different from what they expected (Golde, 1998; Lovitts, 2001).

Efforts to understand why students do not succeed have led researchers to consider the institutional responsibility in student departure. Historically, faculty and administrators have attributed student attrition to individual students' lack of talent or ability (Council of Graduate Schools, 2009; Gardner, 2008a; Lovitts, 2001; Wendler et al., 2010). Today, many scholars question the role of graduate institutions in student 
attrition noting that most students entering graduate programs probably have the ability to complete their chosen degree, but high numbers fail to achieve that goal (Council of Graduate Schools, 2009; Golde, 2010; Lovitts, 2001; Nettles \& Millet, 2006; Wendler et al., 2010). Indeed, research indicates that advising may be a strategy for addressing the factors affecting degree completion. Research indicates that graduate students are aware of the necessity of advising for their success. In a study of doctoral departers, the majority listed issues with their adviser as a reason for leaving their program (Golde, 2000). Doctoral students' recommendations for improving graduate school include regular advising (Austin, 2002). Students want to know "how to negotiate their way through the challenges of graduate education, the expectations and criteria that define student success in academe" (Austin, 2002, p. 111). While regular advising may not address all of the reasons that graduate students leave, it is one way for institutions to reach out to students and may be a way to mitigate student departure.

\section{Advising and Master's Student Success}

Overwhelmingly, scholars agree that advising is important to student success (Barnes \& Austin, 2009; Barnes, Williams, \& Archer, 2010; Barnes, Williams, \& Stassen, 2011; Lovitts, 2001; Schlosser \& Gelso, 2001; Schlosser, Lyons, Talleyrand, Kim, \& Johnson, 2010a; Tinto, 1993). Advising is critical for graduate student success. Lovitts and Nelson (2000) find the "single most important factor in student decisions to continue or withdraw [from graduate school] is the relationship with a faculty adviser" (p. 50). Graduate students with "positive advising relationships excel and feel more satisfied with their programs" (Sallee, 2010, p.145). Girves \& Wemmerus (1998) found that for 
master's students, their perceptions of their advisers' concern as well as quality and utility were correlated with their academic success (p. 184). Finally, "undergirding all of these conceptualizations of success is the involvement of faculty members...they serve as teachers, advisors, committee members, mentors, role models, and future colleagues" (Gardner, 2009, p. 386).

Graduate advisers can be sources of reliable information about degree requirements and policies and procedures. The can be advocates, role models, department and occupational socializers, as well as motivators for stalled students who are not making progress in their program (Barnes \& Austin, 2009). One university encourages students to seek advising as a part of university-wide policy: "all graduate students, especially those in a conditional admission status, are expected to keep in close communication with their departments and to avail themselves of departmental advising" (Portland State University, 2011, p.66). While advising is universally praised in the literature as supporting student success and is touted as a means of promoting student progress toward degree completion, it is not clear what about the advising experience specifically promotes student success.

Advising can be divided into two primary categories. The first is the official institutionally mandated advising, which includes the faculty adviser providing information about degree requirements, having office hours, and being accessible to students, referred to in this inquiry as administrative advising. The second is mentoring advising which focuses on the advising relationship and students educational development. 
As such, this dissertation examines the existing research on advising undergraduate and doctoral students to define the possible advising functions that are relevant to master's students. Faculty advisers have "the greatest responsibility for helping guide the advisee through the graduate program" (Schlosser \& Gelso, 2001, p. 158). These functions relate to two larger dimensions of advising: administrative advising, which is the expected institutionalized role of advising including signing paperwork and spending time with students, and mentoring where senior faculty members "shepherd" their advisees through the graduate process (Nettles \& Millet, 2006, p. 98).

\section{Administrative Advising}

Administrative advising covers the institutionalized aspects of advising and has two parts: informational advising and organizational advising. Informational advising includes providing accurate information and knowledge about how to navigate policies and procedures (Smith \& Allen, 2006). Additionally, it includes help with forming an education plan. Informational advising is critical for students because advising errors can lead students to take the wrong course and to potentially delay graduation or pay for additional coursework. Informational advising often comes from faculty advisers, but may be supplemented by department handbooks, websites, and office staff. While informational advising provides the necessary information for students to be successful, there are organizational aspects of administrative advising as well.

Organizational advising includes faculty being accessible to meet with students (Barnes \& Austin, 2009). Advising is often one part of faculty members' workload and is 
one that is often not rewarded in promotion and tenure (Fairweather, 1993). It can be challenging for students and faculty to find time to meet. Furthermore, with growing numbers of non-traditional students attending graduate school part-time, commuting to campus, and juggling work and family, it may be difficult for students to meet with faculty during office hours on-campus. Adviser match is critical for student success, so another important aspect of Organizational advising is the method for matching students with advisers. The adviser/advisee match may occur before a student begins graduate work or it may occur during their graduate program. Programs may involve students in adviser selection (Nelson \& Lovitts, 2001) or have a process for switching advisers if students and advisers find that they are mismatched. Both aspects of administrative advising — informational and organizational—are important factors for student navigation of college process and procedures. However, students' professional development is more likely to be facilitated through a deeper relationship known as mentoring.

\section{Mentoring Advising}

While administrative advising focuses on the information students need and the organizational aspects of advising, the primary goal of mentoring advising is to promote student development. Crookston (1994) notes that in prescriptive advising, which is similar to administrative advising, students are given information about course selection, but their interpersonal development is not addressed. However, in what Crookston refers to as developmental advising student growth is critical:

developmental counseling or advising is concerned not only with a specific personal or vocational decision but also with facilitating the student's rational 
processes, environmental and interpersonal interactions, behavioral awareness, and problem-solving, decision-making, and evaluation skills (Crookston, 1994, p.5).

In developmental advising, the student-adviser relationship is significant: "the nature of the relationship between the academic advisor and the student is of critical importance" (Crookston, 1994, p. 6) because this development cannot happen in a relationship where the student is afraid or voiceless. Crookston (1994) notes that in prescriptive advising because of "the higher status of the advisor in the academic hierarchy and deference to his superior knowledge and status...the relationship is often based on interpersonal games, role expectations, strategies, and, consequently, low trust in the relationship itself' (p. 8). This less-than-ideal power dynamic impacts the student's ability to be open and share information leading to a relationship that is "more likely to be formal and guarded" (p. 8). In contrast, developmental advising and the relational aspects of advising are included in mentoring advising.

The mentoring advising relationship is significant for doctoral student progression toward degree completion (Golde, 2000). One function of mentoring advising is that the adviser knows the advisee as an individual (Smith \& Allen, 2006), cares about his/her academic progress (Barnes et al., 2010), refers him/her to resources to address any academic and non-academic problems s/he might encounter (Smith \& Allen, 2006), and helps him/her identify funding sources (Henderson \& Stassen, 2007). Graduate students with poor advising relationships, which lack mentoring, will usually suffer attrition and career consequences (Girves \& Wemmerus, 1998; Golde, 2005). Additionally, doctoral 
students with a close advising relationship will have a shorter time to degree (Barnes \& Austin, 2009), demonstrating the significance of adviser support in doctoral student progress. As well, part of the mentoring relationship is knowing students well enough to refer them to academic and non-academic support services, and helping them find funding, if needed.

Additionally, mentoring advising includes functions such as the advisers' role in helping a master's student develop professionally and academically. Some examples of how advisers can mentor students in their academic development are giving good feedback on academic work and when needed, encouraging students to make progress on their theses. Advisers can mentor professional development by collaborating with students to guide them through the process of presenting at a conference or writing a publication, and helping students network in their field. Barnes et al. (2010) refer to this form of advising as socializing, which "aids students in extending professional networks and learning the habit of the mind for their discipline as well as encourages professional development" (p. 39).

While one would expect all master's students to have an adviser and receive administrative advising, it is not probable that all students will find a mentor and receive mentoring advising. Reasonably, a student can expect that their adviser will provide accurate information, information about policies and procedures, help forming an educational plan, be accessible, and spend some time with them. Additionally, students may know the way that advisers are matched to advisees either before students are accepted into their program, after they are accepted into their program, or through a 
process in which students actively participate. Transparency in the adviser match process may mitigate student desire for another adviser in their program or department. As such, students may find a mentor in their assigned adviser or they may seek out another individual to serve as a mentor if their assigned adviser simply focuses on administrative advising. In chapter two more literature will be explored regarding administrative and mentoring advising. Both of these dimensions are intended to support student success, which is examined next.

\section{Student Success}

Master's student success can be defined many ways including graduation, licensure, employment, or mastery in a field. For the purposes of this dissertation, graduation will be the primary measure of student success. Graduation represents students earning the necessary credits for their degree and passing the program-specific milestones.

The second and third measures of student success will be the alternate ways to characterize student effort toward graduation, namely retention and Grade Point Average. Retention, or reenrollment, is a measure of student success prior to graduation. Grade Point Average, GPA, represents academic achievement toward graduation. Finally, a fourth conceptualization of student success is commitment. Institutional commitment is students' belief that they selected the right institution, program commitment is students' belief that they chose the program that will teach them the skills they need to advance professionally, and degree commitment is students' belief that their degree will help them advance professionally. Each of these three aspects - institutional, program, and degree 
commitment — create a cumulative sense of students' personal commitment toward success. Thus, four dimensions of students' success — graduation, retention, GPA, and commitment — will be examined in relationship to aspects of advising. However, the relationship between advising and student success is influenced by a number of additional organizational and individual variables. Each of these variables will be briefly highlighted in order to better understand the context in which advising and student success takes place.

\section{Culture and Climate}

While many researchers agree that quality advising is critical for student success, there are other factors that can influence student retention and success. Tinto (1993) notes the significance of the department culture and climate in doctoral student retention, finding that academic integration and social integration are entwined at the graduate level because students are so enmeshed in their departments. As highly intensive education encounters, the graduate experience does not occur in isolation. Rather, departments, faculty, and peers have important influences on graduate student success. Therefore, examining more closely the potential roles of these variables is warranted.

\section{Peer Culture}

Peers play an important role in the master's student experience. Students generally have more access to peers than to faculty (Gardner, 2008b; Sallee, 2011; Weidman \& Stein, 2003). The literature suggests that students may rely upon peers for information (Austin, 2002) and social support (Austin, 2002; Gardner, 2008b; Golde, 1998; Lovitts, 2001; Weidman \& Stein, 2003). The peer culture may be collaborative and 
sharing with more advanced students mentoring new students (Gardner \& Barnes, 2007). Students may form friendships that support them through their master's programs. Conversely, peer cultures can promote alienation and competition. Student who do not fit the mold of the traditional student may feel a sense of alienation from their peers (Gardner, 2008a). This competitiveness can challenge students intellectually, but it can also alienate students. As such, peer culture is a variable to take into account when considering graduate student success. As well, peer culture exists within the academic boundaries of the programmatic department and its culture and climate. These variables are briefly reviewed next.

\section{Department Culture}

Graduate students, because of their specialized programs, are often more connected with their departments rather than the university at large (Tinto, 1993). These connections to the department may impact the way master's students experience advising. One key finding of Bair and Haworth's (1993) meta-synthesis of doctoral student persistence is that department culture affects persistence. Department culture is described as the "perceptions, attitudes and expectations that define the institution and it members" (Hurtado, Milem, Clayton-Pedersen, \& Allen, 1999, p. 5). Students are socialized to these norms and values through interactions with faculty, peers, and the environment (Bair \& Haworth, 1993; Weidman \& Stein, 2003). Two significant aspects of department culture that impact master's students' success are students' sense of faculty accessibility and the students' sense of fit or belonging. While closely related concepts, department culture and climate are distinguished here in order to make the point that culture refers to the 
norms and values of the department from a "power neutral" perspective. In contrast, department climate includes "the nature and distribution of power and authority" and "the degree of consensus and conflict" (Rosen \& Bates, 1967, p. 72) within the department as felt by under-represented groups. Both aspects are critical influences that can affect the student-adviser relationship, especially due to power relationships.

\section{Department Climate}

Department climate is defined as department members' 'attitudes, perceptions, behaviors, and expectations around issues of race, ethnicity, and diversity" (Hurtado, Griffin, Arellano, \& Cuellar, 2008, p. 205). The definition differs from department culture because it specifically acknowledges issues of power and privilege. There may be differential outcomes regarding diverse students' experience of belonging or fit within the department and "diverse views on the environment [may] emerge" (Hurtado et al., 1999, p. 5). In fact, research shows that non-traditional students may not feel they "fit the mold" of graduate school, which may put them at further risk for attrition (Gardner, 2008a). Thus, while not all inclusive, key organizational variables that can impact student success include peer culture, department culture and climate. However, just as importantly, student differentiations interact with these variables and need to be considered.

\section{Student and Educational Characteristics}

While faculty advising is believed to be critical to graduate student success, student and educational characteristics may also impact the interaction of students and faculty advisers. Student characteristics include gender, race/ethnicity, and age. As 
mentioned early, students entering master's programs today are likely to be quite diverse, and their unique characteristics may impact the way they experience graduate school including advisers and peers. Educational characteristics include enrollment status, cohort participation, thesis writing, and characteristics of student advising relationships. The way that students receive advising may impact their success and satisfaction with advising.

\section{Inquiry}

Quality or good advising is a difficult concept to capture, and it seems obvious that poor advising does not promote student success. Alternately, effective advising seems to facilitate student graduation, GPA, retention, and commitment. Still, little is known regarding master's student success even as graduate enrollment and diversity have increased significantly. Moreover, the challenges of today's economy practically make it a necessity to pursue advanced degrees in order to be competitive. Therefore, it is critical to examine the role that faculty advising has on master's student success and the interactive influences of organizational and individual variables on these relationships.

As such, the purpose of this inquiry is to fill the literature void by identifying dimensions of quality advising that promote student success. The intent of the research is to uncover programs, processes, and practices that support master's student professional and academic success relating to retention, GPA, and graduation. Such discovery has potentially wide applications for colleges across the country seeking to facilitate the talents of its master's students. 
Therefore, using a quantitative design methodology — fully described in chapter

three-this study examines various advising functions and their relationship to conceptualizations of student success. As will be fully explicated in the later chapters, since students' perceptions of advising are essentially student satisfaction with such relationships student advising satisfaction is the primary variable driving the study. Thus the primary research questions include

1. Do student and educational characteristics impact master's student satisfaction with advising?

2. Does student satisfaction with advising influence master's student success?

Peer culture, department culture and climate are included to limit the influence of these variables in measuring the connection between master's students' experiences with advising and success.

\section{Chapter Summary}

Master's students are important for the United States' continued economic success, and degree attainment is critical to master's students for their personal and professional fulfillment. Despite the benefits to master's degree attainment, researchers have not adequately addressed the specific needs and challenges of master's education. Existing studies of doctoral and graduate education provide the basis for beginning to explore master's student advising experiences and success. Among other definitions, master's student success can be measured as graduation and progress toward graduation. 
In short, advising is critical to student success. Chapter two more fully investigates the research on advising, student success, and graduate culture and climate, all of which form the foundation for this inquiry. Chapter three will explain the research, questions, methodological design, and analysis in detail. Chapter four reports the data findings in light of the research questions and methodology. Finally, chapter five offers recommendations for college faculty and administrators. 


\section{Chapter 2: Review of Related Literature}

Institutions and faculty have the opportunity to facilitate master's student success through advising. Scholars have found advising to be critical for undergraduate (Habley, 1981) and doctoral student success (Nelson \& Lovitts, 2001; Schlosser, Knox, Moskovitz, \& Hill, 2003; Tinto, 1993; Zhao, Golde, \& McCormick, 2007), especially where diverse and non-traditional students are concerned (Gardner \& Gopaul, 2012; Gardner, 2008a; Schlosser, Talleyrand, Lyons, Kim, \& Johnson, 2010). Given that little literature on master's student success exists, literature on undergraduate and doctoral student success will be reviewed as the framework for this inquiry on master's students. Specifically, this literature is used to identify the most salient advising functions for master's student advising experiences. Notably, the researcher found that these functions fit into two overlapping dimensions of advising identified by Nettles and Millett (2006): administrative advising and mentoring advising. Within these two overarching dimensions, advising can be broken into two functions. Administrative advising divides into the functions of informational and organizational advising. Mentoring advising divides into educational and relational advising.

The following literature review will explore each advising function and the research from which it was drawn. Next, master's student characteristics are explored including race/ethnicity, gender, age, and part-time graduate student status; and educational characteristics including cohorts, thesis writing, mentors, multiple faculty and meeting often with advisers are explored regarding how these characteristics influence student experiences of advising. Following, issues of culture and climate are discussed, 
recognizing that the graduate experience is embedded in the department and that students are both academically and socially integrated in the department in graduate school (Tinto, 1993). Lastly, literature on student success and how it relates to advising is reviewed.

\section{Advising}

Literature on advising defines it as an official faculty role where advisers inform, guide, mentor, and supervise (Nettles \& Millet, 2006). This role can be practiced in differing ways. The review that follows will examine approaches to undergraduate advising including administrative, prescriptive, and mentoring, developmental, advising, and the newly emerging learning paradigm approach to advising.

Winston and Sandor (1984) equate prescriptive advising with the doling out of information and solutions like doctors who write prescriptions to solve patients' problems. Prescriptive advising relies on a hierarchical power dynamic where the adviser tells the advisee what to do and solves his/her problem. With prescriptive advising, the “adviser may remain relatively uninvolved, if not aloof” (Crookston, 1994, p. 6). While this form of advising may be quick and direct, it does not allow the advisee to make a personal connection with a faculty or staff member on campus or to develop important problem solving skills and self-efficacy (Winston \& Sandor, 1984).

In contrast, developmental advising provides opportunities for students to reflect, consider life goals, and problem-solve with advisers. Scholars and professional organizations have promoted developmental as the preferred method of advising at the undergraduate level. While Crookson (1994) defines prescriptive and developmental 
advising as a dichotomy, other researchers perceive of these styles of advising as a continuum (Grites \& Gordon, 2000; Winston \& Sandor, 1984).

From their literature review of 30 years of undergraduate research on advising, Smith \& Allen (2006) find that students need holistic advising that combines elements from both styles of advising. From prescriptive advising, students need accurate information and information about how to navigate the institution (Smith \& Allen, 2006). From developmental advising, students need advising that connects their academic, career, and life goals. Likewise, students need referral to academic and non-academic services, advising relationships where they are known as individuals, and to learn to share responsibility for their success (Smith \& Allen, 2006). They propose a model of advising functions that incorporates five constructs: Information, Connect, Referral, Individuation, and Shared Responsibility.

While this exhaustive list of advising functions encompasses the undergraduate experience, it may not relate as well to the graduate experience. Graduate students may not need support developing the skills of shared responsibility. Nor might they need help connecting their academic, career, and life goals around the concepts of degree choice or major choice. Generally, these three goals have been addressed by the students' selection of a graduate program and initiative in applying and being accepted into a graduate program. Additionally, graduate students do not pick courses in the same way as undergraduates. Depending upon their graduate program, master's students may have little to no choice in the sequence of their classes. Thus, additional models in the literature were examined. 


\section{Learning Paradigm Model}

An emerging advising concept is the learning paradigm model in which student development through the advising experience is re-conceptualized as learning outcomes (Hemwell \& Trachte, 1999; Kelley, 2008; Lowenstein, 2005). This paradigm shift stems from the work of Barr and Tagg (1995). This shift promotes the development of student advising competencies. It also expands the dimensions of the advising experience. Whereas prescriptive, administrative, advising prioritizes the dispensing of information, and developmental advising emphasizes student development through relationships and goal setting, the learning paradigm extends prescriptive and developmental advising by adding measurable goals for the outcome of the advising experience. The learning paradigm is beneficial as an advising delivery model because it emphasizes student gains in content and skills related to advising and connects advising to the university teaching mission. This paradigm also aligns more closely with the model of advising traditionally used in graduate school, which is briefly discussed in the NACADA recommendations below.

NACADA's guidelines define "successful graduate advising” as serving students through challenge and support in a "mutually satisfying" advising relationship through a "fully functioning advising delivery system" (McGuire, 1998, p. 1). As such, NACADA identifies mutual satisfaction as a best practice for advising. Furthermore, NACADA identifies satisfaction as a key concept for graduate student success. This correlates to Astin (1977) who stressed that student satisfaction cannot be "legitimately subordinated 
to any other educational outcome" (p. 164). Therefore understanding student satisfaction with advising and student success is a critical next step.

As well, NACADA recommends advising strategies for each sequential academic benchmark including admission, orientation, on-going advising, support services, examinations, thesis and dissertation, practicum or internship, job placement, and outcome assessment. This list points to the myriad of milestones that graduate students face: examinations, thesis and dissertation, and practicum or internship. It also shows that advising needs to address the full cycle of events from admission to assessment.

With ongoing discussions about how to deliver undergraduate advising, a graduate model of advising needs to offer a way to encompass both administrative and mentoring advising models with attention to learning outcomes and the particular milestones of a graduate education. Undergraduate models like Smith and Allen (2006) create a holistic model. But graduate student needs are different. Thus, as noted in chapter one, Nettles \& Millett (2006) defined advising as either an official role focused on information dissemination and course planning or mentoring, involving a more personal relationship that includes advice, support, and encouragement. Nettles \& Millett (2006) contend that official advising, administrative advising, and mentoring, mentoring advising, are distinct. Moreover, since the scholarship on advising master's students is so limited, the best way to extrapolate from the existing literature is to utilize such a heuristic model for organizing of the research. Furthermore, it is critical to break down the dimensions of advising in order to see which aspects of advising specifically support student success. In order to do so, this literature review is divided into sections 
discussing administrative and mentoring advising (Nettles \& Millet, 2006) and within those dimensions, four factors of advising: informational, organizational, relational, and educational advising.

\section{Administrative Advising}

Researchers refer to administrative advising as the official capacity of the adviser role. This official role includes signing paper work and giving course information (Nettles \& Millet, 2006). Administrative advising includes informational elements: providing accurate information, helping students understand policy and procedures and create an educational plan. It also includes organizational advising elements: creating good adviser matches between advisers and students, being accessible to students, and spending time with students.

\section{Informational Advising}

Researchers and practitioners agree that information is critical to advising and student success. The role of faculty is to "convey all essential information to the neophyte [graduate student] accurately and completely" (Rosen \& Bates, 1967). Informational advising requires that the professor have all the requisite knowledge to pass along. Faculty may be experts within their discipline, but that does not mean they are experts in university, department, and program policy. Thus, advising materials may be critical in informing both faculty and students. NACADA recommends that "advising materials...include up-to-date and accurate information" and that these materials highlight "program admission requirements, program and course pre-requisites, research opportunities, and available financial, personal and family support services on the 
campus and in the community" (McGuire, 1998, p. 1). Clearly, accurate information is important for students to succeed in graduate school.

Students who perceive advising as merely informational may attempt to selfadvise using department websites and handbooks. Horn and Elliot (2011) found graduate students asserted that they used other sources than their adviser for information because they thought the quality of information was better from the website, handbook, staff member, or peer, and also because they did not want to waste precious time with their adviser on informational advising. If the whole advising experience is about degree requirements, then presumably students could do their own advising. Two common institutional policies challenge this notion. First, the fact that nearly all students are assigned a faculty adviser upon entrance into graduate school. Programs and institutions understand the important role of advising in graduate student success. Secondly, programs and institutions force students interact with an adviser by requiring an adviser's signature on formal paperwork (Nettles \& Millet, 2006). These institutional requirements demonstrate the value that institutions place on the work of the faculty adviser in disseminating information, enacting policy and procedure, and helping students create an educational plan.

Research into the adviser characteristics that help students be successful finds that graduate students value helpful, supportive, accessible and caring advisers. Helpful was one of the top positive traits of faculty advisers identified by doctoral students (Barnes et al., 2010). Helpful advisers were able to transmit formal and informal rules to students (Barnes et al., 2010). In contrast, unhelpful faculty advisers transmitted "limited or 
incorrect information about formal or informal rules" (Barnes et al., 2010, p. 39). Students need accurate information in order to be successful. They also need to know policies and procedures.

There is an assumption that students can negotiate graduate programs and university policies and procedures because they have successfully graduated from a bachelor's program previously (Polson, 2003). However, this may not be the case when students are attending new universities in a new city, when they are experiencing a new department and possibly new responsibilities as a graduate student, and/or a graduate assistantship. Horn \& Elliott (2011) found in their focus groups that students hesitate to visit their advisers because they recognize that their advisers are busy and they do not want to burden them with questions about policy and procedure. Additionally, they may perceive that faculty advisers do not know formal policy and procedures. Therefore they may try to self-advise or seek out other sources of information including department resources, office managers, or peers (Horn \& Elliott, 2011). While information is critical to advising students, it is also important for advisers to be accessible and spend time with advisees. Information cannot be shared if advisers and advisees do not communicate.

\section{Organizational Advising}

While students need accurate information on policy and procedures, scholars and practitioners agree that organizational elements are critical for student success (Barnes et al., 2010; Golde, 2000). Organizational advising addresses organizational elements that impact the advising functions such as accessibility, defined as the availability of one's adviser; time, defined as the amount of time spent with your adviser; and adviser 
selection/match, defined as the way advisers and advisees are paired, which may differ by discipline and program. Accessibility is a top positive trait of faculty advisers identified by doctoral students (Barnes et al., 2010). Accessible advisers are able to provide "inperson meetings and prompt answering of advisees' questions” (Barnes et al., 2010). Accessibility leads students to feel connected to their advisers:

Because most students realize that their faculty advisors are very busy, they seem to appreciate those who will meet with them regularly or at odd times that are convenient for the student or at places that relax the power differential (e.g., the advisor's home or a coffee shop). Such faculty accommodations appear to give these students very positive feelings about their advisors and their relationships with them (Barnes et al., 2010, p. 39).

In contrast, inaccessible faculty members are unavailable to help students and meet with students, leading to negative feelings about the advising relationship (Barnes et al., 2010). Furthermore, accessibility was found to be an important advising behavior according to faculty as well (Barnes \& Austin, 2009).

While studies find that accessibility is significant for student satisfaction, time spent with one's adviser is also important for student success (Golde, 2000). "More frequent interactions with faculty help students feel as if they belong in academe" (Sallee, 2011, p. 190). It may be difficult for faculty to devote time to advising students, even though it is part of their job. Advising is a low priority in promotion and tenure for faculty at research institutions, which educate the most graduate students (Barnes \& Austin, 2009). Accessibility and time are part of the organizational aspects of advising. 
Another important organizational element is how advisers and advisees are matched and how programs and departments handle mismatched pairs. Adviser match is critical to the success of the doctoral students because of the significance of the faculty adviser to graduate student success (Girves \& Wemmerus, 1998; Golde \& Dore, 2001; Zhao et al., 2007). Moreover, adviser match is significant across disciplines (Zhao et al., 2007). It is an important issue because adviser mismatch is one reason for student departure (Golde, 1998, 2000). Therefore, it is important to create systems for "facilitating good advisor-advisee matches at the outset of graduate training" (Schlosser, Lyons, Talleyrand, Kim, \& Johnson, 2010b, p. 49). One recommendation is that doctoral students be assigned a provisional adviser, and then universities would employ a process for adviser selection such as having students interview with potential advisers (Boyle \& Boice, 1998; Nelson \& Lovitts, 2001; Schlosser, Lyons, et al., 2010b). This recommendation invites students to be part of the advising match, which may not be feasible for all programs.

Some programs admit graduate students based on the availability of faculty with shared interests to work with them. Adviser match becomes complicated when faculty members leave or students' interests change, and may be more critical in programs where faculty and students work together on research. When students find themselves mismatched because of personality clashes, changing research interests, or faculty departure, it is important that there be systems or policies in place so that students can switch advisers with "no harm" (Schlosser, Lyons, et al., 2010b, p. 49). This may necessitate the creation of an advising oversight system (Nelson \& Lovitts, 2001). 
Organizational advising identifies the structural elements that inhibit or facilitate advising. The perception of availability may be more important to student satisfaction than the actual time spent together (Barnes et al., 2010). This perception of accessibility demonstrates care and support to students. Amount of time spent with an adviser is critical to the advising process as well. Additionally, the way advisers and students are matched is significant to the advising experience, and it is important to have policies in place for mismatched students to make changes without penalty.

For some students administrative advising — informational and organizational — is all the advising they will receive. It is the official form of advising sanctioned by the university through faculty guidelines. Other students may attempt to self-advise using department handbooks and websites and traverse the university bureaucracy independently. While self-efficacy and independence are positive developmental traits, the literature shows that students with access to mentoring advising may be more satisfied with their graduate school experience and therefore, more successful (Barnes et al., 2010). Indeed, NACADA posits that student satisfaction with advising correlates to student success. This demonstrates the importance of mentoring advising, which is examined next.

\section{Mentoring Advising}

Scholars categorize advising functions in different ways. "Some have distinguished between the terms 'advisor' and 'mentor' in order to emphasize the distinctive aspects of each role" (Barnes \& Austin, 2009, p. 299). Some juxtapose advising and mentoring as two ends of a continuum of student support (Nettles \& Millet, 
2006). Others use the "terms advisor and mentor...interchangeably to describe the relationship between a faculty member and a doctoral student" (Barnes \& Austin, 2009, p. 299). Schlosser \& Gelso (2001) equate mentoring with good advising. In keeping with these sentiments, Nettles and Millet (2006) argue that administrative and mentoring advising encompass different advising functions. Mentoring advising includes developmental advising where "the goal [of the adviser-advisee relationship] is toward openness, acceptance, trust, sharing of data, and collaborative problem-solving, decisionmaking, and evaluation" (Crookston, 1994, p. 9). In other words, mentoring advising is the affective support and professional development that students receive. Similarly, NACADA defines mentoring as "interactive communication, socialization into the academic community, and sponsorship into the profession" (McGuire, 1998, p. 1). Thus, mentoring advising extends administrative advising by adding relational and educational advising factors. A detailed description of mentoring by Johnson (2002) states:

Mentoring is a personal relationship in which a more experienced (usually older) faculty member or professional acts as a guide, role model, teacher, and sponsor of a less experienced (usually younger) graduate student....A mentor provides the protégé with knowledge, advice, challenge, counsel, and support in the protégé's pursuit of becoming a full member of a particular profession. (p. 88)

Most advisers see their role as supporting and advocating for their advisees by serving as mentors and role models, addressing their advisees' professional goals, and tailoring the advising relationship to meet the needs of the advisee (Knox, Schlosser, Pruitt, \& Hill, 2006). Nyquist \& Woodford (2000) find that students want mentoring in graduate 
school: "an overwhelming number of students reported that the lack of quality mentoring and support they expect to receive from faculty was disappointing" (p. 13). Furthermore, "students wished their mentors were more explicit in providing concrete direction, performance feedback, and emotional support" (Nyquist \& Woodford, 2000, p. 14). In order to better understand these aspects of mentoring advising, the two overlapping factors: relational and educational advising are explored.

\section{Relational Advising}

Relational advising encompasses the relationship between advisers and advisees. The studies below identify positive relationship traits and increased student satisfaction with advising. The adjectives "trusting, supporting, encouraging, praising, and energizing" were identified by master's students in a study of student-faculty mentoring relationships (Schwartz and Holloway, 2012, p. 127). In another study, graduate students noted increased satisfaction with advisers that provided psychosocial help, social and emotional support (Tenenbaum, Crosby, \& Gliner, 2001). And in Barnes et al. (2010), doctoral students identified caring as one of the top positive traits of a faculty adviser. Caring faculty demonstrate a holistic interest in students' academic progress and general well-being (Barnes et al., 2010). Furthermore, Tenebaum, Crosby, and Gliner (2001) found a connection to student satisfaction with advising and positive relationship attributes. These studies all demonstrate that caring faculty and relational advising are significant for student advising success.

In contrast, uninterested advisers lack interest in students' program, research, and person (Barnes et al., 2010), negating the possibility of a relationship with the student and 
thereby negating the possibility of mentoring advising. Similarly, in Schlosser, Knox, Moskovitz, and Hill's (2003) study of advising, negative attributes of advising included advisers who were cold, disinterested, or superficial. Negative relationship advising attributes lead to student dissatisfaction and may play a role in student attrition (Girves \& Wemmerus, 1998; Golde, 2005). The adviser-advisee relationship may be even more important to non-traditional students. Students outside of the traditional characteristics of the graduate student (single, white, male, straight, with no children and not working fulltime outside of academia) may require more validation and support by faculty advisers (Gardner \& Gopaul, 2012).

Significant advising functions identified by Barnes and Austin (2009) in their study of faculty perceptions of advising include collaborating, mentoring, advocating, and chastising. Through the adviser role, faculty can collaborate with students on research, publications, and presentations, they can mentor by guiding and role modeling, and they can advocate by sticking up for their students in the department and during the graduate process. Faculty may also feel obligated to offer correction to students who are making mistakes or demonstrating inappropriate behavior.

Relational advising includes adviser care, knowing the student as an individual, and the academic and non-academic referral functions (Smith \& Allen, 2006), as well as providing help identifying funding. These functions support relational advising because an adviser has to know a student well enough to know their needs and have a rapport in order offer appropriate referral or support. While there is not a great deal of literature on these subjects, they are critical to student success. 
Referral. Studies acknowledge that, in addition to connecting and engaging with students, faculty may need to refer students to additional services (Smith \& Allen, 2006). While faculty may be able to mentor and support students, some students may need additional academic or non-academic services. Students may indicate a need for academic referral through their test scores, GPA, or disability designation, or communications with advisers. Advisers "should be skilled in referring students with interpersonal problems or learning difficulties and in identifying and suggesting remediation for problems in academic research and communication" (McGuire, 1998, p. 1). In their study of undergraduate student advising, Smith and Allen (2006) define academic referral as "referral to campus resources that address academic problems" and nonacademic referral as "referral to campus resources that address nonacademic problems" (p. 59). Similarly, graduate students may also demonstrate a need for academic services such as writing support and non-academic services including childcare and financial aid.

Funding. Funding is a crucial component of graduate student success (Patton, 2012). Indeed, Nettles and Millet (2006) began their own research on the central premise that funding was the most critical component for graduate student success. As the price of graduate education continues to rise, master's students find themselves in the position of having fewer resources to pay for graduate school. Research indicates that for a majority of students, financial support is the most significant factor contributing to the ability to complete the doctoral degree" (Council of Graduate Schools, 2009; Wendler et al., 2010). Nearly forty-four percent of students received loans, $21.4 \%$ received support 
from their institutions, and $25.9 \%$ received support from their employer (National Center for Education Statistics, 2011). Bell (2009) notes a "relatively small percentages of master's-level students [have] institutional support and assistantships" (p. 3). Less than one quarter of master's level students receive institutional aid. This number shows a low commitment by institutions to support master's level student education.

Master's education costs less than doctoral education; however, doctoral students are $13 \%$ more likely than master's students to receive grants, $12 \%$ less likely to have student loans, and 36\% more likely to have an assistantship (Bell, 2009). However, a higher percentage of master's students, $25 \%$, are receiving funding from their employer (National Center for Education Statistics, 2011). This means that at least a quarter of master's students are working while attending school. Students continue to attend master's programs despite the cost of the programs and the low level of fiscal support. However, identifying funding may be critical for master's students to attend or persist in graduate school. Funding is a significant issue for master's students of which faculty advisers may have little awareness.

To conclude, in relational advising students need caring, helpful, and socializing advisers, who will support, advocate and role model for them. They need advisers who can pass along norms and values both formal and informal and appropriate ways of acting within the department and profession. Referring students to services may represent the rapport established between adviser and advisee. It may also represent a form of care by the adviser for the advisee. In addition to relational advising, students also need educational advising aimed at supporting their academic and career goals. 


\section{Educational Advising}

Research suggests that educational advising is significant because students' primary goal in attending graduate school is to gain knowledge in the field or discipline (Anderson \& Swazey, 1998). Furthermore, students are increasingly attending graduate school in order to meet professional goals. It was noted in chapter one that master's degree enrollment is growing and one reason for this growth is the perceived necessity of the graduate credential for professional advancement and financial benefit (Stewart, 2010). Professional development builds the necessary skills and dispositions of the discipline or field, but also fosters opportunities to network with other professionals and demonstrate knowledge through presentations, publications, and research.

Master's students want to discuss their academic and professional development with their faculty adviser (Horn \& Elliott, 2011). Research indicates that students are more successful when faculty support students' academic development through feedback of their work and monitoring their academic progress. Examples of educational advising include: giving good feedback, encouraging students to write their theses, faculty-student collaboration, and networking.

Advisers are responsible for monitoring the academic progress and success of their students and in some programs, such as teacher and counselor preparation, may also be charged with monitoring the development of professional skills through practicum or internships. This section covers the elements of academic development including feedback on students' work, and, when appropriate, encouragement on their theses; and 
also professional development including networking and collaborating on academic work such as research, presentations, or publications.

Academic Development. Scholarship on graduate students emphasizes the importance of academic development. It includes advising for student academic growth. The graduate student must learn "enough content of the discipline so that he can achieve his personal goal of being certified as competent in his field of study and then begin a career" (Rosen \& Bates, 1967, p. 175). Advisers should help students with the development of "habits of mind" (Barnes et al., 2010, p. 39), which are defined as learning ways of thinking within the field. Advisers who are able to aid in the development of "habits of mind" support the educational development of their advisees. One way that advisers provide information about habits of mind is to give students feedback in the form of chastisement when they are not forming the appropriate habits of mind or praise when they are. This feedback can be given more formally through written comments on papers, formal meetings about student progress, and through milestones and GPA. Research shows that faculty feedback can be critical to student success. Another form of feedback is instrumental help including writing support which “increases student productivity “(Tenenbaum et al., 2001, p. 339).

Professional Development. In addition to academic development, master's students may need professional development:

Graduate programs should encourage and reinforce faculty investment in advisees' success both within the graduate program and during advisees' careers thereafter. As more career-helping functions are integrated into the advising 
relationship, it is reasonable to anticipate more positive outcomes for students and doctoral programs. (Schlosser, Lyons, et al., 2010b, p. 48)

In a challenging job market, students are increasingly aware of the necessity of career planning. Many students are returning to universities to gain additional skills in order to gain entry into a particular career or advance professionally. This desire for career outcomes, paired with the ever-rising cost of graduate education, leaves students with a strong desire for professional skills and knowledge as well as job seeking skills. Faculty advisers can help students gain the necessary professional skills through advising behaviors including collaboration and networking. Additionally, students can gain professional skills through working in their departments as graduate assistants. Faculty can help students grow professionally by collaborating with them on research, presentations, and publications (Gardner \& Mendoza, 2010). Graduate students identified networking as one form of professional development that advisers provide (Tenenbaum et al., 2001). Another way is to encourage networking is through professional organizations.

Students define graduate involvement as professional development (Gardner \& Barnes, 2007). This professional development includes joining professional organizations, attending and presenting at conferences, and publishing, which is very different from undergraduate involvement. The difference stems primarily from the connection of graduate involvement to academic interests (Gardner \& Barnes, 2007). Educational advising is a factor of mentoring since students are supported in their academic and professional development. This happens when faculty advisers give good 
feedback on written work, encourage students on their thesis, collaborate with students, and/or help them network in their field.

As described in the literature, two overarching dimensions of advisingadministrative and mentoring — effect student success. Within each of these dimensions, the factors of informational and organizational advising and educational and relational advising, respectively, operate. Concurrently, they inhibit or promote student progress. Further, each of the four factors contains multiple functions (e.g. referrals, funding, feedback) that further facilitate student achievement. While the advising functions listed above are likely to be universally helpful, the experiences students have with advising may be impacted by their individual and educational characteristics. This next section explores student demographic and educational characteristics that should be considered in advising for student success.

\section{Master's Students' Characteristics}

Student characteristics may impact satisfaction with or experience of the advising functions described above. To capture these differences, demographic characteristics of gender, race, and age as well as educational characteristics having to do with enrollment status, cohort participation, thesis writing, and characteristics of their advising relationships are discussed.

\section{Demographically Diverse Students}

One strategy to increase the success of diverse students in higher education is for members of the university community to provide encouragement and to help diverse and non-traditional students acclimate and connect with the institution. When students do not 
feel a sense of connection with the institution, department, program, faculty or peers, then they are at risk for attrition-leaving without completing their degree. Motivated by the high drop-out rate for women and minority graduate students, Girves \& Wemmerus' (1998) retention study found that "student relationships with faculty members are crucial to the student's educational and professional development and ultimately to the students' graduate degree progress" (p. 165). Faculty outreach to non-dominant groups can be critical. The negative outcomes of not having faculty connection and/or "validation" can be feelings of incongruence, dissatisfaction, which lead to the potential for departure. In a qualitative study of diverse doctoral students, Gardner (2008a) found that diverse students (women, students of color, part-time students, older students, and students with children) struggled to "fit the mold" of doctoral programs and when students perceived themselves as not "fitting the mold," they were at risk for leaving their programs (p.130).

Race/Ethnicity. Undergraduate studies show that faculty outreach to nontraditional students increases students' success. Research on undergraduates found that "nontraditional students expect active outreach and intervention in order to become involved" (Rendon, Jalomo, \& Nora, 2000, p. 146). Faculty members can validate students by acknowledging them and legitimizing their presence in college. Validation is defined as faculty and staff reaching out to undergraduate students, giving encouragement, and demonstrating a belief that students are capable of succeeding academically as well as offering support (Rendon et al., 2000, pp. 146-147). Institutions can potentially provide support for non-traditional students through advising. 
Doctoral students of color brought up challenges with "integration" and experienced a "lack of satisfaction in their overall experiences" (Gardner, 2008a, p. 132). Race/ethnicity can impact students' experiences with advising which is critical for doctoral student success (Barker, 2011). Barker (2011) found that "the majority of advisors and students agreed that it was important for black doctoral students to connect with same-race peers, mentors, or faculty. However, the same-race connection did not have to be the faculty advisor" (p. 394). This leads to recommendations to "identify positive mentors and allies, same-race and cross-race, in addition to advisors" (p. 395). Additionally, both advisers and students should address racial contexts and racial currency, leverage as perceived by white advisers and liability as perceived by black doctoral students; and finally same-race connections and networks (Barker, 2011, p. 396). In “A Multiculturally Infused Model of Graduate Advising Relationships," one of the challenges to advising diverse pairs is that "students and faculty members, like friends and even romantic partners, are most attracted to and therefore most likely to form connections with those with whom they share traits in common" (Schlosser, Lyons, et al., 2010b, p. 45). The human preference toward the known may makes it difficult for diverse students to form advising and mentoring connections. Therefore, there is a need for a "critical mass" of diverse faculty members and an institutional investment in diversity. Finally, when the adviser identifies as a mentor and takes on the functions of mentorship, it leads to greater engagement with students and more satisfied students. Schlosser, Lyons, et al. (2010b) recommend increasing diversity, validating diverse 
master's students, recruiting and retaining enough students to have a "critical mass," $\mathrm{n}$ and development of cultural empathy in and cross-cultural competence in faculty (p. 54).

Heterogeneous advising relationships may be challenging. However, Barker (2011) provides insight into negotiating these heterogeneous relationships, finding that advising relationships do not need to be the sole source of support for graduate students and that students can seek out role models and mentors that share the same racial/ethnic identity from others on campus in addition to the advising they receive from their faculty adviser. Furthermore, students from other non-traditional groups may find advisee matching to be challenging.

Gender. Research demonstrates that gender dynamics affect advising and socialization. "Men and women report having different types of advisor-advisee relationships with their advisers" (Sallee, 2010, p. 145). Research shows that the doctoral students who receive mentoring are most likely to be single, childless, white female students and are likely to be teaching or research assistants (Waldeck, Orrego, Plax, \& Kearney, 1997). Moreover, they are likely to be mentored by a white, male, middle-aged full professor in their department, who serves as their thesis or dissertation adviser and mentors them for 13-18 months (Waldeck et al., 1997). Waldeck et al. (1997) speculated that one reason for the cross-gender pairing was that most full professors were likely to male.

While gender impacts advising relationships, it may also impact students' experiences of their departments. Gardner (2008a) found that female students in science related fields identified their graduate school as a "male-dominated environment" ( $\mathrm{p}$. 
131). Research finds that this male-dominated environment is demonstrated through "a culture of competition" and leads women to have "a sense of isolation" (Sallee, 2010, p. 143). This is not surprising because academia tends to reproduce the values of young, white males and therefore the socialization of women is more challenging (Gardner, 2008a).

Older Students. Master's students are likely to be older, more diverse, and employed (Glazer-Raymo, 2005). Research on this population notes that older master's level students may have more commitments outside of school as compared to younger master's students. These commitments may impact the amount of time older students have to devote to their graduate studies. Full-time, full-year master's students are 28.8 years old on average and the least likely to be married or have dependents: whereas parttime, part-year master's students are the most likely to be married with dependents and have the oldest average age of 35.9 years (Choy \& Geis, 2002; Glazer-Raymo, 2005). Older students, defined by Gardner (2008a) as those over 30, commented on a sense of “displacement and an overall lack of integration with peers" in their 20's (p. 133).

Gardner notes the inflexibility of academia as more challenging to students with children, and women brought up issues regarding children more than their male counterparts.

\section{Educational Characteristics}

Educational characteristics that impact graduate student success include enrollment status, cohort participation, thesis writing, and advising relationship characteristics. 
Part-time Students. Research suggests that full-time and part-time attendance is more than just a difference in time commitment; it may also be a barrier to department integration (Tinto, 1993). Fisher \& Reynolds (2012) note that time-to-degree is significant for measuring persistence. Students who attend school part-time or take longer to graduate are less likely to graduate from doctoral programs. Currently, information about how time-to-degree affects completion rates is not available at the master's level. Studies suggest that obstacles to completion arise because students belong to more than one community. Students who work and attend school may have to juggle commitments to both communities. Part-time student "regretted not being able to spend more time with their peers and felt they were missing a large part of the overall graduate experience" (Gardner, 2008a, p. 134). Fisher \& Reynolds (2012) note that time-to-degree is significant for measuring persistence because it has been shown that shorter time-todegree leads to greater graduation rates at the doctoral level. These studies suggest consequences for students' sense of involvement in education, with the potential for negative impact on their sense of success.

Cohort. Students in a cohort may require less advising because they may have little choice about the courses they take and they have a built-in support network of peers. Cohorts are defined as students taking the same courses in the same order with the same students. These groups typically do not need help selecting courses because they are taking them in a particular order. However, they may need informational advising about electives taken separately from their cohort. Furthermore, cohorts may be advised as a 
group with courses being taught by faculty advisers or advising sessions built into class meetings. Cohorts may serve as an alternative form of advising.

Thesis writing. Students in the thesis-writing phase may experience graduate school and their advising relationship differently than in the course-taking phase. They are facing a large project that may be open-ended and unlike previous graduate course work they have done before. The thesis may serve as a gate-keeping milestone. Some students may not be able to complete an adequate thesis and therefore not obtain their master's degree. In the thesis-writing phase, students may need to access their adviser more frequently for feedback and support.

Advising relationship characteristics. Some student characteristics are purported to support student success more than others. These characteristics include seeing an adviser frequently (PSU, 2011), identifying as having a mentor (Nettles \& Millett, 2006), and having more than one faculty member that they can rely upon for information (Nettles \& Millett, 2006). These characteristics ensure that students are getting the advising, mentoring and faculty support they need to be successful in their program.

The student demographic and educational characteristics above are likely to be significant in the faculty-student advising relationship. But these relationships and students' graduate experiences occur within the graduate department. Tinto (1993) asserts that the department is significant for graduate students because they are more enmeshed in their specialized department than in the rest of the university. Thus, 
department culture and climate may impact student advising experiences and their success.

\section{Climate and Culture}

This section reviews literature relevant to the broader graduate student experience including peer climate, department culture, and department climate in order to more deeply understand factors that influence master's student success. As will be more fully described, peer culture and department culture impact the way that students experience advising and their graduate program. Department climate captures the students' experiences within the department or program with respect to the power dynamics.

\section{Peer Culture}

Research on socialization defines Peer culture as the relationship with peers in the program or department, which may include collaboration or competition. Peer relationships may also involve socializing and mentoring. Peer groups also help with anxiety about the unknown, give informal information, and can provide encouragement and support (Rosen \& Bates, 1967, pp. 62-63). Multiple benefits, including greater social integration into the department, stem from collegial peer interaction and peer mentoring between more advanced students and incoming students (Boyle \& Boice, 1998). Students listed peers as a source of information about what classes to take and how to navigate the graduate program (Horn \& Elliott, 2011). Additionally, Anderson \& Swayze (1998) found that 55\% of the student surveyed agreed that, "Students who go through the program together learn more from each other than from faculty" (p. 5). Students, who often spend a good deal of time together, may do effective peer advising. 
However, peer groups can also promote competition, which may increase student learning or interfere with students' sense of department integration and belonging. Competition between students and a competitive peer climate may impact diverse and non-traditional students differently, potentially reinforcing a sense of inadequacy and a feeling of not belonging in graduate school or in the department.

In graduate school, "students interact with their peers more than their faculty" (Sallee, 2011, p. 190). These peer relationships can have an important impact on the graduate student experience. For students in cohorts, these relationships may be even more significant because they take most of their classes together for a year or more. In addition, cohorts can influence the peer culture and the socialization process: cohorts that "share similarities" are likely to have stronger bonds than when the groups are diverse (Weidman \& Stein, 2003, p. 62). It is easier for students who are similar to form common bonds, but Pascarella and Terenzini (2005) find that diversity promotes learning. Diverse cohorts thus may not provide the same level of support but may ultimately promote greater learning and student success if one's feelings of difference are not too extreme.

\section{Department Culture}

Scholarship asserts that graduate student communities are at once more local and more national than undergraduate student communities (Golde, 2005; Tinto, 1993). Graduate students take classes and spend more time within their specialized departments. At the same time, graduate students are learning in disciplines that are national or international in nature and are characterized by publications, conferences, and 
professional organizations. Researchers speculate that graduate students do not inhabit the university with the same breadth as undergraduate students, and they stay within the confines of their departments. Because of these ideas, Tinto's (1993) model of doctoral student retention combines the concepts of academic and social integration. In this model, doctoral persistence is linked to socialization, which, he asserts, takes place within the department where students take classes, learn the skills of their discipline, and interact with faculty and peers.

Research on socialization also documents how students attend graduate programs to obtain specialization in a field, and part of that experience is taking on the norms and participating in the culture of the field. Rosen \& Bates (1967) define the socialization that occurs in graduate schools as the "prolonged interaction" with the "norms and values of the group" expressed through "relationships between members of a social system" through the "division of labor, the expression of affect and the flow of communication, the nature and distribution of power and authority, and the degree of consensus and conflict" (p. 72). Therefore, scholars look at the social interactions between faculty and students and students and their peers to see how they work together, relate, communicate, and negotiate power and conflict. This dynamic creates a department culture through which values, norms, and expectations for success become shared understanding. Indeed, the literature demonstrates that graduate programs explicitly transmit formal requirements, while also signaling implicit informal requirements. Furthermore, departments pose sanctions and offer rewards as a part of the socializing system; the most obvious are grades and scholarships. Faculty can reward student's good work with 
positive grades and access to scholarships, funded research, and fellowships, or they can chastise students by giving them poor grades and not hiring them or recommending them for funding. Faculty may be evaluating students throughout the graduate process, which can heighten the "sense of threat felt by the student" (Rosen \& Bates, 1967, p. 82). Essentially, faculty members may be informally evaluating student progress all the time, and students may feel a sense of competition and threat not felt at the undergraduate level. Furthermore, students may feel more is at stake at the graduate level. Therefore, scholars attach significance to whether students feel a sense of investiture or divestiture by graduate faculty: whether the new students are welcomed into the socialization process or not (Weidman et al., 2001, p. 8).

In a study of doctoral student socialization to the scholar role, Weidman and Stein (2003) found that through social interaction with peers, faculty, and department climate, students are socialized to the department scholarly norms. In this study, student perceptions of faculty encouragement and mentoring impacted students' scholarly production and success. Significantly, department scholarship norms were transmitted through the constructs of social interaction and department climate. Graduate students' sense of fit with their program (Golde, 1998) and sense of belonging in their department— department culture — can put them at risk for attrition (Gardner \& Mendoza, 2010).

\section{Department Climate}

As differentiated from department culture, department climate includes the student experience of power, privilege, and status in their department. Hurtado et al. 
(1999) defines campus climate as the "perceptions, attitudes and expectations that define the institution and its members" (p. 5). As research suggests, increasing diversity can enhance experiences of power and privilege difference since the academy is still made up primarily of white professors. Certainly, it is important to note that campus racial tension is about more than population numbers. It is "a configuration of external influences (historical and contemporary), structural characteristics of institutions and group relations, and institutionalized ideologies (Hurtado, 1992, p. 564). However, numbers are important because the research "consistently calls attention to the isolation, alienation, and stereotyping with which these students are often forced to contend on campuses where they are not the majority" (Harper \& Hurtado, 2007, p. 12). Both majority and minority students are aware if negative campus climate and discrimination exist (Harper \& Hurtado, 2007).

Addressing department climate is critical to the success of diverse and nontraditional students because the effects of negative campus climate can alienate students and potentially lead to attrition. When black students experience racial micro-aggressions (subtle verbal, nonverbal, or visual insults), they begin to feel academically and socially alienated in spaces where such oppression occurs, and as a defense mechanism they create their own academic and social counterspaces (ethnic enclaves that offer shelter from the psycho-emotional harms of racial micro-aggressions) (Solorzano, Ceja, \& Yosso, 2000). In the face of negative department climate, these students form their own alternate social networks away from their programs and departments. This may lead to a lack of integration and may increase their risk of attrition. 
Similarly, department climate can affect female student success:

Scholars find that department climate can impact the experiences of women: "chilly" departmental climate — one in which students had the impression that they were wasting the time of the faculty or encountered few expressions of concern about their personal and professional advancement—often exacerbated other difficulties (such as lack of funding or personal problems) and contributed to their decision to withdraw form the university (Nerad \& Miller, 1996, p. 71) Women can struggle to remain in graduate school when they encounter a "chilly climate" (Nerad \& Miller, 1996, p. 71). Thus, department climate is critical for student success along with the corresponding factors of peer culture and department culture. The organizational influences combine to create a background against which the advising relationship dwindles or thrives.

\section{Master's Student Success}

Similar to undergraduate and doctoral student success, master's student success can be conceived of and measured as a single variable or multiple variables. These include graduation, retention, student commitment, and GPA (Astin, 1984; Kuh et al., 2005; Tinto, 1993).

\section{Graduation}

Graduation is a clear and obvious measure of student success. Master's degrees serve as the credential for certain professions and may open doors to a doctoral degree. 


\section{Retention}

Only half of all doctoral students who begin a program will finish (Council of Graduate Schools, 2008; Gardner, 2008a; Golde, 1998; Nelson \& Lovitts, 2001; Nettles \& Millet, 2006; Tinto, 1993) and attrition rates - the rates of students leaving their programs without graduation — are higher for women and racial and ethnic minorities (Lovitts, 2001). While the actual statistics for master's students are unknown, it stands to reason that diverse master's students may face similar attrition rates. As well, students who attend school part-time are more likely to depart without graduating (Nettles \& Millett, 2006).

\section{Student commitment to progress}

Cooke (1995) found that attitudes and intentions were significant predictors of attrition and retention. Students thinking about or intending to quit were more likely to leave without graduating. Perhaps not surprising, full-time enrollment status in graduate school correlates to goal commitment and retention (Girves \& Wemmerus, 1998).

Apparently, students who are able to commit full-time to their graduate program also show a stronger commitment to the attainment of a graduate degree. Of course, full-time students may also be more likely to graduate because they have fewer commitments to work outside of school, may be employed by their departments, and may have more internal connections to faculty and peers, all factors associated with commitment, retention, and graduation. 


\section{Grade Point Average}

GPA is a predictor of academic development and student success in undergraduate studies (Kuh et al., 2005). At the master's level, Girves and Wemmerus (1998) found that GPA was a predictor of student success. Certainly, the variability of GPA at the graduate level is less likely to be clearly predictive of success due to the heightened minimum requirements. Still, it is important proxy of student success.

\section{Chapter 2 Summary}

This study of master's students' experiences with advising seeks to fill a gap in the literature. Advising is crucial for undergraduates and critical to doctoral student success, but very little scholarship has investigated master's student advising specifically. Such advising takes place within a complex and changing context. Therefore, examining the role and impact of differing types of advising and master's student success is imperative. Expanding master's programs as well as calls for graduate education by business leaders, government officials, and companies assert the need for master's degree graduates who will be the community leaders and professionals of the future. This investigation offers a starting point for determining the trends and terminology critical for examination of this little studied group. Chapter 3 follows, detailing the methodological design analysis guiding this inquiry. 


\section{Chapter 3: Methods}

Master's students make up the majority of students enrolled in graduate education. And yet, little is known about this population and the facilitators of their success. The lack of knowledge about master's students is compounded by the lack of data collected nationally. We know how many students enter master's program and how many graduate each year, but we do not know their rates of attrition. Studies on undergraduate and doctoral retention offer strategies that may also support master's student success. Advising is the most often-cited retention solution for undergraduate (Habley, 1981) and doctoral student success (Barnes, Williams, \& Archer, 2010; Gardner, 2008; Golde, 2005; Lovitts, 2001; Tinto, 1993).

The majority of research on advising has asserted its importance to student success but has not delved into the specific functions of the advising experience (Smith \& Allen, 2006). This study closes that gap by investigating master's student satisfaction with advising and its correlation to student success. Utilizing Nettles and Millett's (2006) division of advising as two primary dimensions_-administrative and mentoring advising — as explicated in chapters one and two, each dimension will be examined in light of its effect on student success. Furthermore, each of the primary advising dimensions has binary subcategories. Administrative advising is comprised of the informational and organizational advising factors. Mentoring advising is comprised of relational and educational advising factors. Thus, the concept of advising will be defined and measured using these categorizations and their relating variables of student success. 


\section{Research Questions}

Advising experiences and satisfaction may differ for students depending upon their background characteristics (Gardner, 2008a; Lovitts, 2004; Nettles \& Millet, 2006; Smith \& Allen, 2006) including race/ethnicity (Barker, 2011; Gardner, 2008a), gender (Gardner, 2008; Sallee, 2011), age (Gardner, 2008), and part-time status (Gardner \& Gopaul, 2012; Gardner, 2008a). The presence of these characteristics leads first research question: do student characteristic impact master's students satisfaction with advising? This question, asked by Smith and Allen (2006), investigates the potentially different advising experiences of students with different demographic and educational characteristics. Student experiences with graduate school may vary depending upon their identity and time spent on campus and in their department (Gardner, 2008a). As well, graduate school and advising experiences may differ for non-traditional graduate students who are older and may attend school part-time (Gardner, 2008a).

The primary assumption in this study is that if advising supports undergraduate and doctoral student success then it should support master's student success. In order to test this hypothesis, the research question is does student satisfaction with faculty advising influence master's student success? Advising is believed to be critical to student success, but not all advising is the same. The kind of advising students receive varies. Most students receive administrative advising, but not all students receive mentoring advising. This leads to a sub-research question exploring the particular kind of advising master's students receive and their success: does satisfaction with a particular advising function impact master's student success? 


\section{Study Design}

Since advising is believed to be critical for student success, it would be unethical to knowingly withhold this benefit to prove that students without advising are likely to depart the university without a degree. Therefore, the design of this study is not experimental and employs a correlational survey design. Most students will receive some form of advising during their master's program and this study investigates student satisfaction with the kinds of advising they receive and how it affects their success.

\section{Participants}

Study participants were graduate students at a large, public, urban university with the Carnegie classification of high research activity (RU/H). All graduate students, who had been enrolled both fall term 2011 and spring term 2012, were invited to participate in the master's and doctoral versions of the Graduate Student Advising survey. The survey was administered spring term 2012.

The survey was intended to measure student experiences with advising, so it was imperative that students had been enrolled long enough to have had the opportunity to access advising. Some graduate programs have rolling admission where students can be accepted fall, winter, spring, or summer to their graduate programs. Students who began their program in winter or spring 2012 might not have had adequate time to access faculty advising. Therefore, the parameters of the survey sample ensured participants had at least two terms and potentially one academic year to access advising. Student demographic information for the sample and population is reported in Chapter Four. 


\section{Instrument}

There was no existing instrument to collect information about graduate student experiences with advising. Therefore, the researcher looked to existing surveys for examples of questions regarding advising including those by Smith and Allen (2006), Inventory of Academic Advising Functions: Student Version survey instrument, Henderson \& Stassen (2007) Graduate Student Experience Survey, Nettles and Millett (2006) Survey of Doctoral Student Finances, Experiences, and Achievements; regarding student success: the National Survey of Student Engagement (NSSE); and regarding culture and climate: the HERI (1997) College Student Survey (Senior Survey), and Sax, Astin, Arredondo, and Korn (1996) 1995-1996 HERI Faculty Survey.

The graduate office hired the university-affiliated Survey Research Lab to conduct focus groups with master's and doctoral students on their experiences with advising. The report generated from these focus groups (Horn \& Elliott, 2011) also informed the Graduate Advising Survey, as did the literature review from in this study. The items on the survey include 16 items on graduate advising functions; 1 item on student characteristics; 5 items on educational characteristics, 4 items on peer culture; 5 items on department culture, and 9 items on department climate; as well as 3 items on student success.

Graduate Advising Survey: Master's Student Version was piloted winter 2012 with master's students in the Graduate School of Education taking a Research Methods course. A significant finding from the pilot was that some students had an adviser but had never met with that adviser even after a year of being in their master's program. This led 
to the addition of a question after "do you have a faculty adviser?" querying whether students had met with their adviser prior to querying about their satisfaction with their adviser. Due to the small sample size, the instrument could not be tested for reliability, but the advising items on the survey are straight forward and queried direct questions about student satisfaction with their experiences so this omission should not pose a threat to the reliability.

\section{Graduate Advising}

The survey queried students to rate, on a Likert-type scale where 1=not satisfied and $6=$ very satisfied, how satisfied are you with your advising experiences regarding informational, organizational, relational, and educational advising elements (see Table 1). Questions about informational advising focus on how the advising process has conveyed accurate information, including policies and procedures, and programs of study. Questions about organizational advising refer to the logistics of the advising experience including access to the adviser, amount of time spent with the adviser and the process of matching students to their adviser. Questions about relational advising queried students about their satisfaction with the relationship they have with their adviser measuring the students' perception of the degree to which their adviser knows them as an individual, cares about their academic progress, would refer them to academic and non-academic resources, and help them find funding. Questions about educational advising refer to students' satisfaction with their advisers' contribution toward the students' educational and professional development including the feedback students' receive on their academic work and when appropriate encouragement to make progress on their thesis, 
opportunities to collaborate on research, writing, or presentations, and help with

networking. Table 1: Graduate Advising lists the 16 advising variables from the survey

and places them in the corresponding advising category (informational, organizational,

relational, or educational).

\section{Table 1: Graduate Advising Variables}

\begin{tabular}{|c|c|}
\hline \multicolumn{2}{|l|}{ Graduate Advising } \\
\hline \multicolumn{2}{|l|}{ Informational } \\
\hline Accurate Information & Ability to give you accurate information about program requirements. \\
\hline Policies \& Procedures & Assisting you with understanding policies and procedures. \\
\hline Educational Plan & Helping you create a program of study (educational plan). \\
\hline \multicolumn{2}{|l|}{ Organizational } \\
\hline Accessible & Your faculty adviser's accessibility. \\
\hline Time & The amount of time you spend with your adviser. \\
\hline Adviser Wish & $\begin{array}{l}\text { There is another faculty member in my department that I wish was my } \\
\text { adviser. }\end{array}$ \\
\hline Adviser Assigned & $\begin{array}{l}\text { I am satisfied with how faculty advisers are assigned in my } \\
\text { department/program. }\end{array}$ \\
\hline \multicolumn{2}{|r|}{ 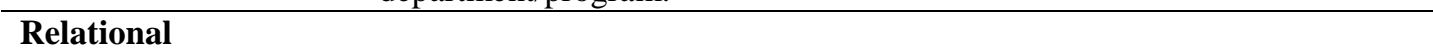 } \\
\hline Know Individual & Knowing you as an individual. \\
\hline Care Academic & Caring about your academic progress \\
\hline Referral Academic & $\begin{array}{l}\text { When needed, referring you to campus services for academic support (i.e., } \\
\text { writing center, learning center, disability resource center). }\end{array}$ \\
\hline $\begin{array}{l}\text { Referral Non- } \\
\text { Academic }\end{array}$ & $\begin{array}{l}\text { When needed, referring you to campus services for non-academic support } \\
\text { (i.e., childcare, financial aid, student health and counseling center). }\end{array}$ \\
\hline Help Funding & $\begin{array}{l}\text { Helping you find funding (i.e., graduate assistantships, fellowships, } \\
\text { scholarships, and/or providing letters of recommendation). }\end{array}$ \\
\hline \multicolumn{2}{|l|}{ Educational } \\
\hline Good Feedback & Giving you good feedback on your academic work. \\
\hline Encourage Thesis & When appropriate, encouraging you to make progress on your thesis. \\
\hline Collaborate & $\begin{array}{l}\text { Collaborating with you (i.e., conducting research together, writing together, } \\
\text { or co-presenting). }\end{array}$ \\
\hline Network & $\begin{array}{l}\text { Helping you network in your field (i.e., introducing you to colleagues at the } \\
\text { university or at a conference, etc.) }\end{array}$ \\
\hline
\end{tabular}

\section{Master's Student Success Variables}

Student success includes 6 items. Three are measured by the survey: institutional commitment, degree commitment, and educational satisfaction. And three are collected through the university's student information system: graduation, retention, and graduate GPA (See Table 2: Student Success Variables). 


\title{
Table 2: Student Success Variables
}

\author{
Student Success Variables \\ Graduation: Enrollment data Fall 2012, Winter 2013, Spring 2013 (SIS)* \\ Enrollment: Enrollment data Fall 2012, Winter 2013, Spring 2013 (SIS)* \\ Institutional Commitment: I am confident that I made the right decision in choosing to attend \\ [university]. \\ Degree commitment: My graduate degree will help me advance professionally. \\ Program commitment: In my program, I am learning the skills and knowledge I need to work in my \\ field. \\ Grade Point Average: GPA (SIS)* \\ * Items not included on the survey, but collected through the student information system are marked (SIS).
}

\section{Student Characteristics}

Advising experiences may vary, so this study looked for patterns of student satisfaction ratings based upon student characteristics. Demographic information was collected from the student information system regarding race/ethnicity, gender, and age. In the survey, students were queried whether they saw themselves as full-time or parttime students. This designation can change over the course of a student's program or on a term-by-term basis, and so students were queried to self-identify. Students were queried to identify if they were part of a cohort: "I am part of a cohort program" (yes, no) (See Table 3: Student Characteristics). Additionally, recognizing the significance of multiple faculty relationships, students were queried to give the number of "different faculty/staff members [they] rely upon for advice/guidance about program requirements, academics, or career matters." Students' response to the number of mentors was rewritten as a dummy variable and grouped on the survey under student characteristics as 0 faculty guidance, 1 faculty guidance, 2+ faculty guidance.

\section{Table 3: Student Characteristics}

\section{Student Characteristics}

Race/Ethnicity: (SIS)*




\begin{tabular}{|c|c|}
\hline $\begin{array}{l}\text { Gender: } \\
\text { Age: }\end{array}$ & $\begin{array}{l}(\mathrm{SIS})^{*} \\
(\mathrm{SIS})^{*} \\
\end{array}$ \\
\hline \multicolumn{2}{|c|}{ Educational Characteristics } \\
\hline Part/Full-Time: & Do you consider yourself a full-time or part-time student? \\
\hline Cohort: & $\begin{array}{l}\text { I am part of a cohort program (I take the same classes with the same students in the } \\
\text { same order). }\end{array}$ \\
\hline Writing Thesis: & Are you currently working on your thesis? \\
\hline Meet once per & \\
\hline term or more: & On average, how many times per term do you meet with your faculty adviser? \\
\hline Multiple Faculty: & $\begin{array}{l}\text { How many different faculty/staff members [they] rely upon for advice/guidance } \\
\text { about program requirements, academics, or career matters? }\end{array}$ \\
\hline Mentored: & $\begin{array}{l}\text { [Graduate students may have a faculty member whom they rely upon for advice, } \\
\text { support, and encouragement. This mentor may be their faculty adviser or another } \\
\text { faculty member.] Do you have a mentor? }\end{array}$ \\
\hline
\end{tabular}

\section{Peer Culture}

The survey queried students to rate, on a Likert-type scale where 1=strongly disagree and $6=$ strongly agree, student relationships in their program (See Table 4: Peer Culture). Students were queried about the nature of peer relationships including collaboration and sharing: "students collaborate with one another" and "students share resources and information." Additionally, students were queried about peer mentorship: "Experienced students mentor new students," friendship: "I am friends with students in my program," and competition: "Students compete for faculty time."

\section{Table 4: Peer Culture}

\section{Peer Culture Variables}

Students collaborate with one another. Students share resources and information. Students compete for faculty time.

Experienced students mentor new students. I am friends with students in my program. 


\section{Department culture}

Students were queried about their experiences with their departments regarding accessing faculty. Items included: "faculty are accessible;" "social events are planned to bring faculty and students together;" "I feel like I belong in my department;" and fit "I feel like I 'fit' in my program”' (See Table 5: Department Culture).

\section{Table 5: Department Culture}

\section{Department Culture}

Faculty are accessible.

Social events are planned to bring faculty and students together.

How many different [university] faculty/staff members do you rely upon for advice/guidance about program requirements, academics, or career matters?

I feel like I belong in my department.

I feel like I "fit" in my program.

\section{Department climate}

Students were queried about their department climate and if they experienced "an inclusive and respectful learning environment;" whether they "have been singled out or treated disrespectfully because of gender" or "race/ethnicity"; and whether "faculty treat students the same regardless of gender" or "race/ethnicity." Also, students were queried to identify whether they have "observed discriminatory words, behaviors, or gestures directed toward students who are: ethnic/racial minorities; females or males" (See Table 6: Department Climate).

\section{Table 6: Department Climate}

\section{Department Climate}

I experience an inclusive and respectful learning environment.

I have been singled out in my program or treated disrespectfully because of my gender.

I have been singled out in my program or treated disrespectfully because of my race/ethnicity.

Faculty treat students the same regardless of gender.

Faculty treat students the same regardless of race/ethnicity. 
I have observed discriminatory words, behaviors, or gestures directed toward students who are: ethnic/racial minorities; female; male.

Singled out variables and discrimination variables were recoded as Not Singled Out and Not Discrimination $(1=6,2=5,3=4,4=3,5=2,6=1)$. These recoded variables were used in the inferential statistics. Recoding the variables was necessary because the singled out and discrimination variables captured negative climate experiences and the other variables captured positive climate experiences. In order to use these variables together as a factor they had to have the same measurement.

\section{Data Collection}

Data were collected through an electronic survey. A link to the survey was sent in an email that included the elements of informed consent. Students were informed that they did not have to take the survey and could quit at any time. Additionally, their information would be stripped of all identifiers and represented in reports with the responses of other students to protect their privacy. The survey could not be completely confidential because a unique identifier was used to link data from the student information system to their responses. If students read the email and clicked onto the link for the survey, then they gave implied consent. The Human Subjects Research Review Committee also known as the Institutional Review Board approved the methodology for this study.

The survey, Graduate Student Advising: Master's Student version, was emailed to all degree-seeking master's students, enrolled both fall term 2011 and spring term 2012, on May, 14, 2012 at 11:00 a.m. (See Appendix A: Graduate Student Advising Survey: Master's Student Version). The survey was distributed using Qualtrics survey software. 
Graduate students received an initial email with a consent letter and survey link from the graduate office inviting them to participate in the study (See Appendix B: Advising Survey Letters). Then two follow-up emails were sent. Qualtrics generated a new email list from the survey panel for each follow-up email and filtered out students who had submitted their survey. The first follow-up email was sent one week after the initial email on May 21, 2012, and the second follow-up email was sent two weeks after the initial email on May 28, 2012. Students who did not want to participate were unsubscribed from future emails requesting their participation.

Data collection began May 14, 2012, which was the first day of fall 2012 registration, a point at which students could have been making contact with their adviser regarding program planning and registration. Students in their programs can more accurately remember their learning experiences while they are actively participating in them and are therefore better able to articulate their attitudes and behaviors. However, critics of student self-report data argue that people struggle to accurately remember behaviors even one week later (Dowd, Swatzky, \& Korn, 2011).

\section{Data Analysis}

This study on master's student advising and student success is non-experimental in design. "In non-experimental research there is no manipulation of an independent variable. There also is no random assignment to group by the researcher" (Johnson \& Christensen, 2012, p. 42). In this study, the researcher used SPSS 19, SPSS 21, and SPSS AMOS. 


\section{Logistic Regression}

The researcher intended to use logistic regression to look for the probability a master's student retention. Because retention is a binary outcome variable, logistic regression is the appropriate statistical test. Logistic regression can "predict which of two categories a person is likely to belong to given certain other information" (Field, 2009, p. 265). In this case, there are two possible outcomes for master's students, and they are retained 2012-2013 or they dropout. In this particular case, the retention rate for the survey sample was nearly $100 \%$. Of the 942 participants, 941 were retained. The high retention rate meant that there was no way to compare retained students and dropouts, so this test was not run.

\section{Factor Analysis}

Factor analysis is used to identify latent underlying concepts represented by survey items. To determine if survey items are measures of the same constructs (e.g. department culture), exploratory and confirmatory factor analysis was done. Factor Analysis allows for the combining of many variables into fewer variables and is used to get at "things that cannot directly be measured (so-called latent variables)" (Field, 2009, p. 628). In this case, the multiple survey responses to questions about the concepts of peer culture, department culture, and department climate can potentially be combined into single factors. SPSS 19 can run variable reduction tests in the form of Exploratory Factory Analysis (EFA). After doing EFA on SPSS 19, the researcher used SPSS AMOS to run CFA. Then the CFA factor scores were used in the linear regressions. 


\section{Linear Regression}

While retention and graduation are significant success outcomes for master's students, they are not the only success outcomes for master's students included in this study. Some student satisfaction ratings appear to be proxies for student retention. These include institutional commitment, degree commitment, and educational satisfaction. Students who are satisfied with the institution they are attending, the degree they are pursuing, and the educational content of their program are more likely to complete their degree (Astin, 1984). The next three linear regressions address retention proxies in the form of student satisfaction. Also, Girves and Wemmerus (1998) found that GPA was a significant factor for master's student success. GPA serves as benchmark for master'slevel work and students who do not achieve the benchmark may be forced to take additional coursework, get academic support, or leave their graduate program.

SPSS 21 was used to run the multiple linear regressions exploring the success outcomes: GPA, institutional commitment, degree commitment, and educational satisfaction. These multiple linear regressions were run to determine if there was a correlation between advising satisfaction and these student success dependent variables. Multiple linear regression was chosen for these statistical tests because with GPA there is a continuous numerical dependent variable. The satisfaction dependent variables were measured in a Likert-type scale. The Likert-style scale data was converted from categorical, ordinal data to scale data. The underlying assumption is that students taking the survey understood the categories 1-6 to be equally distant from each other. The endpoints were the only given categories: $1=$ not satisfied and $6=$ very satisfied. 
Regression analysis was selected because it can account for numerous variables. While the goal was to isolate advising and student success, measured as GPA and satisfaction, there are numerous potentially confounding variables that may also account for a student's lack of success. Multiple linear regressions can take all these variables into account and create the most parsimonious model of master's student advising for student success. Student experiences with graduate school, including peer culture, department culture, and climate, were entered as factors. Student characteristics may have influenced student satisfaction ratings. In order to measure the difference between student characteristics and each of the 16 advising variables, linear regression was used. Student characteristics were entered identically for each of 16 regressions where the dependent variables were the advising outcome.

\section{Limitations}

The data collected comes from a single institution and may not be generalizable to other institutions. The responses may only reflect the experiences of students at this particular institution. The researcher created the survey and collected the data in collaboration with the graduate office prior to the passing of this research proposal. Therefore, the survey instrument, while informed by the early stages of this dissertation proposal, did not benefit from a fully realized and passed dissertation proposal. The survey instrument was not rigorously tested. The survey instrument was developed from a number of existing surveys and draws from the literature on advising and the graduate student focus group report. The instrument was tested with master's students in an educational research course winter 2012 prior to dissemination in spring 2012. It is not 
known that administering the survey on a different campus would produce similar findings. The findings from this study may not be generalizable to master's students at large.

The researcher has a long-standing connection to the institution as a master's student, doctoral student, and instructor. She was listed on the email informed consent letter as a contact, and her connection to the project may have encouraged or discouraged students who know her from participating in the study. The students who respond to surveys are more likely to feel strongly about the topic, whether those feelings are positive or negative. Therefore, the findings may be skewed toward the extremes.

Another challenge with this study was the sample size. The response rate for this population survey was good at $30 \%$, but the survey was large and many students did not answer all of the questions. There appears to have been survey attrition possibly caused by questions that queried about advising functions students may have not been getting. The response rate drops for the survey items querying about mentoring advising especially referral items. Referral to Academic Support and Non-Academic Support may not have been important to students, who did not need this kind of advising. Students were given the opportunity to mark N/A or not applicable to survey items that measured mentoring functions. Students within the sample may have self-selected out of answering survey items. This is especially problematic with the referral items, which may only reflect the opinion of students who needed referral and not the sample population at large.

Also, this study involves numerous tests. Ordinarily one would use a Bonferroni correction to compensate for over testing data. However, due to a paucity of research on 
this population and the exploratory nature of this study, the researcher chose not apply this correction.

Graduation could not be used as a measure of success because the students who answered the survey were retained for a year after survey administration. This suggests that the sample population may not be representative of the general population. This was not a longitudinal study and the students in the study self-selected to take the survey.

\section{Chapter 3 Summary}

This study offers a distinct focus on master's level students, a group rarely studied by scholars. In order to better understand the needs and experiences of master's students, this study analyzes data gathered by a survey designed to assess the impact of advising master's student success. The findings led to recommendations for best practices in master's student advising discussed in detail in chapter five. The recommendations take into account the potentially different needs of diverse and non-traditional master's students as well as the distinctive types of advising that can facilitate master's student success. This study expands our knowledge of master's students and of the advising that best supports student success. This knowledge can improve practice by faculty advisers and serve the university by supporting master's student success. 


\section{Chapter 4: Results}

This chapter presents the results of the Graduate Advising Survey: Master's Student Version. The survey was administered spring 2012. The survey was taken by 942 master's students enrolled in a master's degree program who were registered fall 2011 and spring 2012. The study examines faculty advising as a means of facilitating master's student success. The primary research questions are

1. Do student and educational characteristics impact master's student satisfaction with advising?

2. Does student satisfaction with advising influence master's student success?

Good faculty advising, or quality advising, promotes student retention and success (Habley, 1981; Lovitts, 2001; Tinto, 1993). While good advising is subjective and probably best judged by the individual receiving the advising, student satisfaction captures student perceptions of good advising experiences (Sallee, 2010). Advising is a complex process. As such, the inquiry examined administrative and mentoring advising, four advising factors, and 16 advising variables drawn from the literature.

As an outcome measure, student success is another concept that can be defined many ways. While student knowledge and skills might be the best way to measure student success - as well as perhaps improved quality of life, career placement or advancement $—$ for the purposes of this study, progress toward graduation dependent variables were used to define student success. Progress toward graduation was measured using GPA, and student commitment to their institution, program and degree. 


\section{Descriptive Statistics}

\section{Student and Educational Characteristics}

Students in the sample were similar to the population in race/ethnicity and age.

Female students were nearly $10 \%$ higher in the sample than in the population and female students make up more than $70 \%$ of the respondents.

\section{Table 7: Student Demographics Gender}

\begin{tabular}{lcccc}
\hline \hline & \multicolumn{2}{c}{$\begin{array}{c}\text { Sample } \\
(\mathbf{n = 8 9 0 )}\end{array}$} & \multicolumn{2}{c}{$\begin{array}{c}\text { Population } \\
(\mathbf{N}=\mathbf{3 4 8 5})\end{array}$} \\
& $\mathbf{n}$ & $\boldsymbol{\%}$ & $\mathbf{n}$ & $\boldsymbol{\%}$ \\
\hline Female & 633 & 71.1 & 2175 & 62.4 \\
Male & 257 & 28.9 & 1310 & 37.6 \\
\hline \hline
\end{tabular}

There was very little variation in race/ethnicity between the sample and population.

Table 8: Student Demographics Race/Ethnicity

\begin{tabular}{lcc|cc}
\hline \hline & \multicolumn{2}{c|}{$\begin{array}{c}\text { Sample } \\
\text { (n=826) }\end{array}$} & \multicolumn{2}{c}{ Population } \\
& $\mathbf{2}=\mathbf{3 5 0 2})$ \\
& $\mathbf{n}$ & $\mathbf{\%}$ & $\mathbf{n}$ & $\mathbf{\%}$ \\
\hline American Indian/Alaska Native & 8 & 1.0 & 37 & 1.1 \\
Asian & 69 & 8.4 & 307 & 8.8 \\
Black/African American & 17 & 2.1 & 93 & 2.7 \\
Native Hawaiian or Other Pacific Islander & 3 & 0.4 & 12 & 0.3 \\
White & 699 & 84.6 & 2918 & 83.3 \\
Multiracial & 30 & 3.6 & 135 & 3.9 \\
\hline \hline
\end{tabular}

Students in the sample had the same average age as master's students in the population.

The average age of the population and sample was 34 years old. The range of age was similar for the population and sample from early twenties to late sixties early seventies.

\section{Table 9: Student Demographics Age}




\begin{tabular}{lrrrrr}
\hline \hline \multicolumn{1}{c}{ Age } & \multicolumn{1}{c}{ N } & \multicolumn{1}{c}{ Min } & \multicolumn{1}{c}{ Max } & \multicolumn{1}{c}{ Mean } & \multicolumn{1}{c}{ SD } \\
\hline Sample & 826 & 22 & 68 & 33.69 & 9.008 \\
Population & 3502 & 21 & 70 & 33.56 & 8.551 \\
\hline \hline
\end{tabular}

There was only one student of the 942 sampled who did not register for classes the following fall, winter, or spring of 2012-2013. The students graduated, had continuous enrollment, or discontinuous enrollment, i.e., stopped out one or more term or dropped out.

Table 10: Enrollment 2012-2013

\begin{tabular}{lc}
\hline \multicolumn{1}{c}{ Enrollment [n(\%)] } & $(\mathbf{N}=\mathbf{9 4 2})$ \\
\hline Continuous Enrollment & 805 \\
& $(85.5)$ \\
Discontinuous Enrollment & 136 \\
& $(14.4)$ \\
Drop-Out & 1 \\
& $(0.1)$ \\
\hline \hline
\end{tabular}

Before investigating student advising satisfaction and success, student experiences with advising and mentoring were examined.

\section{Advising and Mentoring}

In order to look for a connection between advising and student success, the researcher started by working to understand student access to advising. The definition of the faculty adviser was drawn from Nettles and Millett (2006): they argue that students have an adviser that fulfills a bureaucratic role, but that some students may also have a mentor who provides additional guidance and support. In the survey, students were queried if they had an adviser. It was expected that all students would have been assigned 
an adviser upon entrance to their master's program. However, when the survey was piloted, some students noted that they didn't have an adviser or that even after a year in a program they had not met with their adviser. This was also the case with the survey responses. Students were given the definition of a faculty adviser and then queried to identify whether they had an adviser: "A faculty adviser is usually assigned to you when you begin your graduate program. He/she can help you create a program of study, approve coursework, and sign official paperwork. This person may or may not be your mentor. Do you have a faculty adviser?" One hundred students (11\%) responded that they did not have an adviser, while 813 (89\%) indicated that they did have an adviser. In order for advising to be effective, students need to meet with their adviser. Of the $89 \%$ who did have an adviser, $3.9 \%$ of these students had not been in contact with their adviser and $35 \%$ had meet with their adviser less than once per term. Nearly $40 \%$ of students had one or fewer encounters with their adviser during the course of the term. The majority of the students sampled (61.1\%) were meeting with their adviser at least once per term, so most students had some contact with their adviser. 
Table 11: Student Meetings with Adviser

\begin{tabular}{ll}
\hline \hline Student Meetings with Adviser [n, (\%)] & $(\mathbf{N}=\mathbf{8 1 1})$ \\
\hline Less than once per term & 284 \\
& $(35)$ \\
Once per term & 204 \\
& $(25.2)$ \\
Twice per term & 113 \\
& $(13.9)$ \\
3 times per term & 39 \\
& $(4.8)$ \\
4 times per term & 33 \\
& $(4.1)$ \\
5 times per term & 21 \\
& $(2.6)$ \\
6 or more times per term & 85 \\
& $(10.5)$ \\
I have not been in contact with my adviser & 32 \\
& $(3.9)$ \\
\hline \hline
\end{tabular}

Student satisfaction with advising is impacted by the idea of faculty accessibility (Barnes et al., 2010). Students may not feel welcome to visit their advisers, or may perceive that their adviser is not the best source for the information they need at different points in their program (Horn \& Elliott, 2011). Students from disadvantaged populations including students of color, women and men in certain fields, as well as part-time students, may feel unwelcome in their program or department (Gardner \& Gopaul, 2012). The primary ways that students connected with their master's adviser was by email $(50.1 \%)$ and in person $(46.2 \%)$. Students rarely used the phone $(1.8 \%)$ or other methods $(1.9 \%)$.

Table 12: Methods of Contact with Adviser

\begin{tabular}{ll}
\hline \hline $\mathbf{n}(\boldsymbol{\%})]$ & $(\mathbf{n}=\mathbf{7 7 7})$ \\
\hline In person & 359 \\
& $(46.2)$ \\
Phone & 14 \\
& $(1.8)$ \\
\hline
\end{tabular}




\begin{tabular}{ll}
\hline Email & 389 \\
& $(50.1)$ \\
Other & 15 \\
& $(1.9)$ \\
\hline \hline
\end{tabular}

Part-time students used email $65.3 \%$ of the time to communicate with their advisers as opposed to full-time students who used email $44.7 \%$ of the time. This result was statistically significant $(\mathrm{p}<0.001)$.

Recognizing that advising and mentoring can be different roles and may be filled by multiple people, students were queried if they had a mentor and if that person was their adviser (Nettles \& Millet, 2006). More than half (55.1\%) responded that they did not have a mentor (See Table 13: Mentor). Of the students who did have a mentor, $22.1 \%$ said that the mentor was also their adviser and $22.8 \%$ said their mentor was someone other than their assigned adviser (See Table 13: Mentor).

\section{Table 13: Mentor}

\begin{tabular}{llll}
\hline \hline Mentor [n (\%)] & $\mathbf{( n = 8 9 9 )}$ & Mentor [n (\%)] & $(\mathbf{n = 8 9 9 )}$ \\
\hline No & 495 & No & 495 \\
& $(55.1)$ & & $(55.1)$ \\
Yes (same as adviser) & 199 & Yes & 404 \\
& $(22.1)$ & & $(42.9)$ \\
Yes (not same as adviser) & 205 & & \\
& $(22.8)$ & & \\
\hline \hline
\end{tabular}

All students were queried to identify their primary source of information (See Table 14: Primary Source of Information). Nearly $40 \%$ indicated that faculty members were their primary source for information. Over seventeen percent selected the department website and $16.0 \%$ looked to peers for help with information. Informational advising items may be delivered through websites and handbooks, but over $60 \%$ of 
students indicated that their primary source of information was a person-either a faculty member, staff member, or peer.

\section{Table 14: Primary Source of Information}

\begin{tabular}{llc}
\hline \hline \multirow{2}{*}{ Information [n, \%] } & \multicolumn{2}{c}{ (n=894) } \\
\cline { 2 - 3 } & $\mathbf{n}$ & $\mathbf{\%}$ \\
\hline Faculty & 353 & 39.6 \\
Department website & 158 & 17.7 \\
Students in my program & 143 & 16.0 \\
University Website & 78 & 8.7 \\
Department Secretary/Staff & 77 & 8.5 \\
Department handbook (printed) & 37 & 4.1 \\
Other & 48 & 5.4 \\
\hline \hline
\end{tabular}

Student responses to the question "what is your primary source of information" provide critical information for university departments and programs about advising and program information delivery. If the students are primarily relying upon the department website, then it is important for pertinent schedules, policies, and information to be made available on the website and for it to be accurate.

In order to understand the impact of student satisfaction with advising on student success, students were queried to indicate their level of satisfaction with the advising they received. Student satisfaction was measured on a Likert-type scale from 1-6 where 1=Not Satisfied and 6=Very Satisfied. Table 15: Advising Responses shows the student responses to the advising questions.

Students' average responses were ranked in order of satisfaction. Student's highest average satisfaction rating were for the variables accessibility, "your faculty adviser's accessibility" $(M=4.64)$, encourage thesis, "encouraging them to make progress 
on their thesis" $(M=4.49)$, and accurate information, "ability to give them accurate information about program requirements" $(\mathrm{M}=4.40)$. Students' lowest satisfaction ratings were for the variables adviser wish, "there is another faculty member in my department that I wish was my adviser" $(\mathrm{M}=3.02)$, referral non-academic, "when needed, referring you to campus services for non-academic support (i.e., childcare, financial aid, student health and counseling center)" (M=3.37) and networking, "helping you network in your field (i.e., introducing you to colleagues at the university or at a conference, etc.)" $(M=3.44)$. The satisfaction scale is $1-6$, so 3.50 is the center of the scale. The lowest ranked items have a mean below 3.50 suggesting that students are not satisfied with the advising they receive on these items. These numbers tell us which of the advising functions students surveyed were most satisfied with, but do not tell us which advising function they rate as most important. It is important to notice that even the advising functions with the highest levels of satisfaction did not rise above 4.6 out of a six point scale. The high satisfaction with accessibility was surprising because the focus groups had indicated student frustration with high advising loads leading to low accessibility. Looking at just the administrative advising student satisfaction ratings, accurate information through adviser assigned, shows that students were at least marginally satisfied with most. Adviser wish (3.02), wishing someone else in the department was their faculty adviser, fell well below the center of the scale (3.50) demonstrating that most student do not wish for another adviser in their department. What this suggests is that overall students are satisfied with informational and organizational advising. The mentoring advising functions are all above average (3.5) except for networking $(\mathrm{M}=3.44)$ 
and referral non-academic $(\mathrm{M}=3.37)$. What this suggests is that there are some categories of mentoring advising with which students are actively dissatisfied. These results were correlated to student success by running regression analyses.

Table 15: Advising Responses

\begin{tabular}{|c|c|c|c|c|c|c|c|c|c|}
\hline $\begin{array}{l}\text { Advising [n } \\
(\%)]\end{array}$ & $\mathbf{n}$ & $\begin{array}{l}1 \text { Not } \\
\text { Satisfied } \\
\end{array}$ & 2 & 3 & 4 & 5 & $\begin{array}{l}6 \text { Very } \\
\text { Satisfied } \\
\end{array}$ & $\begin{array}{l}\text { M } \\
\text { (SD) }\end{array}$ & Rank \\
\hline $\begin{array}{l}\text { Accurate } \\
\text { Information }\end{array}$ & 883 & $\begin{array}{l}31 \\
(3.5)\end{array}$ & $\begin{array}{l}57 \\
(6.5)\end{array}$ & $\begin{array}{l}106 \\
(12.0)\end{array}$ & $\begin{array}{l}207 \\
(23.4)\end{array}$ & $\begin{array}{l}294 \\
(33.3)\end{array}$ & $\begin{array}{l}188 \\
(21.3)\end{array}$ & $\begin{array}{l}4.40 \\
(1.31)\end{array}$ & 3 \\
\hline $\begin{array}{l}\text { Policies \& } \\
\text { Procedures }\end{array}$ & 881 & $\begin{array}{l}46 \\
(5.2)\end{array}$ & $\begin{array}{l}74 \\
(8.4)\end{array}$ & $\begin{array}{l}127 \\
(14.4)\end{array}$ & $\begin{array}{l}214 \\
(24.3)\end{array}$ & $\begin{array}{l}266 \\
(30.2)\end{array}$ & $\begin{array}{l}154 \\
(17.5)\end{array}$ & $\begin{array}{l}4.18 \\
(1.39)\end{array}$ & 6 \\
\hline $\begin{array}{l}\text { Educational } \\
\text { Plan }\end{array}$ & 799 & $\begin{array}{l}74 \\
(9.3)\end{array}$ & $\begin{array}{l}91 \\
(11.4)\end{array}$ & $\begin{array}{l}102 \\
(12.8)\end{array}$ & $\begin{array}{l}168 \\
(21.0)\end{array}$ & $\begin{array}{l}167 \\
(20.9)\end{array}$ & $\begin{array}{l}197 \\
(24.7)\end{array}$ & $\begin{array}{l}4.07 \\
(1.62)\end{array}$ & 7 \\
\hline Accessibility & 754 & $\begin{array}{l}46 \\
(6.1)\end{array}$ & $\begin{array}{l}73 \\
(9.7)\end{array}$ & $\begin{array}{l}87 \\
(11.5)\end{array}$ & $\begin{array}{l}139 \\
(18.4)\end{array}$ & $\begin{array}{l}188 \\
(24.9)\end{array}$ & $\begin{array}{l}221 \\
(29.3)\end{array}$ & $\begin{array}{l}4.64 \\
(1.88)\end{array}$ & 1 \\
\hline Adviser Time & 755 & $\begin{array}{l}58 \\
(7.7)\end{array}$ & $\begin{array}{l}104 \\
(13.8)\end{array}$ & $\begin{array}{l}129 \\
(17.1)\end{array}$ & $\begin{array}{l}129 \\
(17.1)\end{array}$ & $\begin{array}{l}147 \\
(19.5)\end{array}$ & $\begin{array}{l}188 \\
(24.9)\end{array}$ & $\begin{array}{l}4.26 \\
(1.95)\end{array}$ & 4 \\
\hline Adviser Wish* & 895 & $\begin{array}{l}250 \\
(27.9)\end{array}$ & $\begin{array}{l}156 \\
(17.4)\end{array}$ & $\begin{array}{l}156 \\
(17.4)\end{array}$ & $\begin{array}{l}117 \\
(13.1)\end{array}$ & $\begin{array}{l}95 \\
(10.6)\end{array}$ & $\begin{array}{l}121 \\
(13.5)\end{array}$ & $\begin{array}{l}3.02 \\
(1.75)\end{array}$ & 16 \\
\hline $\begin{array}{l}\text { Adviser } \\
\text { Assigned* }\end{array}$ & 773 & $\begin{array}{l}121 \\
(16)\end{array}$ & $\begin{array}{l}102 \\
(13)\end{array}$ & $\begin{array}{l}126 \\
(16)\end{array}$ & $\begin{array}{l}138 \\
(18)\end{array}$ & $\begin{array}{l}148 \\
(19)\end{array}$ & $\begin{array}{l}138 \\
(18)\end{array}$ & $\begin{array}{l}3.65 \\
(1.70)\end{array}$ & 11 \\
\hline Feedback & 622 & $\begin{array}{l}95 \\
(15.3)\end{array}$ & $\begin{array}{l}78 \\
(12.5)\end{array}$ & $\begin{array}{l}74 \\
(11.9)\end{array}$ & $\begin{array}{l}107 \\
(17.2)\end{array}$ & $\begin{array}{l}124 \\
(19.9)\end{array}$ & $\begin{array}{l}144 \\
(23.2)\end{array}$ & $\begin{array}{l}3.83 \\
(1.76)\end{array}$ & 9 \\
\hline Collaborate & 549 & $\begin{array}{l}117 \\
(21.3)\end{array}$ & $\begin{array}{l}67 \\
(12.2)\end{array}$ & $\begin{array}{l}76 \\
(13.8)\end{array}$ & $\begin{array}{l}98 \\
(17.9)\end{array}$ & $\begin{array}{l}97 \\
(17.7)\end{array}$ & $\begin{array}{l}94 \\
(17.1)\end{array}$ & $\begin{array}{l}3.50 \\
(1.78)\end{array}$ & 13 \\
\hline Networking & 626 & $\begin{array}{l}137 \\
(21.9)\end{array}$ & $\begin{array}{l}70 \\
(11.2)\end{array}$ & $\begin{array}{l}101 \\
(16.1)\end{array}$ & $\begin{array}{l}116 \\
(18.5)\end{array}$ & $\begin{array}{l}100 \\
(16.0)\end{array}$ & $\begin{array}{l}102 \\
(16.3)\end{array}$ & $\begin{array}{l}3.44 \\
(1.76)\end{array}$ & 14 \\
\hline $\begin{array}{l}\text { Encourage } \\
\text { Thesis }\end{array}$ & 132 & $\begin{array}{l}6 \\
(4.5)\end{array}$ & $\begin{array}{l}11 \\
(8.3)\end{array}$ & $\begin{array}{l}18 \\
(13.6)\end{array}$ & $\begin{array}{l}21 \\
(15.9)\end{array}$ & $\begin{array}{l}29 \\
(22.0)\end{array}$ & $\begin{array}{l}47 \\
(35.6\end{array}$ & $\begin{array}{l}4.49 \\
(1.52)\end{array}$ & 2 \\
\hline Individual & 732 & $\begin{array}{l}108 \\
(14.8)\end{array}$ & $\begin{array}{l}63 \\
(8.6)\end{array}$ & $\begin{array}{l}83 \\
(11.3)\end{array}$ & $\begin{array}{l}125 \\
(17.1)\end{array}$ & $\begin{array}{l}145 \\
(19.8)\end{array}$ & $\begin{array}{l}208 \\
(28.4)\end{array}$ & $\begin{array}{l}4.04 \\
(1.77)\end{array}$ & 8 \\
\hline Care & 722 & $\begin{array}{l}97 \\
(13.4)\end{array}$ & $\begin{array}{l}59 \\
(8.2)\end{array}$ & $\begin{array}{l}65 \\
(9.0)\end{array}$ & $\begin{array}{l}117 \\
(16.2)\end{array}$ & $\begin{array}{l}140 \\
(19.4)\end{array}$ & $\begin{array}{l}244 \\
(33.8)\end{array}$ & $\begin{array}{l}4.21 \\
(1.77)\end{array}$ & 5 \\
\hline $\begin{array}{l}\text { Referral } \\
\text { Academic }\end{array}$ & 475 & $\begin{array}{l}68 \\
(14.3)\end{array}$ & $\begin{array}{l}61 \\
(12.8)\end{array}$ & $\begin{array}{l}72 \\
(15.2)\end{array}$ & $\begin{array}{l}111 \\
(23.4)\end{array}$ & $\begin{array}{l}85 \\
(17.9)\end{array}$ & $\begin{array}{l}78 \\
(16.4)\end{array}$ & $\begin{array}{l}3.67 \\
(1.64)\end{array}$ & 10 \\
\hline $\begin{array}{l}\text { Referral Non- } \\
\text { academic }\end{array}$ & 429 & $\begin{array}{l}80 \\
(18.6)\end{array}$ & $\begin{array}{l}65 \\
(15.2)\end{array}$ & $\begin{array}{l}72 \\
(16.8)\end{array}$ & $\begin{array}{l}98 \\
(22.8)\end{array}$ & $\begin{array}{l}57 \\
(13.3)\end{array}$ & $\begin{array}{l}57 \\
(13.3)\end{array}$ & $\begin{array}{l}3.37 \\
(1.65)\end{array}$ & 15 \\
\hline Funding & 617 & $\begin{array}{l}119 \\
(19.3)\end{array}$ & $\begin{array}{l}82 \\
(13.3)\end{array}$ & $\begin{array}{l}99 \\
(16.0)\end{array}$ & $\begin{array}{l}106 \\
(17.2)\end{array}$ & $\begin{array}{l}85 \\
(13.8)\end{array}$ & $\begin{array}{l}126 \\
(20.4)\end{array}$ & $\begin{array}{l}3.54 \\
(1.78)\end{array}$ & 12 \\
\hline
\end{tabular}

*Based on Likert-type scale 1-6, 1=Not Satisfied, 6=Very Satisfied

In addition to looking at rates of student satisfaction with each advising function,

Table 15: Advising Responses shows that the number of student responses out of a sample size of 942 for each question varies from $n=895$ for adviser wish, wishing 
someone else in the department was their adviser, to $n=429$ for referral non-academic, when needed referral to services on campus including financial aid, child care, etc. The advising question regarding thesis encouragement was only queried to students who indicated they were working on a thesis. Some students may have self-selected not to answer a question because it was not part of their advising experience. For example, out of a sample size of 140, 132 responded to the question encourage thesis.

The variance in the response rate for the other 15 questions is because students chose not to respond or marked "not applicable." The not applicable option was added to account for the students who may have been self-advising and not working with a faculty adviser. The lowest number of student responses were to the advising functions of referral non-academic $(n=429)$, referral academic $(n=475)$, collaborate $(n=549)$, networking $(n=622)$, and feedback $(n=626)$. The low numbers of students answering referral questions may indicate that such questions are not relevant to students who are self advising or who are not in need of such services. The referral and mentoring functions require a skilled faculty member. They also require an investment of time and energy by that faculty member. Due to workload issues and advising load constraints, faculty may have to limit the number of students to whom they provide mentoring. Faculty may not be able to know all their advisees personally, especially if they have high advising loads. It may be more difficult to provide referrals for academic and nonacademic support as well as help with funding if faculty do not know students well and only have limited advising contact. Due to time constraints they may not be able to collaborate and network with all the students they advise. Similarly, CGS (2010) finds 
that "because mentoring is practiced and valued unevenly in doctoral programs, and because student expectations of mentors differ, it is not surprising that student report having unequal access to quality mentors as they pursue their Ph.D.s" (p.33). The lower response to questions regarding mentoring advising may reflect that students without mentors do not receive advising on these items. Also, referral items are most meaningful for the students who need them. Students who do not need referral to academic and nonacademic support may not have responded to these questions.

Low response rates on some of these questions created a limitation because there is missing data that prevents the inclusion of those students in the regressions. But students not answering questions may also indicate that students are not able to access certain advising functions, except for cases like encourage thesis that were only queried to a subset of students.

These findings demonstrate the complexity of the advising and mentoring relationship. Troubling is the number of students who do not have an adviser $(n=100)$ and of the remaining students the number that had not been in contact with their adviser $(n=32)$. These students are likely self-advising or relying on peers for information. Additionally only 404 of the sample $(\mathrm{N}=942)$ identified as having a mentor. Those students who do not have a mentor are likely missing out on advising around educational and professional development. And only 199 of the students with an adviser noted that their mentor was their adviser. So less that a quarter $(24 \%)$ of the students in the sample with an adviser identified that adviser as a mentor. 


\section{Multivariate analysis: Student characteristics and advising satisfaction}

One of the research questions is do student characteristics correlate to advising satisfaction? Error! Reference source not found. shows the linear regressions for each advising variable. The demographic and educational variables were included as independent variables and each advising variable was listed as the dependent variable. The statistically significant findings are listed.

Female students do not have any statistically significant differences in advising satisfaction compared to male students. Minority students are more satisfied with their advisers help with referral to academic services.

Age is positive for adviser assigned. As students age, they are more satisfied with how advisers are assigned. In Gardner and Gopaul (2012), older doctoral students had more trouble feeling that they "fit" the mold of graduate school. These elements did not arise in this study. This may be because the student sample are master's students and not doctoral students, that the sample has an average age of 32 years, or the fact that this urban institution has a less traditional student population. Older students may be more actively engaged in talking with their departments or selecting their program based upon the adviser they would like to work with because they have more life and work experience. Older students are less likely to wish another adviser in the department was their adviser.

Part-time students were more satisfied with their advisers help with navigating policies and procedures.. The researcher expected part-time students to be less satisfied with access to their adviser, time spent with their adviser, opportunities to collaborate, 
network, and be known as an individual. These findings are similar to Gardner and Gopaul (2012) where part-time students struggle to connect with peers and faculty; however, cohorts were able to mitigate some of these concerns. Gardner and Gopual (2012) found that for part-time students cohorts were critical for connecting them to peers and making them feel a part of the campus experience. It appears that part-time students in this sample do not feel the sense of alienation noted by Gardner and Gopaul (2012) at least as it relates to satisfaction with advising.

Students in a cohort are less satisfied by the accuracy of the information they receive. Students in a cohort may be getting more of their information from peers and find that it is not accurate. Students outside of a cohort may have to be more self-reliant and look to online or printed material, or staff for information.

Students who were writing their thesis were less likely than non-thesis writing students to wish for another adviser in their department. The stakes are higher for students writing a thesis than for students not writing a thesis. They are close to the completion of their degree, but in order to graduate, they must complete a substantial paper. This work requires additional support from advisers and likely leads to stress about their ability to access their adviser. Thesis writers were more satisfied with their adviser's help identifying funding.

The variables that made the most difference in student satisfaction ratings were student who identified as being mentored, rely upon more than one faculty member for advice, and meet with their adviser once or more per term. Students who identified as having a mentor were more satisfied than students who did not have a mentor on 14 of 16 
advising functions including all of the informational, educational, and relational advising variables. Students with a mentor were more satisfied with all the informational advising items: accurate information, policies and procedures, and help forming an educational plan. In terms of organizational advising items, they were more satisfied with adviser accessibility and the amount of time they spend with their adviser. They were satisfied with all of the educational advising items: feedback, collaborating, networking, and getting encouragement for their thesis writing. Also, they were more satisfied with all of the relational advising items: referral academic, referral non-academic, help with finding funding, being known as an individual and having their adviser care about them. Students with mentors are more satisfied with the advising they receive on nearly every advising variable with the exception of wishing for another adviser and being satisfied with how advisers are assigned. This suggests that connecting master's students with mentors would improve their advising experiences. However, we know that only $55.1 \%$ identified as having a mentor.

The students who meet with their adviser once per term or more were more satisfied than their peers who met with their adviser less than once per term on 13 of the 16 advising variables: accurate information, policies and procedures, educational plan, accessibility, amount of time, how advisers are assigned, feedback, networking, referral academic and referral non-academic, help with funding, know as individual and care. These students were less likely to wish another adviser in their department was their adviser. There was no difference in their response to collaborating and encouraging 
thesis. This seems to show that frequency of interaction does not guarantee the mentoring function of collaboration with your adviser.

Students who identified as having relied upon more than one faculty member for advice were more satisfied on 8 of the 16 advising variables in comparison to students who relied on one or no faculty for advice. Students with multiple mentors were more satisfied with all the informational advising items: accurate information, policies and procedures, and help forming an educational plan. It made no difference in regards to organizational advising items, and they were only more satisfied on one educational advising item, which was feedback. Also, they were more satisfied with almost all of the relational advising items: referral academic, referral non-academic, being known as an individual and having their adviser care about them.

\section{Advising Satisfaction}

The findings show that student satisfaction with advising at this institution is not overwhelmingly positive, but students who identified as having a mentor were more satisfied than students without a mentor on 14 out of 16 variables. Student who met with their adviser one or more times per term were more satisfied with 13 of the 16 advising variables. Students who identified as having two or more faculty they could count on for advising information were more satisfied with 8 of the 16 advising functions than students who could only none or one faculty member. These aspects of the advising relationship — mentoring, frequency, and multiple mentors - are significant for student satisfaction with advising. In this study, student satisfaction is used as a measure of quality advising. It is predicted that quality advising leads to student success (Habley, 
1981; Tinto, 1993). It is difficult to capture quality, but students know if they are getting what they need and if they are satisfied.

Student characteristics. Student characteristics also led to advising satisfaction. Male students were more satisfied with their advisers' accessibility. American Indian/Native Alaskan students were more satisfied with the advising they received on accurate information and policies and procedures. Asian students were more satisfied with the advising they receive on accurate information, educational plan, adviser time, and referral academic. Native Hawaiian or Pacific Islander students were more satisfied with accessibility and less satisfied with time spent with adviser. Multiracial students were less satisfied with being known as an individual and adviser care. These characteristics while influential to student satisfaction were not significant to the student success regressions. 
Table 16: Results of regression analyses with student characteristics predicting student satisfaction with advising variables (Full tables available in Appendix C)

\begin{tabular}{|c|c|c|c|c|c|c|c|c|c|c|c|c|c|c|c|c|}
\hline$[\mathrm{B}(\mathrm{SE})]$ & AI & PP & EP & ACC & TM & AW & AA & FB & $\overline{\mathrm{COL}}$ & NET & ET & RA & RNA & FUN & IND & CAR \\
\hline Constant & $\begin{array}{l}3.70 \\
(0.24)\end{array}$ & $\begin{array}{l}3.12 \\
(0.25) \\
\end{array}$ & $\begin{array}{l}3.04 \\
(0.30)\end{array}$ & $\begin{array}{l}3.30 \\
(0.33)\end{array}$ & $\begin{array}{l}2.59 \\
(0.33)\end{array}$ & $\begin{array}{l}4.05 \\
(0.32)\end{array}$ & $\begin{array}{l}2.63 \\
(0.34)\end{array}$ & $\begin{array}{l}2.06 \\
(0.36)\end{array}$ & $\begin{array}{l}2.06 \\
(0.42)\end{array}$ & $\begin{array}{l}2.26 \\
(0.39)\end{array}$ & $\begin{array}{l}3.30 \\
(0.86)\end{array}$ & $\begin{array}{l}2.47 \\
(0.42)\end{array}$ & $\begin{array}{l}1.98 \\
(0.44)\end{array}$ & $\begin{array}{l}2.09 \\
(0.39)\end{array}$ & $\begin{array}{l}2.36 \\
(0.34)\end{array}$ & $\begin{array}{l}2.60 \\
(0.34)\end{array}$ \\
\hline \multicolumn{17}{|l|}{ Female } \\
\hline Minority & & & & & & & & & & & & $\begin{array}{l}0.45^{\circ} \\
(0.21)\end{array}$ & & & & \\
\hline Age & & & & & & $\begin{array}{l}0.02^{*} \\
(0.01)\end{array}$ & $\begin{array}{l}0.02^{\circ} \\
(0.01)\end{array}$ & & & & & & & & & \\
\hline Part-time & & $\begin{array}{l}0.26^{\circ} \\
(0.13)\end{array}$ & & & & & & & & & & & & & & \\
\hline Cohort & $\begin{array}{l}-0.28^{*} \\
(0.10)\end{array}$ & & & & & & & & & & & & & & & \\
\hline Thesis & & & & & & $\begin{array}{l}0.38^{\circ} \\
(0.18)\end{array}$ & & & & & & & & $\begin{array}{l}0.53^{\circ} \\
(0.21)\end{array}$ & & \\
\hline Mentor & $\begin{array}{l}0.27^{*} \\
(0.11)\end{array}$ & $\begin{array}{l}0.31^{*} \\
(0.11)\end{array}$ & $\begin{array}{l}0.57^{\circ *} \\
(0.14)\end{array}$ & $\begin{array}{l}0.33^{*} \\
(0.15)\end{array}$ & $\begin{array}{l}0.42^{*} \\
(0.15)\end{array}$ & & & $\begin{array}{l}1.00^{* *} \\
(0.16)\end{array}$ & $\begin{array}{l}1.03^{* *} \\
(0.18)\end{array}$ & $\begin{array}{l}0.91 * 0 \\
(0.17)\end{array}$ & $\begin{array}{l}1.37^{\circ} \\
(0.34)\end{array}$ & $\begin{array}{l}0.77^{*} \\
(0.18)\end{array}$ & $\begin{array}{l}0.65^{*} \\
(0.20)\end{array}$ & $\begin{array}{l}0.88^{\circ} \\
(0.17)\end{array}$ & $\begin{array}{l}0.99^{\circ *} \\
(0.15)\end{array}$ & $\begin{array}{l}0.99 * * \\
(0.15)\end{array}$ \\
\hline $\begin{array}{l}\text { Multiple } \\
\text { Faculty }\end{array}$ & $\begin{array}{l}0.34^{* *} \\
(0.11)\end{array}$ & $\begin{array}{l}0.53 * * \\
(0.12)\end{array}$ & $\begin{array}{l}0.38^{\circ} \\
(0.14)\end{array}$ & & & & & $\begin{array}{l}0.56^{* *} \\
(0.17)\end{array}$ & & & & $\begin{array}{l}0.57^{*} \\
(0.19)\end{array}$ & $\begin{array}{l}0.62^{*} \\
(0.20)\end{array}$ & & $\begin{array}{l}0.42^{\circ} \\
(0.15)\end{array}$ & $\begin{array}{l}0.56^{* *} \\
(0.15)\end{array}$ \\
\hline $\begin{array}{l}\text { Meeting } \\
\text { Often }\end{array}$ & $\begin{array}{l}0.39^{* *} \\
(0.11)\end{array}$ & $\begin{array}{l}0.34^{*} \\
(0.12)\end{array}$ & $\begin{array}{l}0.60^{* *} \\
(0.14)\end{array}$ & $\begin{array}{l}1.32^{* *} \\
(0.15)\end{array}$ & $\begin{array}{l}1.53^{* *} \\
(0.15)\end{array}$ & $\begin{array}{l}0.93 * \\
(0.15)\end{array}$ & $\begin{array}{l}0.95 * * \\
(0.16)\end{array}$ & $\begin{array}{l}0.75^{* *} \\
(0.17)\end{array}$ & & $\begin{array}{l}0.48^{*} \\
(0.18)\end{array}$ & & $\begin{array}{l}0.37^{*} \\
(0.19)\end{array}$ & $\begin{array}{l}0.38^{\circ} \\
(0.19)\end{array}$ & $0.62 * *$ & $\begin{array}{l}0.57^{* *} \\
(0.16)\end{array}$ & $\begin{array}{l}0.65^{* *} \\
(0.16)\end{array}$ \\
\hline $\mathrm{R}^{2}$ & 0.08 & 0.08 & 0.11 & 0.17 & 0.23 & 0.10 & 0.08 & 0.23 & 0.16 & 0.14 & 0.19 & 0.14 & 0.15 & 0.17 & 0.19 & 0.21 \\
\hline $\mathrm{F}$ & $6.16 * 0$ & $6.56^{* *}$ & $8.40^{\circ *}$ & $14.24^{* *}$ & $20.55^{\circ *}$ & $7.91^{* *}$ & $6.53^{\circ *}$ & $15.23^{* *}$ & $8.72 * *$ & $8.42 * *$ & $3.00^{\circ}$ & $6.34^{\circ}$ & $5.74 * *$ & $10.09^{* *}$ & $13.91^{* *}$ & $15.77^{* *}$ \\
\hline
\end{tabular}


Another research question was how does student satisfaction with advising vary depending upon student characteristics? Overall the findings showed that student characteristics have little impact on advising satisfaction. Gender has no impact, minority students are more satisfied with academic referral, and older students are more satisfied how advisers are assigned and less likely to wish for another adviser.

Educational characteristics had a larger impact on advising satisfaction. Students in a cohort are less satisfied with the accuracy of the information they receive, part-time students are more satisfied with the help they get navigating the policies and procedures, and thesis students are more satisfied with the help they get with finding funding and less likely to wish for another adviser. Unsurprisingly, frequency of contact with an adviser matters. Having more than one faculty member for support was correlated positively to advising satisfaction. Identifying as having a mentor led to higher satisfaction on all the informational, educational, and relational advising variables. These results suggest mentoring is important and that students should seek out faculty connections and meet regularly with their adviser.

\section{Student Success}

Advising is linked to student success in the literature, especially for doctoral students. The goal of this study is to explore the correlation between student success and advising. Student success includes graduation, which is the goal of most students beginning graduate work, and measures of progress toward graduation (See Table 17: Student Success Responses). Progress toward graduation can be measured as Institutional Commitment, Degree Commitment, and Program Commitment, which 
promote student retention by increasing student's connection to their institution, program and goals (Cooke, 1995). Student success is also defined by a passing graduate grade point average. Some master's programs only have course work and no other significant milestones. GPA may be the only cut off—or gate keeping measure—in a master's program, if the program does not require a culminating project, practicum, or thesis. Students indicated their level of agreement from 1-6 where 1=Strongly Disagree and 6=Strongly Agree with the retention proxy items: institutional commitment, program commitment, and degree commitment. Nearly ninety percent (87.9\%) of students agree that their graduate degree will help them advance professionally. Students in the sample see the value of the degree they are working towards. Just over eighty percent $(81.8 \%)$ of students agree that in their program, they are learning the skills and knowledge they need to work in their field. This demonstrates that students feel their programs are teaching them what they need to know. One would expect that students who feel their programs are giving them the necessary skills for their field that they would be motivated to finish their degree. Over three-quarters (77.5\%) of students are confident that they made the right decision in choosing to attend this university. This percentage is lower than the percentages for degree and program commitment. One explanation might be that students choose to attend this institution because they are place-bound and it is local. While they are excited about the benefits of the degree or program, they may feel they had less choice in selecting the institution.

Students are required to maintain a cumulative GPA of 3.0 to remain in good academic standing. Table 18 shows the minimum GPA in the sample was 2.67 , a student 
not in good academic standing, to 4.00 . The average GPA was 3.82 with a standard deviation of 0.19 . The low standard deviation suggests that there is not much variation within the sample meaning most student have a similar GPA. The students with a GPA below 3.0 did not have the necessary credits to move forward in their program.

Table 17: Student Success Responses

\begin{tabular}{|c|c|c|c|c|c|c|c|c|}
\hline $\begin{array}{l}\text { Student } \\
\text { Success } \quad \text { [n } \\
(\%)]\end{array}$ & $\mathbf{N}$ & $\begin{array}{l}1 \\
\text { Strongly } \\
\text { Disagree }\end{array}$ & 2 & 3 & 4 & 5 & $\begin{array}{l}6 \\
\text { Strongly } \\
\text { Agree }\end{array}$ & $\begin{array}{l}\text { M } \\
\text { (SD) }\end{array}$ \\
\hline $\begin{array}{l}\text { Institutional } \\
\text { Commitment }\end{array}$ & 856 & $\begin{array}{l}32 \\
(3.7)\end{array}$ & $\begin{array}{l}73 \\
(8.5)\end{array}$ & $\begin{array}{l}88 \\
(10.3)\end{array}$ & $\begin{array}{l}172 \\
(20.1)\end{array}$ & $\begin{array}{l}254 \\
(29.7)\end{array}$ & $\begin{array}{l}237 \\
(27.7)\end{array}$ & $\begin{array}{l}4.46 \\
(1.40)\end{array}$ \\
\hline $\begin{array}{l}\text { Program } \\
\text { Commitment }\end{array}$ & 857 & $\begin{array}{l}21 \\
(2.5)\end{array}$ & $\begin{array}{l}38 \\
(4.4)\end{array}$ & $\begin{array}{l}98 \\
(11.4)\end{array}$ & $\begin{array}{l}190 \\
(22.2)\end{array}$ & $\begin{array}{l}273 \\
(31.9)\end{array}$ & $\begin{array}{l}237 \\
(27.7)\end{array}$ & $\begin{array}{l}4.60 \\
(1.26)\end{array}$ \\
\hline $\begin{array}{l}\text { Degree } \\
\text { Commitment }\end{array}$ & 856 & $\begin{array}{l}11 \\
(1.3)\end{array}$ & $\begin{array}{l}37 \\
(4.3)\end{array}$ & $\begin{array}{l}56 \\
(6.5)\end{array}$ & $\begin{array}{l}145 \\
(16.9)\end{array}$ & $\begin{array}{l}265 \\
(31.0)\end{array}$ & $\begin{array}{l}342 \\
(40.0)\end{array}$ & $\begin{array}{l}4.92 \\
(1.19)\end{array}$ \\
\hline GPA & $\mathbf{N}$ & Min & Max & & & & & $\begin{array}{l}M \\
\text { (SD) }\end{array}$ \\
\hline GPA & 942 & 2.67 & 4.00 & & & & & $\begin{array}{l}3.82 \\
(0.19)\end{array}$ \\
\hline
\end{tabular}

The primary research question investigated the correlation between advising satisfaction and master's student success. Correlation models work best when the researcher accounts for the confounding variables that may explain the outcome (Field, 2009). Student experiences in graduate school are more focused on the department. Tinto (1993) argues that academic and social integration are combined in graduate school. Advising may correlate to success, but peer culture, department culture and climate may also correlate to success. Therefore, it is important to include student experiences with culture and climate.

\section{Culture \& Climate}

Student experiences with peers and department may help or hinder with master's student success separate from the faculty advising relationship. The variables in the 
factors of peer culture, department culture, and department climate are defined below. Peer culture captures student experiences with their peers (See Table 18: Peer Culture Responses). Students may provide some of the advising functions and peer experiences, especially in cohorts, may account for success. Most students (85.3\%) agree that students share resources and information. This is the highest average agreement for a peer culture item. Over three fourths of students sampled (78.4\%) agree that they are friends with students in their program. Eighty percent $(80.1 \%)$ of students agree that students collaborate with one another.

Table 18: Peer Culture Responses

\begin{tabular}{|c|c|c|c|c|c|c|c|c|}
\hline $\begin{array}{l}\text { Peer } \\
\text { Culture [n } \\
(\%)]\end{array}$ & $\overline{\mathbf{N}}$ & $\begin{array}{l}1 \\
\text { Strongly } \\
\text { Disagree }\end{array}$ & 2 & $\overline{3}$ & $\overline{74}$ & $\overline{5}$ & $\begin{array}{l}6 \\
\text { Strongly } \\
\text { Agree }\end{array}$ & $\overline{\bar{M}}$ \\
\hline $\begin{array}{l}\text { Students } \\
\text { Collaborate }\end{array}$ & 870 & $\begin{array}{l}15 \\
(1.7)\end{array}$ & $\begin{array}{l}52 \\
(6.0)\end{array}$ & $\begin{array}{l}100 \\
(11.5)\end{array}$ & $\begin{array}{l}185 \\
(21.3)\end{array}$ & $\begin{array}{l}237 \\
(27.2)\end{array}$ & $\begin{array}{l}281 \\
(32.3)\end{array}$ & $\begin{array}{l}4.63 \\
(1.30)\end{array}$ \\
\hline $\begin{array}{l}\text { Students } \\
\text { Share }\end{array}$ & 870 & $\begin{array}{l}11 \\
(1.3)\end{array}$ & $\begin{array}{l}44 \\
(5.1)\end{array}$ & $\begin{array}{l}73 \\
(8.4)\end{array}$ & $\begin{array}{l}164 \\
(18.9)\end{array}$ & $\begin{array}{l}257 \\
(29.5)\end{array}$ & $\begin{array}{l}321 \\
(36.9)\end{array}$ & $\begin{array}{l}4.81 \\
(1.23)\end{array}$ \\
\hline $\begin{array}{l}\text { Student do } \\
\text { not Compete }\end{array}$ & 867 & $\begin{array}{l}76 \\
(8.8)\end{array}$ & $\begin{array}{l}98 \\
(11.3)\end{array}$ & $\begin{array}{l}149 \\
(17.2)\end{array}$ & $\begin{array}{l}214 \\
(24.7)\end{array}$ & $\begin{array}{l}206 \\
(23.8)\end{array}$ & $\begin{array}{l}124 \\
(14.3)\end{array}$ & $\begin{array}{l}3.86 \\
(1.49)\end{array}$ \\
\hline $\begin{array}{l}\text { Students } \\
\text { Mentor }\end{array}$ & 864 & $\begin{array}{l}115 \\
(13.3)\end{array}$ & $\begin{array}{l}164 \\
(19.0)\end{array}$ & $\begin{array}{l}173 \\
(20.0)\end{array}$ & $\begin{array}{l}190 \\
(22.0)\end{array}$ & $\begin{array}{l}147 \\
(17.0)\end{array}$ & $\begin{array}{l}75 \\
(8.7)\end{array}$ & $\begin{array}{l}3.36 \\
(1.51)\end{array}$ \\
\hline $\begin{array}{l}\text { Student } \\
\text { Friends }\end{array}$ & 870 & $\begin{array}{l}20 \\
(2.3)\end{array}$ & $\begin{array}{l}60 \\
(6.9)\end{array}$ & $\begin{array}{l}108 \\
(12.4)\end{array}$ & $\begin{array}{l}143 \\
(16.4)\end{array}$ & $\begin{array}{l}220 \\
(25.3)\end{array}$ & $\begin{array}{l}319 \\
(36.7)\end{array}$ & $\begin{array}{l}4.66 \\
(1.38)\end{array}$ \\
\hline
\end{tabular}

Overall, the responses to peer culture indicate that most students found their program to be collaborative and collegial in nature.

The variables included in department culture are defined below in Table 19: Department Culture Responses and then the responses from the survey are listed in Table 20. Department culture includes variables measuring if faculty in the department are accessible, if the overall learning environment is inclusive, if social events are created to 
bring faculty and students together, if students believe they "belong" in their department, and if students feel they "fit" in their program. The response rates were above 4 except for social events (3.49). Student responses to social events suggests a neutral response closer to strongly disagree.

\section{Table 19: Department Culture Responses}

\begin{tabular}{lclllllll}
\hline \hline $\begin{array}{l}\text { Department } \\
\text { Culture [n (\%)] }\end{array}$ & $\mathbf{N}$ & $\begin{array}{l}\mathbf{1} \\
\text { Strongly } \\
\text { Disagree }\end{array}$ & $\mathbf{2}$ & $\mathbf{3}$ & $\mathbf{4}$ & $\mathbf{5}$ & $\begin{array}{l}\mathbf{6} \\
\text { Strongly } \\
\text { Agree }\end{array}$ & $\mathbf{M}$ \\
\hline Faculty Accessible & 865 & 23 & 68 & 153 & 224 & 259 & 138 & 4.20 \\
& & $(2.7)$ & $(7.9)$ & $(17.7)$ & $(25.9)$ & $(29.9)$ & $(16.0)$ & $(1.28)$ \\
Inclusive Learning & 863 & 26 & 38 & 99 & 192 & 294 & 214 & 4.54 \\
& & $(3.0)$ & $(4.4)$ & $(11.5)$ & $(22.2)$ & $(34.1)$ & $(24.8)$ & $(1.27)$ \\
Social Events & 861 & 104 & 166 & 157 & 173 & 162 & 99 & 3.49 \\
& & $(12.1)$ & $(19.3)$ & $(18.2)$ & $(20.1)$ & $(18.8)$ & $(11.5)$ & $(1.56)$ \\
Belong Department & 864 & 45 & 77 & 154 & 196 & 233 & 159 & 4.13 \\
& & $(5.2)$ & $(8.9)$ & $(17.8)$ & $(22.7)$ & $(27.0)$ & $(18.4)$ & \\
Fit Program & 870 & 37 & 68 & 122 & 155 & 266 & 222 & 4.39 \\
& & $(4.3)$ & $(7.8)$ & $(14.0)$ & $(17.8)$ & $(30.6)$ & $(25.5)$ & $(1.42)$ \\
\hline \hline
\end{tabular}

The variables included in department climate listed in Table 20: Department Climate Responses. Department Climate includes Singled Out Gender and Race/Ethnicity, Treat Same Gender and Race/Ethnicity, and Discrimination Female, Male, and International.

\section{Table 20: Department Climate Responses}

\begin{tabular}{|c|c|c|c|c|c|c|c|c|}
\hline $\begin{array}{l}\text { Department } \\
\text { Climate [n } \\
(\%)]\end{array}$ & $\mathbf{N}$ & $\begin{array}{l}1 \\
\text { Strongly } \\
\text { Disagree }\end{array}$ & 2 & 3 & 4 & 5 & $\begin{array}{l}6 \\
\text { Strongly } \\
\text { Agree }\end{array}$ & $\begin{array}{l}\text { M } \\
\text { (SD) }\end{array}$ \\
\hline $\begin{array}{l}\text { Not Singled } \\
\text { Out-Gender }\end{array}$ & 860 & $\begin{array}{l}5 \\
(0.6)\end{array}$ & $\begin{array}{l}15 \\
(1.7)\end{array}$ & $\begin{array}{l}18 \\
(2.1)\end{array}$ & $\begin{array}{l}32 \\
(3.7)\end{array}$ & $\begin{array}{l}61 \\
(7.1)\end{array}$ & $\begin{array}{l}729 \\
(84.8)\end{array}$ & $\begin{array}{l}5.69 \\
(0.86)\end{array}$ \\
\hline $\begin{array}{l}\text { Not Singled } \\
\text { Out- } \\
\text { Race/Ethnicity }\end{array}$ & 858 & $\begin{array}{l}15 \\
(1.7)\end{array}$ & $\begin{array}{l}11 \\
(1.3)\end{array}$ & $\begin{array}{l}14 \\
(1.6)\end{array}$ & $\begin{array}{l}26 \\
(3.0)\end{array}$ & $\begin{array}{l}59 \\
(6.9)\end{array}$ & $\begin{array}{l}733 \\
(85.4)\end{array}$ & $\begin{array}{l}5.68 \\
(0.94)\end{array}$ \\
\hline $\begin{array}{l}\text { Treat Same- } \\
\text { Gender }\end{array}$ & 857 & $\begin{array}{l}34 \\
(4.0)\end{array}$ & $\begin{array}{l}47 \\
(5.5)\end{array}$ & $\begin{array}{l}76 \\
(8.9)\end{array}$ & $\begin{array}{l}85 \\
(9.9)\end{array}$ & $\begin{array}{l}224 \\
(26.1)\end{array}$ & $\begin{array}{l}391 \\
(45.6)\end{array}$ & $\begin{array}{l}4.86 \\
(1.42)\end{array}$ \\
\hline $\begin{array}{l}\text { Treat Same- } \\
\text { Race/Ethnicity }\end{array}$ & 856 & $\begin{array}{l}42 \\
(4.9)\end{array}$ & $\begin{array}{l}37 \\
(4.3)\end{array}$ & $\begin{array}{l}65 \\
(7.6)\end{array}$ & $\begin{array}{l}82 \\
(9.6)\end{array}$ & $\begin{array}{l}207 \\
(24.2)\end{array}$ & $\begin{array}{l}423 \\
(49.4)\end{array}$ & $\begin{array}{l}4.92 \\
(1.44)\end{array}$ \\
\hline $\begin{array}{l}\text { Not } \\
\text { Discrimination } \\
\text { Ethnic/Racial }\end{array}$ & 853 & $\begin{array}{l}29 \\
(3.4)\end{array}$ & $\begin{array}{l}18 \\
(2.1)\end{array}$ & $\begin{array}{l}27 \\
(3.2)\end{array}$ & $\begin{array}{l}22 \\
(2.6)\end{array}$ & $\begin{array}{l}76 \\
(8.9)\end{array}$ & $\begin{array}{l}681 \\
(79.8)\end{array}$ & $\begin{array}{l}5.51 \\
(1.19)\end{array}$ \\
\hline
\end{tabular}


FACILITATING MASTER'S STUDENT SUCCESS

\begin{tabular}{|c|c|c|c|c|c|c|c|c|}
\hline Minorities & & & & & & & & \\
\hline $\begin{array}{l}\text { Not } \\
\text { Discrimination } \\
\text { Female }\end{array}$ & 847 & $\begin{array}{l}10 \\
(1.2)\end{array}$ & $\begin{array}{l}11 \\
(1.3)\end{array}$ & $\begin{array}{l}23 \\
(2.7)\end{array}$ & $\begin{array}{l}38 \\
(4.5)\end{array}$ & $\begin{array}{l}99 \\
(11.7)\end{array}$ & $\begin{array}{l}666 \\
(78.6)\end{array}$ & $\begin{array}{l}5.60 \\
(0.94)\end{array}$ \\
\hline $\begin{array}{l}\text { Not } \\
\text { Discrimination } \\
\text { Male }\end{array}$ & 844 & $\begin{array}{l}13 \\
(1.5)\end{array}$ & $\begin{array}{l}11 \\
(1.3)\end{array}$ & $\begin{array}{l}20 \\
(2.4)\end{array}$ & $\begin{array}{l}43 \\
(5.1)\end{array}$ & $\begin{array}{l}86 \\
(10.2)\end{array}$ & $\begin{array}{l}671 \\
(79.5)\end{array}$ & $\begin{array}{l}5.60 \\
(0.97)\end{array}$ \\
\hline $\begin{array}{l}\text { Not } \\
\text { Discrimination } \\
\text { International }\end{array}$ & 844 & $\begin{array}{l}11 \\
(1.3)\end{array}$ & $\begin{array}{l}10 \\
(1.2)\end{array}$ & $\begin{array}{l}18 \\
(2.1)\end{array}$ & $\begin{array}{l}40 \\
(4.7)\end{array}$ & $\begin{array}{l}89 \\
(10.5)\end{array}$ & $\begin{array}{l}676 \\
(80.1)\end{array}$ & $\begin{array}{l}5.62 \\
(0.93)\end{array}$ \\
\hline
\end{tabular}

\section{Factor Analysis}

The primary research question is does advising influence student success? Before exploring this relationship, a problem with the size of the survey and number of variables needs to be addressed. The survey instrument used for this study was very long, presenting a total of 87 questions. As a result, many students did not answer all of the questions. Regression requires a response from every student on every item included. When a student has a missing piece of data, they are excluded from the regression, thus lowering the number of cases. The number of respondents for the survey was N=942; however when all of the items are added to the regression the number of useful cases drops significantly. The variables are necessary in order to account for the confounding factors that might influence the regression analysis, but the number of cases is also important. One solution for this problem is to run a factor analysis.

Factor analysis allows for the reduction of variables into unobserved or latent factors (Rindskopf \& Rose, 1988). These factors represent larger concepts from the survey and multiple variables. Factor analysis does not require pair-wise reduction and will fill in the missing data as long as it represents less than $10 \%$ of the included variables. Factor scores can then be generated for each factor for each case. These factor 
scores can be included in the regression analysis in order to account for the confounding variables. The researcher wants to know if advising correlates to student success on a number of measures. However, peer culture, department culture, and department climate may impact student success. If we can account for culture and climate factors in the regression, then we can see if advising satisfaction, distinct from these factors, facilitates student success.

\section{Exploratory Factor Analysis}

The first step in grouping the variables is to run an exploratory factor analysis. The goal is to determine the number of factors within the data set. In running an Exploratory Factor Analysis (EFA), the first step is Principal Component Analysis (PCA). The results of the PCA determine the number of factors. The PCA was run using Varimax rotation, which is the most common form of rotation. Rotation improves the interpretability of the results. There were five predicted factors as shown by the Eigen values and the Scree plot. Table 21: Total Variance Explained shows the Eigen values. The factors are defined by the Eigen values above one. There are five components with Eigen values above one. The Scree Plot in Figure 1 shows the same information as the Eigen values in visual form. The number of dots above one in the Scree Plot is five, therefore, there are five factors.

\section{Table 21: Total Variance Explained}

\begin{tabular}{llllllllll}
\hline \hline & & \multicolumn{4}{c}{ Extraction Sums } & \multicolumn{3}{c}{$\begin{array}{c}\text { Rotation Sums of } \\
\text { Squared Loadings }\end{array}$} \\
\cline { 2 - 10 } & \multicolumn{3}{c}{ Initial Eigenvalues } & \multicolumn{3}{c}{ of Squared Loadings } & \multicolumn{3}{c}{$\%$ of } \\
Component & Total & Variance & Cum \% & Total & Variance & Cum \% & Total & Variance & Cum \% \\
\hline 1 & 5.843 & 32.462 & 32.462 & 5.843 & 32.462 & 32.462 & 3.351 & 18.618 & 18.618 \\
2 & 2.830 & 15.720 & 48.182 & 2.830 & 15.720 & 48.182 & 2.988 & 16.601 & 35.219 \\
3 & 1.325 & 7.360 & 55.542 & 1.325 & 7.360 & 55.542 & 2.523 & 14.019 & 49.238
\end{tabular}




\begin{tabular}{llllllllll}
4 & 1.101 & 6.114 & 61.656 & 1.101 & 6.114 & 61.656 & 1.771 & 9.839 & 59.077 \\
5 & 1.027 & 5.703 & 67.359 & 1.027 & 5.703 & 67.359 & 1.491 & 8.283 & 67.359 \\
6 & .906 & 5.034 & 72.393 & & & & & & \\
7 & .792 & 4.398 & 76.792 & & & & & & \\
8 & .718 & 3.990 & 80.782 & & & & & & \\
9 & .644 & 3.580 & 84.362 & & & & & \\
10 & .539 & 2.996 & 87.358 & & & & & \\
11 & .533 & 2.959 & 90.317 & & & & & \\
12 & .388 & 2.155 & 92.472 & & & & & \\
13 & .347 & 1.931 & 94.402 & & & & \\
14 & .307 & 1.705 & 96.107 & & & & \\
15 & .218 & 1.213 & 97.320 & & & & \\
16 & .183 & 1.015 & 98.335 & & & & \\
17 & .158 & .876 & 99.211 & & & & \\
18 & .142 & .789 & 100.000 & & & & \\
\hline \hline
\end{tabular}

Figure 1: Scree Plot

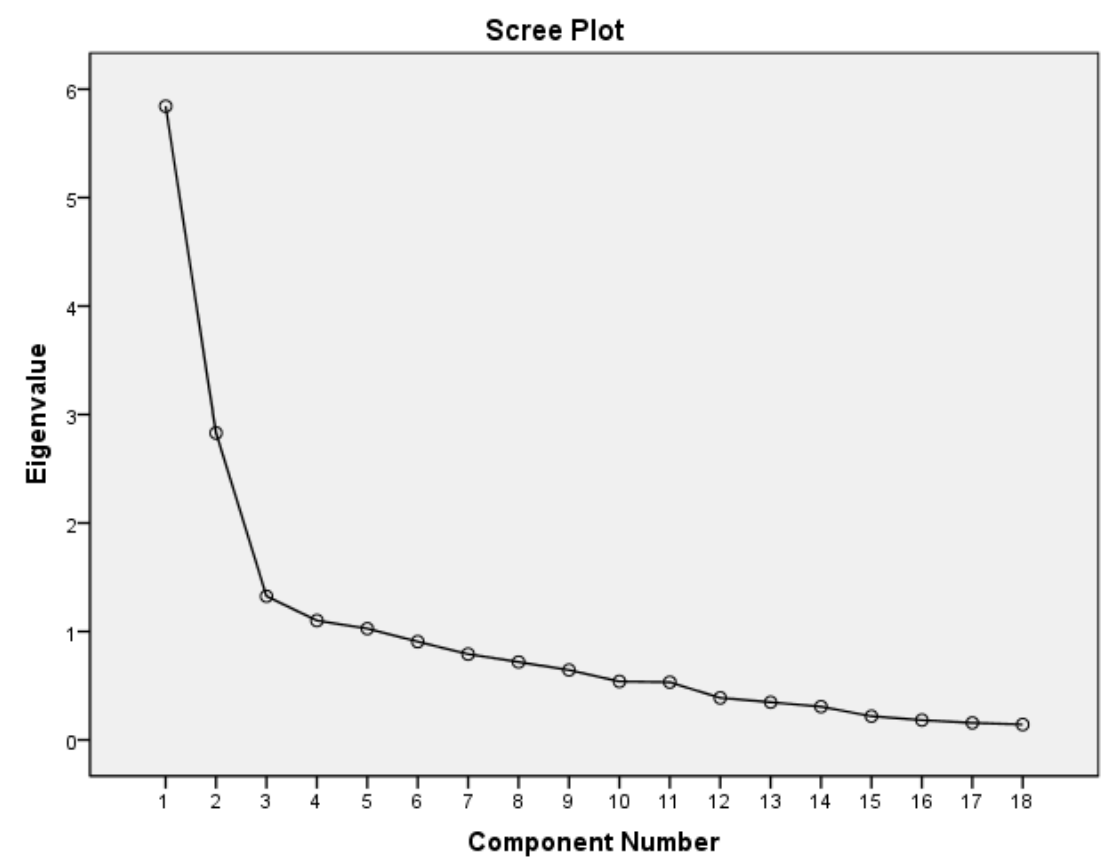

Principal Axis Factoring (PAF) was used to determine the number of variables.

The results of the PAF were used to determine how the variables were loaded into the factors (Table 22: Exploratory Factor Analysis with five factors in a rotated factor 
matrix $^{\mathbf{a}}$ ). The Kaiser-Meyer-Olkin (KMO) measure of sampling adequacy is 0.848 , which shows the data is suited for this test because it is nearly 0.9 , the recommended threshold for EFA. And the Bartlett's Test of Sphericity has a significance level of $\mathrm{p}<0.001$, far below the alpha-level of 0.05 , which indicates that the variables relate to one another well enough to run a useful EFA. The factor loadings range from +1 to -1 . The closer the factor loading is to 1 or -1 the stronger the correlation between the variable and the factor.

In the five-factor model, Factor 2 includes most of the measures of peer culture; Factor 3 includes most of the measures of department culture. The latent variable, department climate, is measured by three factors: Factor 1 captures student-observed discrimination; Factor 4 captures faculty treatment of students; and Factor 5 represents students being singled out.

To limit to three latent variables representing peer culture, department culture, and department climate, the analysis was run against the PAF within the EFA with three variables (Table 23: Exploratory Factor Analysis with three factors in a rotated factor matrix $^{\mathrm{a}}$ ). The Kaiser-Meyer-Olkin (KMO) measure of sampling adequacy remains the same at 0.848 which shows the data is suited for this test. And the Bartlett's Test of Sphericity has the same significance level of $\mathrm{p}<0.001$, which indicates that the variables relate to one another well enough to run a useful EFA. In the three-factor model peer culture and department culture are combined into Factor 2. Department climate is split into two factors: observation of discrimination is Factor 1 and faculty treatment of students is Factor 2. In this model, a student being singled out is left out of the factors. 
The loading of variables onto factors is the next step. This is done using

Confirmatory Factor Analysis (CFA). When the researcher knows the variables that

should be loaded to each factor because of previous research studies, model testing, or confirming EFA, then CFA should be employed (Field, 2009).

Table 22: Exploratory Factor Analysis with five factors in a rotated factor matrix ${ }^{a}$

\begin{tabular}{lrrrrr}
\hline \hline \multirow{2}{*}{ EFA Five Factor } & \multicolumn{5}{c}{ Factor } \\
\cline { 2 - 6 } & 1 & 2 & 3 & 4 & 5 \\
\hline Peer Culture & & & & & \\
Students Collaborate & .101 & .849 & .136 & .073 & .039 \\
Students Share & .100 & .867 & .137 & .041 & .028 \\
Students do not Compete & .113 & -.003 & .214 & .121 & .061 \\
Students Mentor & .047 & .462 & .281 & .077 & -.023 \\
Student Friends & -.005 & .638 & .303 & .018 & .058 \\
Department Culture & & & & & \\
Faculty Accessible & .094 & .195 & .660 & .144 & -.006 \\
Inclusive Learning & .254 & .261 & .648 & .170 & .079 \\
Social Events & .150 & .237 & .480 & .057 & .009 \\
Belong Department & .096 & .350 & .782 & .016 & .112 \\
Fit Program & .037 & .573 & .533 & .017 & .173 \\
Department Climate & & & & & \\
Not Singled Out Gender & .291 & .074 & .098 & .112 & .893 \\
Not Singled Out Race/Ethnicity & .384 & .074 & .121 & .176 & .464 \\
Treat Same Gender & .251 & .086 & .206 & .809 & .179 \\
Treat Same Race/Ethnicity. & .310 & .109 & .195 & .822 & .061 \\
Not Discrimination Ethnic/Racial minorities & .799 & .083 & .118 & .157 & .113 \\
Not Discrimination Female & .635 & .051 & .127 & .141 & .248 \\
Not Discrimination Male & .610 & .009 & .135 & .183 & .137 \\
Not Discrimination International students & .720 & .067 & .056 & .087 & .072 \\
\hline \hline
\end{tabular}

Extraction Method: Principal Axis Factoring. Rotation Method: Varimax with Kaiser Normalization. a. Rotation converged in 6 iterations.

The EFA found a five-factor model as shown in Table 22: Exploratory Factor Analysis with five factors in a rotated factor matrix ${ }^{\mathrm{a}}$ and proven by the Figure 1:

Scree Plot and Table 21: Total Variance Explained. The goal was to create a three-factor model, so the EFA was run as a three-factor analysis and is shown in Table 23:

Exploratory Factor Analysis with three factors in a rotated factor matrix ${ }^{\mathrm{a}}$. 
Table 23: Exploratory Factor Analysis with three factors in a rotated factor matrix ${ }^{\mathrm{a}}$

\begin{tabular}{|c|c|c|c|}
\hline \multirow{2}{*}{ EFA Three Factor } & \multicolumn{3}{|c|}{ Factor } \\
\hline & 1 & 2 & 3 \\
\hline \multirow{3}{*}{$\begin{array}{l}\text { Peer Culture } \\
\text { Students Collaborate } \\
\text { Students Share }\end{array}$} & .113 & .741 & -.010 \\
\hline & & & \\
\hline & .110 & .756 & -.039 \\
\hline Students do not Compete & .118 & .104 & .209 \\
\hline Students Mentor & .045 & .539 & .083 \\
\hline Student Friends & .014 & .711 & .016 \\
\hline Department Culture & .094 & .502 & .335 \\
\hline \multicolumn{4}{|l|}{ Faculty Accessible } \\
\hline Inclusive Learning & .263 & .554 & .362 \\
\hline Social Events & .149 & .453 & .193 \\
\hline Belong Department & .126 & .700 & .260 \\
\hline Fit Program & .076 & .786 & .143 \\
\hline Department Climate & 441 & .137 & .258 \\
\hline \multicolumn{4}{|l|}{ Not Singled Out Gender } \\
\hline Not Singled Out Race/Ethnicity & .458 & .125 & .271 \\
\hline Treat Same Gender & .274 & .127 & .796 \\
\hline Treat Same Race/Ethnicity. & .317 & .141 & .724 \\
\hline Not Discrimination Ethnic/Racial minorities & .806 & .113 & .173 \\
\hline Not Discrimination Female & .670 & .099 & .205 \\
\hline Not Discrimination Male & .622 & .061 & .231 \\
\hline Not Discrimination International students & .722 & .071 & .080 \\
\hline
\end{tabular}

The three-factor model in EFA created a single factor to capture peer and department culture and two factors to capture department climate. After exploring the latent factors with EFA, it was time to test them with CFA.

\section{Confirmatory Factor Analysis}

In Confirmatory Factor Analysis (CFA), the observed variables from the survey are loaded into a model and assigned the latent variable or factor. The factors captured in the analysis are reflective constructs that already exist. The survey contains questions to capture the aspects of the factors of peer culture, department culture, and department climate. Most of the variables that make up the factors are interchangeable, and they are 
expected to be correlated to each other. CFA requires the software add-on of SPSS

AMOS 19 (AMOS). AMOS allows the researcher to create a drawing of the model and show the relationship between the variables and the factors, as well as the covariance between the variables.

Regression weights were generated (Table 24: CFA Standardized Regression Weights). These regression weights were used to calculate new variables in SPSS for peer culture, department culture, and department climate. These regression weights take into account all of the variables in the factor analysis and the correlation between the latent variables: Peer culture, department culture, and department climate. These new variables were used in the following regressions to control for the influence of peers and department on student satisfaction with advising and success outcomes.

Table 24: CFA Standardized Regression Weights

\begin{tabular}{llll}
\hline \hline Variable & Relationship & Factor & Estimate \\
\hline Students Collaborate & $<---$ & Peer Culture & 0.895 \\
Students Share & $<---$ & Peer Culture & 0.910 \\
Students Mentor & $<---$ & Peer Culture & 0.514 \\
Student Friends & $<--$ & Peer Culture & 0.650 \\
Faculty Accessible & $<---$ & Department Culture & 0.624 \\
Inclusive Learning & $<---$ & Department Culture & 0.730 \\
Belong Department & $<---$ & Department Culture & 0.868 \\
Fit Program & $<---$ & Department Culture & 0.778 \\
Not Singled Out Gender & $<---$ & Department Climate & 0.523 \\
Not Singled Out Race/Ethnicity & $<--$ & Department Climate & 0.606 \\
Treat Same Gender & $<---$ & Department Climate & 0.615 \\
Treat Same Race/Ethnicity. & $<---$ & Department Climate & 0.589 \\
Not Discrimination Ethnic/Racial minorities & $<---$ & Department Climate & 0.812 \\
Not Discrimination Female & $<---$ & Department Climate & 0.705 \\
Not Discrimination Male & $<---$ & Department Climate & 0.642 \\
Not Discrimination International students & $<---$ & Department Climate & 0.709 \\
\hline \hline
\end{tabular}

The factor scores for the latent variables, peer culture, department culture, and department climate, were calculated using the regression weights from the CFA above. 
The factor scores were calculated in SPSS 19 and used in the following regression analyses.

\section{Advising satisfaction and master's student enrollment and graduation}

The primary research question is: does advising facilitate master's student

success? One of the main definitions of student success is graduation and retention. All the students in this survey sample were retained except for one. The small sample of students that dropped out reduces the meaningfulness of running a logistic regression. It is difficult to compare the outcome of two groups when there is really only one group of students. It may be that the students who selected to take the survey were those who were successful and committed master's students. Students on the cusp of dropping out likely chose not to take the survey.

\section{Advising satisfaction and master's student Grade Point Average (GPA)}

This section examines student success as defined by graduate grade point average (GPA). The linear regression uses GPA as the dependent variable and includes the demographic variables of female $(0=$ male, $1=$ female $)$, minority $(0=$ white, $1=$ minority $)$, part-time $(0=$ full-time, $1=$ part-time $)$, age, cohort $(0=$ no cohort, $1=$ cohort $)$, thesis $(0=$ not working a thesis, $1=$ working on a thesis). Tables $25-40$ include one of 16 advising variables and include student and educational characteristics, as well as culture and climate. The advising variables are run in individual regressions to avoid correlations with the other advising variables. In the following regressions, normality and multicollinearity were tested. The variance represented by the models is $5-18 \%$, which is 
very low indicating that the models are not capturing all the relevant variables for predicting graduate GPA.

Multiple regression was used to test if student satisfaction with accurate information in advising predicted GPA while controlling for student and educational characteristics and culture and climate (See Table 25: Results of regression analysis of student satisfaction with accurate information predicting student graduate GPA). The results of the regression indicate that the variable accurate information does not predict GPA.

Table 25: Results of regression analysis of student satisfaction with accurate information predicting student graduate GPA

\begin{tabular}{|l|l|l|l|l|}
\hline Model & B & Std. Error & Beta & Sig. \\
\hline (Constant) & 3.814 & 0.077 & & 0.000 \\
\hline Female & 0.025 & 0.016 & 0.063 & 0.115 \\
\hline Minority & -0.075 & 0.021 & -0.147 & 0.000 \\
\hline Age & 0.000 & 0.001 & 0.012 & 0.773 \\
\hline Part-time & -0.015 & 0.018 & -0.035 & 0.417 \\
\hline Cohort & 0.011 & 0.016 & 0.030 & 0.492 \\
\hline Thesis & -0.004 & 0.020 & -0.009 & 0.833 \\
\hline Mentored & 0.008 & 0.016 & 0.023 & 0.607 \\
\hline Multiple Faculty & -0.014 & 0.017 & -0.036 & 0.399 \\
\hline Meeting Often & -0.008 & 0.017 & -0.022 & 0.625 \\
\hline Accurate Information & -0.006 & 0.006 & -0.041 & 0.365 \\
\hline Peer Culture & 0.038 & 0.070 & 0.028 & 0.590 \\
\hline Department Culture & 0.250 & 0.078 & 0.189 & 0.001 \\
\hline Department Climate & -0.224 & 0.132 & -0.078 & 0.090 \\
\hline
\end{tabular}


$\mathrm{R}^{2}=0.06, \mathrm{~F}=2.90, \mathrm{p}<0.001$

Multiple regression was used to test if student satisfaction with help understanding policies and procedures in advising predicted GPA while controlling for student and educational characteristics and culture and climate (See Table 26: Results of regression analysis with student satisfaction with policies and procedures predicting student graduate GPA). The results of the regression indicate that the variable policy and procedures does not predict GPA.

Table 26: Results of regression analysis with student satisfaction with policies and procedures predicting student graduate GPA

\begin{tabular}{|l|l|l|l|l|}
\hline Model & B & Std. Error & Beta & Sig. \\
\hline Constant) & 3.832 & 0.076 & & 0.000 \\
\hline Female & 0.022 & 0.016 & 0.057 & 0.161 \\
\hline Minority & -0.071 & 0.021 & -0.141 & 0.001 \\
\hline Age & 0.000 & 0.001 & 0.004 & 0.932 \\
\hline Part-time & -0.014 & 0.018 & -0.033 & 0.446 \\
\hline Cohort & 0.013 & 0.016 & 0.036 & 0.402 \\
\hline Thesis & -0.006 & 0.020 & -0.013 & 0.749 \\
\hline Mentored & 0.009 & 0.016 & 0.024 & 0.583 \\
\hline Multiple Faculty & -0.010 & 0.017 & -0.027 & 0.536 \\
\hline Meeting Often & -0.010 & 0.017 & -0.028 & 0.536 \\
\hline $\begin{array}{l}\text { Policy and } \\
\text { Procedures }\end{array}$ & -0.001 & 0.006 & -0.011 & 0.816 \\
\hline Peer Culture & 0.024 & 0.070 & 0.018 & 0.731 \\
\hline Department Culture & 0.231 & 0.077 & 0.176 & 0.003 \\
\hline Department Climate & -0.250 & 0.131 & -0.088 & 0.057 \\
\hline
\end{tabular}


$\mathrm{R}^{2}=0.05, \mathrm{~F}=2.62, \mathrm{p}<0.001$

Multiple regression was used to test if student satisfaction with help creating an educational plan in advising predicted GPA while controlling for student and educational characteristics and culture and climate (See Table 27: Results of regression analysis with student satisfaction with adviser help with educational plan predicting student graduate GPA). The results of the regression indicate that the variable educational plan does not predict GPA.

Table 27: Results of regression analysis with student satisfaction with adviser help with educational plan predicting student graduate GPA

\begin{tabular}{|l|l|l|l|l|}
\hline Model & B & Std. Error & Beta & Sig. \\
\hline (Constant) & 3.78 & 0.08 & & 0.00 \\
\hline Female & 0.03 & 0.02 & 0.07 & 0.09 \\
\hline Minority & -0.09 & 0.02 & -0.17 & 0.00 \\
\hline Age & 0.00 & 0.00 & 0.01 & 0.84 \\
\hline Part-time & -0.01 & 0.02 & -0.03 & 0.57 \\
\hline Cohort & 0.01 & 0.02 & 0.03 & 0.50 \\
\hline Thesis & 0.00 & 0.02 & 0.01 & 0.86 \\
\hline Mentored & 0.01 & 0.02 & 0.02 & 0.62 \\
\hline Multiple Faculty & -0.01 & 0.02 & -0.04 & 0.40 \\
\hline Meeting Often & -0.01 & 0.02 & -0.03 & 0.49 \\
\hline Ed Plan & -0.01 & 0.01 & -0.05 & 0.31 \\
\hline Peer Culture & 0.07 & 0.07 & 0.05 & 0.38 \\
\hline Department Culture & 0.24 & 0.08 & 0.18 & 0.00 \\
\hline Department Climate & -0.19 & 0.14 & -0.07 & 0.17 \\
\hline
\end{tabular}


$\mathrm{R}^{2}=.06, \mathrm{~F}=2.78, \mathrm{p}<0.001$

Multiple regression was used to test if student satisfaction with his/her advisers accessibility predicted GPA while controlling for student and educational characteristics and culture and climate (See Table 28: Results of regression analysis with student satisfaction with adviser accessibility predicting student graduate GPA) The results of the regression indicate that the variable adviser accessibility does not predict GPA.

Table 28: Results of regression analysis with student satisfaction with adviser accessibility predicting student graduate GPA

\begin{tabular}{|l|l|l|l|l|}
\hline Model & B & Std. Error & Beta & Sig. \\
\hline (Constant) & 3.79 & 0.08 & & 0.00 \\
\hline Female & 0.03 & 0.02 & 0.07 & 0.09 \\
\hline Minority & -0.08 & 0.02 & -0.16 & 0.00 \\
\hline Age & 0.00 & 0.00 & 0.01 & 0.80 \\
\hline Part-time & -0.02 & 0.02 & -0.04 & 0.32 \\
\hline Cohort & 0.01 & 0.02 & 0.04 & 0.39 \\
\hline Thesis & -0.01 & 0.02 & -0.02 & 0.67 \\
\hline Mentored & 0.01 & 0.02 & 0.02 & 0.72 \\
\hline Multiple Faculty & -0.01 & 0.02 & -0.04 & 0.41 \\
\hline Meeting Often & -0.02 & 0.02 & -0.05 & 0.27 \\
\hline Adviser Accessibility & 0.01 & 0.00 & 0.07 & 0.14 \\
\hline Peer Culture & 0.04 & 0.07 & 0.03 & 0.58 \\
\hline Department Culture & 0.18 & 0.08 & 0.14 & 0.02 \\
\hline Department Climate & -0.20 & 0.13 & -0.07 & 0.13 \\
\hline $\mathrm{R}^{2}=0.06$, F=2.95, $<0.001$ & & & \\
\hline
\end{tabular}


Multiple regression was used to test if student satisfaction with the amount of time students spend with their advisers predicted GPA while controlling for student and educational characteristics and culture and climate (See Table 29: Results of regression analysis with student satisfaction with adviser time predicting student graduate GPA).

The results of the regression indicate that the variable adviser time does not predict GPA.

Table 29: Results of regression analysis with student satisfaction with adviser time predicting student graduate GPA

\begin{tabular}{|l|l|l|l|l|}
\hline Model & B & Std. Error & Beta & Sig. \\
\hline (Constant) & 3.79 & 0.08 & & 0.00 \\
\hline Female & 0.03 & 0.02 & 0.07 & 0.09 \\
\hline Minority & -0.08 & 0.02 & -0.16 & 0.00 \\
\hline Age & 0.00 & 0.00 & 0.01 & 0.80 \\
\hline Part-time & -0.02 & 0.02 & -0.04 & 0.32 \\
\hline Cohort & 0.01 & 0.02 & 0.04 & 0.39 \\
\hline Thesis & -0.01 & 0.02 & -0.02 & 0.67 \\
\hline Mentored & 0.01 & 0.02 & 0.02 & 0.72 \\
\hline Multiple Faculty & -0.01 & 0.02 & -0.04 & 0.41 \\
\hline Meeting Often & -0.02 & 0.02 & -0.05 & 0.27 \\
\hline Adviser Time & 0.01 & 0.00 & 0.07 & 0.14 \\
\hline Peer Culture & 0.04 & 0.07 & 0.03 & 0.58 \\
\hline Department Culture & 0.18 & 0.08 & 0.14 & 0.02 \\
\hline Department Climate & -0.20 & 0.13 & -0.07 & 0.13 \\
\hline R ${ }^{2}=.06$, F=3.01, $<<0.001$ & & & \\
\hline
\end{tabular}


Multiple regression was used to test if student agreement with how advisers are assigned predicted GPA while controlling for student and educational characteristics and culture and climate (See Table 30: Results of regression analysis with student satisfaction with how advisers are assigned predicting student graduate GPA). The results of the regression indicate that the variable adviser assigned does not predict GPA.

Table 30: Results of regression analysis with student satisfaction with how advisers are assigned predicting student graduate GPA

\begin{tabular}{|l|l|l|l|l|}
\hline Model & B & Std. Error & Beta & Sig. \\
\hline (Constant) & 3.80 & 0.08 & & 0.00 \\
\hline Female & 0.03 & 0.02 & 0.06 & 0.12 \\
\hline Minority & -0.08 & 0.02 & -0.15 & 0.00 \\
\hline Age & 0.00 & 0.00 & 0.01 & 0.85 \\
\hline Part-time & -0.02 & 0.02 & -0.04 & 0.35 \\
\hline Cohort & 0.01 & 0.02 & 0.03 & 0.46 \\
\hline Thesis & -0.01 & 0.02 & -0.01 & 0.79 \\
\hline Mentored & 0.01 & 0.02 & 0.02 & 0.60 \\
\hline Multiple Faculty & -0.02 & 0.02 & -0.04 & 0.37 \\
\hline Meeting Often & -0.01 & 0.02 & -0.03 & 0.48 \\
\hline Adviser Assigned & 0.00 & 0.00 & 0.03 & 0.52 \\
\hline Peer Culture & 0.04 & 0.07 & 0.03 & 0.55 \\
\hline Department Culture & 0.21 & 0.08 & 0.16 & 0.01 \\
\hline Department Climate & -0.23 & 0.13 & -0.08 & 0.08 \\
\hline R ${ }^{2}=.06$, F=2.87, $<0.001$ & & & \\
\hline
\end{tabular}

Multiple regression was used to test if student agreement with wishing for another adviser in their department predicted GPA while controlling for student and educational 
characteristics and culture and climate (See Table 31: Results of regression analysis with student satisfaction with adviser wish predicting student graduate GPA). The results of the regression indicate that the variable adviser wish does not predict GPA.

Table 31: Results of regression analysis with student satisfaction with adviser wish predicting student graduate GPA

\begin{tabular}{|l|l|l|l|l|}
\hline Model & B & Std. Error & Beta & Sig. \\
\hline (Constant) & 3.84 & 0.08 & & 0.00 \\
\hline Female & 0.02 & 0.02 & 0.06 & 0.13 \\
\hline Minority & -0.08 & 0.02 & -0.15 & 0.00 \\
\hline Age & 0.00 & 0.00 & 0.01 & 0.85 \\
\hline Part-time & -0.02 & 0.02 & -0.04 & 0.38 \\
\hline Cohort & 0.01 & 0.02 & 0.04 & 0.40 \\
\hline Thesis & -0.01 & 0.02 & -0.02 & 0.71 \\
\hline Mentored & 0.01 & 0.02 & 0.02 & 0.62 \\
\hline Multiple Faculty & -0.01 & 0.02 & -0.03 & 0.45 \\
\hline Meeting Often & -0.02 & 0.02 & -0.04 & 0.37 \\
\hline Adviser Wish & -0.01 & 0.00 & -0.06 & 0.15 \\
\hline Peer Culture & 0.05 & 0.07 & 0.04 & 0.46 \\
\hline Department Culture & 0.20 & 0.08 & 0.15 & 0.01 \\
\hline Department Climate & -0.23 & 0.13 & -0.08 & 0.08 \\
\hline
\end{tabular}

$\mathrm{R}^{2}=.06, \mathrm{~F}=3.01, \mathrm{p}<0.001$

Multiple regression was used to test if student satisfaction with advisers feedback regarding their work predicted GPA while controlling for student and educational characteristics and culture and climate (See Table 32: Results of regression analysis with 
student satisfaction good feedback with predicting student graduate GPA). The results of the regression indicate that the variable good feedback does not predict GPA.

Table 32: Results of regression analysis with student satisfaction good feedback with predicting student graduate GPA

\begin{tabular}{|l|l|l|l|l|}
\hline Model & B & Std. Error & Beta & Sig. \\
\hline Constant) & 3.77 & 0.09 & & 0.00 \\
\hline Female & 0.02 & 0.02 & 0.04 & 0.42 \\
\hline Minority & -0.11 & 0.03 & -0.20 & 0.00 \\
\hline Age & 0.00 & 0.00 & 0.01 & 0.77 \\
\hline Part-time & 0.00 & 0.02 & 0.01 & 0.87 \\
\hline Cohort & 0.03 & 0.02 & 0.06 & 0.20 \\
\hline Thesis & 0.00 & 0.02 & -0.01 & 0.92 \\
\hline Mentored & 0.01 & 0.02 & 0.01 & 0.80 \\
\hline Multiple Faculty & -0.03 & 0.02 & -0.06 & 0.21 \\
\hline Meeting Often & 0.01 & 0.02 & 0.03 & 0.63 \\
\hline Good Feedback & -0.01 & 0.01 & -0.05 & 0.37 \\
\hline Peer Culture & 0.03 & 0.08 & 0.02 & 0.70 \\
\hline Department Culture & 0.29 & 0.09 & 0.22 & 0.00 \\
\hline Department Climate & -0.21 & 0.16 & -0.07 & 0.19 \\
\hline R ${ }^{2}=.08$, F=2.87, p $<0.001$ & & & \\
\hline
\end{tabular}

Multiple regression was used to test if student satisfaction with his/her advisers collaboration predicted GPA while controlling for student and educational characteristics and culture and climate (See Table 33: Results of regression analysis with student satisfaction with faculty collaboration with predicting student graduate GPA). The results of the regression indicate that the variable collaboration does not predict GPA. 
FACILITATING MASTER'S STUDENT SUCCESS

Table 33: Results of regression analysis with student satisfaction with faculty collaboration with predicting student graduate GPA

\begin{tabular}{|l|l|l|l|l|}
\hline Model & B & Std. Error & Beta & Sig. \\
\hline (Constant) & 3.74 & 0.10 & & 0.00 \\
\hline Female & 0.02 & 0.02 & 0.04 & 0.47 \\
\hline Minority & -0.11 & 0.03 & -0.20 & 0.00 \\
\hline Age & 0.00 & 0.00 & 0.03 & 0.63 \\
\hline Part-time & -0.01 & 0.03 & -0.03 & 0.62 \\
\hline Cohort & 0.04 & 0.02 & 0.10 & 0.07 \\
\hline Thesis & -0.01 & 0.03 & -0.02 & 0.78 \\
\hline Mentored & 0.02 & 0.02 & 0.05 & 0.41 \\
\hline Multiple Faculty & -0.03 & 0.02 & -0.07 & 0.20 \\
\hline Meeting Often & 0.00 & 0.02 & 0.01 & 0.83 \\
\hline Collaboration & -0.01 & 0.01 & -0.11 & 0.07 \\
\hline Peer Culture & 0.11 & 0.09 & 0.08 & 0.21 \\
\hline Department Culture & 0.22 & 0.10 & 0.16 & 0.03 \\
\hline Department Climate & -0.16 & 0.17 & -0.06 & 0.33 \\
\hline R ${ }^{2}=.09$, F=2.89, p<0.001 & & & \\
\hline
\end{tabular}

Multiple regression was used to test if student satisfaction with his/her advisers help with networking predicted GPA while controlling for student and educational characteristics and culture and climate (See Table 34: Results of regression analysis with student satisfaction with faculty networking with predicting student graduate GPA). The results of the regression indicate that the variable networking does not predict GPA.

Table 34: Results of regression analysis with student satisfaction with faculty networking with predicting student graduate GPA 
FACILITATING MASTER'S STUDENT SUCCESS

\begin{tabular}{|l|l|l|l|l|}
\hline Model & B & Std. Error & Beta & Sig. \\
\hline (Constant) & 3.77 & 0.09 & & 0.00 \\
\hline Female & 0.03 & 0.02 & 0.07 & 0.16 \\
\hline Minority & -0.11 & 0.03 & -0.20 & 0.00 \\
\hline Age & 0.00 & 0.00 & 0.02 & 0.71 \\
\hline Part-time & -0.01 & 0.02 & -0.03 & 0.61 \\
\hline Cohort & 0.03 & 0.02 & 0.07 & 0.14 \\
\hline Thesis & -0.01 & 0.03 & -0.02 & 0.67 \\
\hline Mentored & 0.01 & 0.02 & 0.02 & 0.75 \\
\hline Multiple Faculty & -0.02 & 0.02 & -0.06 & 0.24 \\
\hline Meeting Often & 0.01 & 0.02 & 0.01 & 0.80 \\
\hline Networking & 0.00 & 0.01 & -0.04 & 0.44 \\
\hline Peer Culture & 0.09 & 0.08 & 0.06 & 0.30 \\
\hline Department Culture & 0.21 & 0.09 & 0.15 & 0.03 \\
\hline Department Climate & -0.20 & 0.15 & -0.07 & 0.19 \\
\hline
\end{tabular}

$\mathrm{R}^{2}=.08, \mathrm{~F}=2.78, \mathrm{p}<0.001$

Multiple regression was used to test if student satisfaction with his/her advisers referral to academic support when needed predicted GPA while controlling for student and educational characteristics and culture and climate (See Table 35: Results of regression analysis of student satisfaction with referral to academic support with predicting student graduate GPA). The results of the regression indicate that the variable academic support $(\beta=-0.15, \mathrm{p}<0.05)$ does predict GPA. The negative Beta indicates the higher the student satisfaction with referral to academic support the lower their GPA indicating that students with a low GPA are in need of academic support services. 
Additionally, this survey item had a not applicable answer option so students who did not need academic support may have selected not applicable.

Table 35: Results of regression analysis of student satisfaction with referral to academic support with predicting student graduate GPA

\begin{tabular}{|l|l|l|l|l|}
\hline Model & B & Std. Error & Beta & Sig. \\
\hline (Constant) & 3.69 & 0.11 & & 0.00 \\
\hline Female & 0.03 & 0.02 & 0.06 & 0.25 \\
\hline Minority & -0.09 & 0.03 & -0.17 & 0.00 \\
\hline Age & 0.00 & 0.00 & 0.05 & 0.37 \\
\hline Part-time & -0.03 & 0.03 & -0.06 & 0.32 \\
\hline Cohort & 0.04 & 0.02 & 0.10 & 0.11 \\
\hline Thesis & 0.00 & 0.03 & 0.01 & 0.88 \\
\hline Mentored & 0.00 & 0.03 & 0.01 & 0.85 \\
\hline Multiple Faculty & -0.01 & 0.03 & -0.01 & 0.85 \\
\hline Meeting Often & -0.02 & 0.03 & -0.05 & 0.44 \\
\hline Academic Support & -0.02 & 0.01 & -0.15 & 0.02 \\
\hline Peer Culture & 0.16 & 0.10 & 0.11 & 0.13 \\
\hline Department Culture & 0.29 & 0.11 & 0.21 & 0.01 \\
\hline Department Climate & -0.19 & 0.18 & -0.07 & 0.29 \\
\hline $\mathrm{R}^{2}=.12$, F=3.26, $\mathrm{p}<0.001$ & & & \\
\hline
\end{tabular}

Multiple regression was used to test if student satisfaction with his/her advisers referral to non-academic support when needed predicted GPA while controlling for student and educational characteristics and culture and climate (See Table 36: Results of regression analysis with student satisfaction with referral to non-academic support with 
predicting student graduate GPA). The results of the regression indicate that the variable non-academic support does not predict GPA.

Table 36: Results of regression analysis with student satisfaction with referral to non-academic support with predicting student graduate GPA

\begin{tabular}{|l|l|l|l|l|}
\hline Model & B & Std. Error & Beta & Sig. \\
\hline (Constant) & 3.66 & 0.11 & & 0.00 \\
\hline Female & 0.02 & 0.03 & 0.03 & 0.56 \\
\hline Minority & -0.11 & 0.03 & -0.21 & 0.00 \\
\hline Age & 0.00 & 0.00 & 0.10 & 0.11 \\
\hline Part-time & -0.03 & 0.03 & -0.07 & 0.24 \\
\hline Cohort & 0.03 & 0.03 & 0.08 & 0.17 \\
\hline Thesis & 0.01 & 0.03 & 0.01 & 0.82 \\
\hline Mentored & 0.01 & 0.03 & 0.02 & 0.76 \\
\hline Multiple Faculty & -0.02 & 0.03 & -0.05 & 0.42 \\
\hline Meeting Often & 0.00 & 0.03 & -0.01 & 0.91 \\
\hline $\begin{array}{l}\text { Non-Academic } \\
\text { Support }\end{array}$ & -0.01 & 0.01 & -0.12 & 0.07 \\
\hline Peer Culture & 0.10 & 0.11 & 0.07 & 0.34 \\
\hline Department Culture & 0.32 & 0.11 & 0.23 & 0.00 \\
\hline Department Climate & -0.17 & 0.18 & -0.06 & 0.36 \\
\hline R ${ }^{2}=13$, F=3.14, p $<0.001$ & & & \\
\hline
\end{tabular}

$\mathrm{R}^{2}=.13, \mathrm{~F}=3.14, \mathrm{p}<0.001$

Multiple regression was used to test if student satisfaction with his/her advisers help identifying funding predicted GPA while controlling for student and educational characteristics and culture and climate (See Table 37: Results of regression analysis with 
student satisfaction with help identifying funding with predicting student graduate GPA).

The results of the regression indicate that the variable funding does not predict GPA.

Table 37: Results of regression analysis with student satisfaction with help identifying funding with predicting student graduate GPA

\begin{tabular}{|l|l|l|l|l|}
\hline Model & B & Std. Error & Beta & Sig. \\
\hline (Constant) & 3.78 & .09 & & .00 \\
\hline Female & .02 & .02 & .04 & .37 \\
\hline Minority & -.10 & .03 & -.20 & .00 \\
\hline Age & .00 & .00 & .02 & .64 \\
\hline Part-time & -.02 & .02 & -.05 & .34 \\
\hline Cohort & .02 & .02 & .06 & .25 \\
\hline Thesis & -.01 & .02 & -.02 & .71 \\
\hline Mentored & -.01 & .02 & -.02 & .68 \\
\hline Multiple Faculty & -.02 & .02 & -.04 & .40 \\
\hline Meeting Often & .00 & .02 & .00 & .93 \\
\hline Funding & .00 & .01 & .01 & .89 \\
\hline Peer Culture & .10 & .09 & .07 & .27 \\
\hline Department Culture & .24 & .09 & .18 & .01 \\
\hline Department Climate & -.27 & .15 & -.10 & .08 \\
\hline $\mathrm{R}^{2}=.09$, F=3.03, p $<0.001$ & & & \\
\hline
\end{tabular}

Multiple regression was used to test if student satisfaction with their advisers encouragement to make progress on their thesis predicted GPA while controlling for student and educational characteristics and culture and climate (See Table 38: Results of regression analysis with student satisfaction with encouraging students to make progress 
on their thesis with predicting student graduate GPA). The results of the regression indicate that the variable encourage thesis does not predict GPA.

Table 38: Results of regression analysis with student satisfaction with encouraging students to make progress on their thesis with predicting student graduate GPA

\begin{tabular}{|l|l|l|l|l|}
\hline Model & $\mathrm{B}$ & Std. Error & Beta & Sig. \\
\hline (Constant) & 3.55 & .23 & & .00 \\
\hline Female & .04 & .04 & .10 & .30 \\
\hline Minority & -.11 & .05 & -.22 & .04 \\
\hline Age & .00 & .00 & .14 & .21 \\
\hline Part-time & -.01 & .04 & -.01 & .90 \\
\hline Cohort & .04 & .04 & .12 & .23 \\
\hline Mentored & .00 & .05 & .01 & .95 \\
\hline Multiple Faculty & -.01 & .05 & -.02 & .84 \\
\hline Meeting Often & -.04 & .06 & -.06 & .56 \\
\hline Encourage Thesis & .02 & .01 & .13 & .27 \\
\hline Peer Culture & .17 & .17 & .13 & .33 \\
\hline Department Culture & .19 & .19 & .15 & .34 \\
\hline Department Climate & -.16 & .34 & -.05 & .64 \\
\hline R ${ }^{2}=.18$, F=1.72, p<0.001 & & & \\
\hline
\end{tabular}

$\mathrm{R}^{2}=.18, \mathrm{~F}=1.72, \mathrm{p}<0.001$

Multiple regression was used to test if student satisfaction with their adviser knowing them as an individual predicted GPA while controlling for student and educational characteristics and culture and climate (See Table 39: Results of regression analysis with student satisfaction with their adviser knowing them as an individual with 
predicting student graduate GPA). The results of the regression indicate that the variable know individual does not predict GPA.

Table 39: Results of regression analysis with student satisfaction with their adviser knowing them as an individual with predicting student graduate GPA

\begin{tabular}{|l|l|l|l|l|}
\hline Model & B & Std. Error & Beta & Sig. \\
\hline (Constant) & 3.78 & .08 & & .00 \\
\hline Female & .02 & .02 & .05 & .29 \\
\hline Minority & -.09 & .02 & -.18 & .00 \\
\hline Age & .00 & .00 & -.01 & .89 \\
\hline Part-time & .00 & .02 & -.01 & .91 \\
\hline Cohort & .03 & .02 & .07 & .13 \\
\hline Thesis & -.02 & .02 & -.04 & .44 \\
\hline Mentored & .02 & .02 & .04 & .40 \\
\hline Multiple Faculty & -.02 & .02 & -.05 & .24 \\
\hline Meeting Often & .00 & .02 & .00 & .96 \\
\hline Know Individual & .00 & .01 & -.04 & .47 \\
\hline Peer Culture & .05 & .08 & .04 & .51 \\
\hline Department Culture & .22 & .09 & .16 & .01 \\
\hline Department Climate & -.17 & .15 & -.06 & .26 \\
\hline R ${ }^{2}=.07$, F=2.74, p<0.001 & & & \\
\hline
\end{tabular}

Multiple regression was used to test if student satisfaction with their adviser caring about their academic progress predicted GPA while controlling for student and educational characteristics and culture and climate (See Table 40: Results of regression analysis with student satisfaction with their adviser caring about their academic progress 
with predicting student graduate GPA). The results of the regression indicate that the variable care does not predict GPA.

Table 40: Results of regression analysis with student satisfaction with their adviser caring about their academic progress with predicting student graduate GPA

\begin{tabular}{|l|l|l|l|l|}
\hline Model & B & Std. Error & Beta & Sig. \\
\hline Constant) & 3.78 & .08 & & .00 \\
\hline Female & .03 & .02 & .06 & .15 \\
\hline Minority & -.09 & .02 & -.18 & .00 \\
\hline Age & .00 & .00 & -.01 & .85 \\
\hline Part-time & .00 & .02 & .01 & .82 \\
\hline Cohort & .02 & .02 & .06 & .20 \\
\hline Thesis & -.02 & .02 & -.04 & .41 \\
\hline Mentored & .02 & .02 & .05 & .29 \\
\hline Multiple Faculty & -.02 & .02 & -.04 & .35 \\
\hline Meeting Often & .00 & .02 & .00 & .96 \\
\hline Care & .00 & .01 & -.04 & .45 \\
\hline Peer Culture & .06 & .08 & .04 & .46 \\
\hline Department Culture & .20 & .09 & .15 & .03 \\
\hline Department Climate & -.16 & .14 & -.06 & .28 \\
\hline R ${ }^{2}=.06$, F=2.59, p $<0.05$ & & & & \\
\hline
\end{tabular}

Only one advising variable — student satisfaction with adviser referral to academic support - is positively correlated with graduate GPA (See Table 35: Results of regression analysis of student satisfaction with referral to academic support with predicting student graduate GPA). This suggests that students who were referred to help were able to 
improve their GPA. Girves and Wemmerus's (1998) found advising was significant for GPA at the master's student level, but they looked at student perceptions of faculty relationships and GPA. This study looked at student perceptions in advising functions, which is different. The lack of finding in this study may be a result of the similarity of GPA for graduate students. There was not a lot of variability in the sample, which may be a result of the sample or grade inflation. This study takes place 15 years after Girves and Wemmerus.

\section{Advising Satisfaction and Institutional Commitment}

Institutional commitment is defined as, "I am confident that I made the right decision in choosing to attend [this university]." Students indicated their level of agreement on a 6 point Likert-type scale where $1=$ Strongly Disagree and $6=$ Strongly Agree. In tables $42-58$, the 16 advising variables are tested individually while controlling for student and educational characteristics and culture and climate satisfaction. The $\mathrm{R}^{2}$ indicates the 16 models account for $41-55 \%$ of the variance. These are strong models.

All of the informational advising variables: accurate information, policies and procedures and educational plan are correlated with institutional commitment. The more satisfied students are with accurate information, help with policies and procedures, and help creating an educational plan the more satisfied they are with their decision to choose this institution. Half of the organizational advising variables are correlated to institutional commitment. Students who agree more strongly with how advisers are assigned and do not wish for another adviser have stronger institutional commitment. Adviser accessibility and time spent with adviser do not correlate to student satisfaction with their 
institution. Satisfaction with collaborating with faculty and having networking support correlate to institutional commitment, but the educational advising variables of good feedback and encouragement on thesis do not. Finally, student satisfaction with help identifying funding, being known as an individual, having an adviser care about your academic progress correlate to institutional commitment, but the academic and nonacademic referral items do not.

Multiple regression was used to test if student satisfaction with accurate information in advising predicted institutional commitment while controlling for student and educational characteristics and culture and climate (See Table 41: Results of regression analysis with student satisfaction with accurate information predicting student institutional commitment). The results of the regression indicate that the variable accurate information $(\beta=0.16, \mathrm{p}<0.001)$ does predict institutional commitment indicating that as student satisfaction with accurate information increases so does satisfaction with institutional commitment.

Table 41: Results of regression analysis with student satisfaction with accurate information predicting student institutional commitment

\begin{tabular}{|l|l|l|l|l|}
\hline Model & B & Std. Error & Beta & Sig. \\
\hline Constant $)$ & .48 & .45 & & .29 \\
\hline Female & .11 & .10 & .04 & .24 \\
\hline Minority & -.22 & .12 & -.06 & .08 \\
\hline Age & .01 & .01 & .09 & .01 \\
\hline Part-time & .00 & .11 & .00 & .97 \\
\hline Cohort & -.09 & .09 & -.03 & .34 \\
\hline Thesis & -.18 & .12 & -.05 & .13 \\
\hline
\end{tabular}




\begin{tabular}{|l|l|l|l|l|}
\hline Mentored & .06 & .10 & .02 & .52 \\
\hline Multiple Faculty & -.03 & .10 & -.01 & .73 \\
\hline Meeting Often & .13 & .10 & .04 & .20 \\
\hline Accurate Information & .18 & .04 & .16 & .00 \\
\hline Peer Culture & -1.00 & .42 & -.10 & .02 \\
\hline Department Culture & 6.10 & .47 & .60 & .00 \\
\hline Department Climate & -.10 & .78 & .00 & .90 \\
\hline
\end{tabular}

$\mathrm{R}^{2}=0.43, \mathrm{~F}=35.34, \mathrm{p}<0.001$

Multiple regression was used to test if student satisfaction with help

understanding policies and procedures in advising predicted institutional commitment while controlling for student and educational characteristics and culture and climate (See Table 42: Results of regression analysis with student satisfaction with policies and procedures predicting student institutional commitment). The results of the regression indicate that the variable policy and procedure $(\beta=0.11, \mathrm{p}<0.05)$ does predict institutional commitment indicating that as student satisfaction with faculty help understanding institutional policies and procedures increases so does satisfaction with institutional commitment.

Table 42: Results of regression analysis with student satisfaction with policies and procedures predicting student institutional commitment

\begin{tabular}{|l|l|l|l|l|}
\hline Model & B & Std. Error & Beta & Sig. \\
\hline (Constant) & .77 & .46 & & .09 \\
\hline Female & .10 & .10 & .03 & .33 \\
\hline Minority & -.20 & .13 & -.05 & .10 \\
\hline Age & .01 & .01 & .09 & .01 \\
\hline
\end{tabular}




\begin{tabular}{|l|l|l|l|l|}
\hline Part-time & .03 & .11 & .01 & .80 \\
\hline Cohort & -.13 & .09 & -.05 & .17 \\
\hline Thesis & -.18 & .12 & -.05 & .15 \\
\hline Mentored & .06 & .10 & .02 & .54 \\
\hline Multiple Faculty & -.05 & .10 & -.02 & .64 \\
\hline Meeting Often & .15 & .10 & .05 & .13 \\
\hline Policy and Procedures & .11 & .04 & .11 & .002 \\
\hline Peer Culture & -1.12 & .42 & -.11 & .01 \\
\hline Department Culture & 6.39 & .46 & .63 & .00 \\
\hline Department Climate & -.19 & .79 & -.01 & .81 \\
\hline
\end{tabular}

Multiple regression was used to test if student satisfaction with help creating an educational plan in advising predicted institutional commitment while controlling for student and educational characteristics and culture and climate (See Table 43: Results of regression analysis with student satisfaction with help creating an educational plan predicting student institutional commitment). The results of the regression indicate that the variable ed plan $(\beta=0.21, \mathrm{p}<0.001)$ does predict institutional commitment indicating that as student satisfaction with faculty help creating an educational plan increases so does satisfaction with institutional commitment.

Table 43: Results of regression analysis with student satisfaction with help creating an educational plan predicting student institutional commitment

\begin{tabular}{|l|l|l|l|l|}
\hline Model & B & Std. Error & Beta & Sig. \\
\hline (Constant) & .88 & .46 & & .06 \\
\hline Female & .08 & .10 & .03 & .41 \\
\hline
\end{tabular}




\begin{tabular}{|l|l|l|l|l|}
\hline Minority & -.19 & .13 & -.05 & .14 \\
\hline Age & .02 & .01 & .10 & .002 \\
\hline Part-time & .00 & .11 & .00 & .99 \\
\hline Cohort & -.16 & .10 & -.06 & .09 \\
\hline Thesis & -.13 & .12 & -.03 & .30 \\
\hline Mentored & .02 & .10 & .01 & .82 \\
\hline Multiple Faculty & -.07 & .10 & -.02 & .48 \\
\hline Meeting Often & .03 & .11 & .01 & .77 \\
\hline Ed Plan & .18 & .03 & .21 & .00 \\
\hline Peer Culture & -1.09 & .43 & -.10 & .01 \\
\hline Department Culture & 6.16 & .48 & .61 & .00 \\
\hline Department Climate & -.58 & .80 & -.03 & .47 \\
\hline
\end{tabular}

$\mathrm{R}^{2}=.47, \mathrm{~F}=36.06, \mathrm{p}<0.001$

Multiple regression was used to test if student satisfaction with his/her advisers accessibility predicted institutional commitment while controlling for student and educational characteristics and culture and climate (See Table 44: Results of regression analysis with student satisfaction with adviser accessibility predicting student institutional commitment). The results of the regression indicate that the variable adviser accessibility does not predict institutional commitment.

Table 44: Results of regression analysis with student satisfaction with adviser accessibility predicting student institutional commitment

\begin{tabular}{|l|l|l|l|l|}
\hline Model & B & Std. Error & Beta & Sig. \\
\hline (Constant) & .87 & .46 & & .06 \\
\hline
\end{tabular}




\begin{tabular}{|l|l|l|l|l|}
\hline Female & .10 & .10 & .03 & .33 \\
\hline Minority & -.18 & .13 & -.05 & .14 \\
\hline Age & .02 & .01 & .10 & .002 \\
\hline Part-time & .00 & .11 & .00 & .98 \\
\hline Cohort & -.14 & .09 & -.05 & .14 \\
\hline Thesis & -.20 & .12 & -.05 & .10 \\
\hline Mentored & .07 & .10 & .02 & .50 \\
\hline Multiple Faculty & -.01 & .10 & .00 & .94 \\
\hline Meeting Often & .11 & .11 & .04 & .30 \\
\hline Adviser Accessibility & .04 & .03 & .05 & .16 \\
\hline Peer Culture & -.90 & .43 & -.09 & .04 \\
\hline Department Culture & 6.56 & .47 & .65 & .00 \\
\hline Department Climate & -.30 & .80 & -.01 & .71 \\
\hline $\mathrm{R}^{2}=41$, F=31.46, p<0.001 & & & & \\
\hline
\end{tabular}

$\mathrm{R}^{2}=.41, \mathrm{~F}=31.46, \mathrm{p}<0.001$

Multiple regression was used to test if student satisfaction with the amount of time students spend with their advisers predicted institutional commitment while controlling for student and educational characteristics and culture and climate (See Table 45: Results of regression analysis with student satisfaction with adviser time predicting student institutional commitment). The results of the regression indicate that the variable adviser time does not predict institutional commitment.

Table 45: Results of regression analysis with student satisfaction with adviser time predicting student institutional commitment

\begin{tabular}{|l|l|l|l|l|}
\hline Model & B & Std. Error & Beta & Sig. \\
\hline (Constant) & .83 & .46 & & .07 \\
\hline
\end{tabular}


FACILITATING MASTER'S STUDENT SUCCESS

\begin{tabular}{|l|l|l|l|l|}
\hline Female & .10 & .10 & .03 & .28 \\
\hline Minority & -.19 & .13 & -.05 & .14 \\
\hline Age & .02 & .01 & .10 & .002 \\
\hline Part-time & -.01 & .11 & .00 & .95 \\
\hline Cohort & -.12 & .09 & -.04 & .21 \\
\hline Thesis & -.19 & .12 & -.05 & .11 \\
\hline Mentored & .05 & .10 & .02 & .63 \\
\hline Multiple Faculty & -.01 & .10 & .00 & .91 \\
\hline Meeting Often & .08 & .11 & .03 & .47 \\
\hline Adviser Time & .05 & .03 & .07 & .07 \\
\hline Peer Culture & -.93 & .43 & -.09 & .03 \\
\hline Department Culture & 6.56 & .48 & .65 & .00 \\
\hline Department Climate & -.24 & .80 & -.01 & .76 \\
\hline $\mathrm{R}^{2}=0.42$, F=32 $24, \mathrm{p}<0.001$ & & & \\
\hline
\end{tabular}

$\mathrm{R}^{2}=0.42, \mathrm{~F}=32.24, \mathrm{p}<0.001$

Multiple regression was used to test if student agreement with how advisers are assigned predicted institutional commitment while controlling for student and educational characteristics and culture and climate (See Table 46: Results of regression analysis with student satisfaction with adviser assigned predicting student institutional commitment).

The results of the regression indicate that the variable adviser assigned $(\beta=0.10, p<0.05)$ does predict institutional commitment indicating that as student agreement with how faculty are assigned increases so does satisfaction with institutional commitment.

Table 46: Results of regression analysis with student satisfaction with adviser assigned predicting student institutional commitment

\begin{tabular}{|l|l|l|l|l|}
\hline Model & B & Std. Error & Beta & Sig. \\
\hline
\end{tabular}




\begin{tabular}{|l|l|l|l|l|}
\hline (Constant) & .87 & .45 & & .06 \\
\hline Female & .13 & .10 & .04 & .18 \\
\hline Minority & -.19 & .13 & -.05 & .14 \\
\hline Age & .01 & .01 & .09 & .01 \\
\hline Part-time & .03 & .11 & .01 & .81 \\
\hline Cohort & -.15 & .09 & -.05 & .11 \\
\hline Thesis & -.18 & .12 & -.05 & .14 \\
\hline Mentored & .10 & .10 & .04 & .31 \\
\hline Multiple Faculty & -.02 & .10 & -.01 & .81 \\
\hline Meeting Often & .12 & .10 & .04 & .24 \\
\hline Adviser Assigned & .07 & .03 & .10 & .01 \\
\hline Peer Culture & -.92 & .42 & -.09 & .03 \\
\hline Department Culture & 6.46 & .47 & .64 & .00 \\
\hline Department Climate & -.40 & .79 & -.02 & .61 \\
\hline
\end{tabular}

$\mathrm{R}^{2}=.42, \mathrm{~F}=33.53, \mathrm{p}<0.001$

Multiple regression was used to test if student agreement with wishing for another adviser in their department predicted institutional commitment while controlling for student and educational characteristics and culture and climate (See Table 47: Results of regression analysis with student satisfaction with adviser wish predicting student institutional commitment). The results of the regression indicate that the variable adviser wish $(\beta=-0.08, \mathrm{p}<0.05)$ does predict institutional commitment indicating that as student agreement with wishing for another faculty member in their department to be their adviser decreases satisfaction with institutional commitment increases. 
FACILITATING MASTER'S STUDENT SUCCESS

Table 47: Results of regression analysis with student satisfaction with adviser wish predicting student institutional commitment

\begin{tabular}{|l|l|l|l|l|}
\hline Model & B & Std. Error & Beta & Sig. \\
\hline Constant $)$ & 1.20 & 0.48 & & 0.01 \\
\hline Female & 0.11 & 0.10 & 0.04 & 0.24 \\
\hline Minority & -0.20 & 0.13 & -0.05 & 0.12 \\
\hline Age & 0.01 & 0.01 & 0.09 & 0.004 \\
\hline Part-time & 0.04 & 0.11 & 0.01 & 0.69 \\
\hline Cohort & -0.13 & 0.09 & -0.05 & 0.17 \\
\hline Thesis & -0.20 & 0.12 & -0.05 & 0.11 \\
\hline Mentored & 0.08 & 0.10 & 0.03 & 0.42 \\
\hline Multiple Faculty & 0.01 & 0.10 & 0.00 & 0.93 \\
\hline Meeting Often & 0.13 & 0.10 & 0.04 & 0.22 \\
\hline Adviser Wish & -0.06 & 0.03 & -0.08 & 0.02 \\
\hline Peer Culture & -0.89 & 0.43 & -0.09 & 0.04 \\
\hline Department Culture & 6.55 & 0.46 & 0.65 & 0.00 \\
\hline Department Climate & -0.29 & 0.79 & -0.01 & 0.72 \\
\hline
\end{tabular}

$\mathrm{R}^{2}=.42, \mathrm{~F}=33.07, \mathrm{p}<0.001$

Multiple regression was used to test if student satisfaction with advisers feedback

regarding their work predicted institutional commitment while controlling for student and educational characteristics and culture and climate (See Table 48: Results of regression analysis with student satisfaction good feedback with predicting student institutional commitment). The results of the regression indicate that the variable good feedback does not predict institutional commitment. 
FACILITATING MASTER'S STUDENT SUCCESS

Table 48: Results of regression analysis with student satisfaction good feedback with predicting student institutional commitment

\begin{tabular}{|l|l|l|l|l|}
\hline Model & B & Std. Error & Beta & Sig. \\
\hline Constant) & .71 & .55 & & .20 \\
\hline Female & .13 & .12 & .04 & .26 \\
\hline Minority & -.14 & .16 & -.03 & .38 \\
\hline Age & .01 & .01 & .09 & .02 \\
\hline Part-time & -.08 & .14 & -.02 & .58 \\
\hline Cohort & -.26 & .11 & -.09 & .02 \\
\hline Thesis & -.20 & .14 & -.05 & .17 \\
\hline Mentored & -.05 & .12 & -.02 & .67 \\
\hline Multiple Faculty & .04 & .13 & .01 & .75 \\
\hline Meeting Often & .22 & .13 & .07 & .08 \\
\hline Good Feedback & .07 & .04 & .08 & .07 \\
\hline Peer Culture & -.81 & .49 & -.08 & .10 \\
\hline Department Culture & 6.35 & .56 & .63 & .00 \\
\hline Department Climate & .11 & .94 & .01 & .91 \\
\hline
\end{tabular}

$\mathrm{R}^{2}=.43, \mathrm{~F}=25.15, \mathrm{p}<0.001$

Multiple regression was used to test if student satisfaction with his/her advisers collaboration predicted institutional commitment while controlling for student and educational characteristics and culture and climate (See Table 49: Results of regression analysis with student satisfaction with faculty collaboration with predicting student institutional commitment). The results of the regression indicate that the variable collaboration $(\beta=0.13, \mathrm{p}<0.001)$ does predict institutional commitment indicating that as 
student agreement with how faculty collaborate with them increases so does satisfaction with institutional commitment.

Table 49: Results of regression analysis with student satisfaction with faculty collaboration with predicting student institutional commitment

\begin{tabular}{|l|l|l|l|l|}
\hline Model & B & Std. Error & Beta & Sig. \\
\hline Constant $)$ & .51 & .58 & & .38 \\
\hline Female & .07 & .13 & .02 & .59 \\
\hline Minority & -.12 & .16 & -.03 & .46 \\
\hline Age & .02 & .01 & .11 & .01 \\
\hline Part-time & -.09 & .15 & -.02 & .57 \\
\hline Cohort & -.14 & .13 & -.05 & .25 \\
\hline Thesis & -.24 & .16 & -.06 & .12 \\
\hline Mentored & -.03 & .14 & -.01 & .83 \\
\hline Multiple Faculty & .00 & .13 & .00 & .98 \\
\hline Meeting Often & .08 & .14 & .03 & .54 \\
\hline Collaboration & .11 & .04 & .13 & .00 \\
\hline Peer Culture & -1.57 & .53 & -.15 & .003 \\
\hline Department Culture & 6.66 & .59 & .66 & .00 \\
\hline Department Climate & .55 & .97 & .03 & .57 \\
\hline $\mathrm{R}^{2}=.44$, F=22.44, $\mathrm{p}<0.001$ & & & & \\
\hline
\end{tabular}

Multiple regression was used to test if student satisfaction with his/her advisers help with networking predicted institutional commitment while controlling for student and educational characteristics and culture and climate (See Table 50: Results of regression analysis with student satisfaction with faculty networking with predicting 
student institutional commitment). The results of the regression indicate that the variable networking $(\beta=0.10, \mathrm{p}<0.05)$ does predict institutional commitment indicating that as student agreement with how faculty help them network increases so does satisfaction with institutional commitment.

Table 50: Results of regression analysis with student satisfaction with faculty networking with predicting student institutional commitment

\begin{tabular}{|l|l|l|l|l|}
\hline Model & B & Std. Error & Beta & Sig. \\
\hline Constant) & .73 & .55 & & .19 \\
\hline Female & .15 & .12 & .05 & .23 \\
\hline Minority & -.17 & .16 & -.04 & .28 \\
\hline Age & .02 & .01 & .09 & .03 \\
\hline Part-time & -.02 & .14 & .00 & .90 \\
\hline Cohort & -.16 & .12 & -.05 & .18 \\
\hline Thesis & -.19 & .15 & -.05 & .21 \\
\hline Mentored & -.06 & .13 & -.02 & .64 \\
\hline Multiple Faculty & .00 & .13 & .00 & .97 \\
\hline Meeting Often & .25 & .13 & .08 & .06 \\
\hline Networking & .08 & .04 & .10 & .02 \\
\hline Peer Culture & -1.22 & .51 & -.12 & .02 \\
\hline Department Culture & 6.40 & .57 & .63 & .00 \\
\hline Department Climate & .21 & .93 & .01 & .82 \\
\hline
\end{tabular}

$\mathrm{R}^{2}=.41, \mathrm{~F}=22.73, \mathrm{p}<0.001$

Multiple regression was used to test if student satisfaction with his/her advisers referral to academic support when needed predicted institutional commitment while controlling for student and educational characteristics and culture and climate (See Table 
51: Results of regression analysis with student satisfaction with referral to academic support with predicting student institutional commitment). The results of the regression indicate that the variable academic support does not predict institutional commitment.

Table 51: Results of regression analysis with student satisfaction with referral to academic support with predicting student institutional commitment

\begin{tabular}{|l|l|l|l|l|}
\hline Model & B & Std. Error & Beta & Sig. \\
\hline Constant) & 1.41 & 0.60 & & 0.02 \\
\hline Female & 0.21 & 0.14 & 0.07 & 0.13 \\
\hline Minority & -0.25 & 0.17 & -0.07 & 0.14 \\
\hline Age & 0.01 & 0.01 & 0.05 & 0.26 \\
\hline Part-time & 0.04 & 0.16 & 0.01 & 0.83 \\
\hline Cohort & -0.22 & 0.14 & -0.08 & 0.10 \\
\hline Thesis & -0.20 & 0.18 & -0.05 & 0.28 \\
\hline Mentored & -0.22 & 0.15 & -0.08 & 0.13 \\
\hline Multiple Faculty & -0.09 & 0.15 & -0.03 & 0.53 \\
\hline Meeting Often & 0.32 & 0.15 & 0.11 & 0.03 \\
\hline Academic Support & 0.06 & 0.04 & 0.07 & 0.15 \\
\hline Peer Culture & -1.07 & 0.58 & -0.10 & 0.07 \\
\hline Department Culture & 7.36 & 0.61 & -0.08 & \\
\hline Department Climate & -1.61 & 1.04 & & \\
\hline S & & & & \\
\hline & & & & \\
\hline
\end{tabular}

$\mathrm{R}^{2}=.45, \mathrm{~F}=19.70, \mathrm{p}<0.001$

Multiple regression was used to test if student satisfaction with his/her advisers referral to non-academic support when needed predicted institutional commitment while controlling for student and educational characteristics and culture and climate (See Table 52: Results of regression analysis with student satisfaction with referral to non-academic 
support with predicting student institutional commitment). The results of the regression indicate that the variable non-academic support does not predict institutional commitment.

Table 52: Results of regression analysis with student satisfaction with referral to non-academic support with predicting student institutional commitment

\begin{tabular}{|l|l|l|l|l|}
\hline Model & B & Std. Error & Beta & Sig. \\
\hline (Constant) & 1.18 & .64 & & .06 \\
\hline Female & .18 & .15 & .06 & .24 \\
\hline Minority & -.29 & .18 & -.08 & .11 \\
\hline Age & .01 & .01 & .07 & .16 \\
\hline Part-time & .08 & .17 & .02 & .63 \\
\hline Cohort & -.22 & .15 & -.07 & .15 \\
\hline Thesis & -.26 & .20 & -.06 & .19 \\
\hline Mentored & -.08 & .16 & -.03 & .62 \\
\hline Multiple Faculty & -.13 & .16 & -.04 & .42 \\
\hline Meeting Often & .14 & .15 & .05 & .38 \\
\hline Non-Academic Support & .06 & .05 & .07 & .18 \\
\hline Peer Culture & -1.43 & .62 & -.14 & .02 \\
\hline Department Culture & 7.20 & .64 & .72 & .00 \\
\hline Department Climate & -.68 & 1.07 & -.03 & .53 \\
\hline
\end{tabular}

$\mathrm{R}^{2}=.43, \mathrm{~F}=16.11, \mathrm{p}<0.001$

Multiple regression was used to test if student satisfaction with his/her advisers help identifying funding predicted institutional commitment while controlling for student and educational characteristics and culture and climate (See Table 53: Results of regression analysis with student satisfaction with help identifying funding with predicting 
student institutional commitment). The results of the regression indicate that the variable funding $(\beta=0.19, \mathrm{p}<0.001)$ does predict institutional commitment indicating that as student satisfaction with his/her advisers help identifying funding increases so does satisfaction with institutional commitment.

Table 53: Results of regression analysis with student satisfaction with help identifying funding with predicting student institutional commitment

\begin{tabular}{|l|l|l|l|l|}
\hline Model & B & Std. Error & Beta & Sig. \\
\hline Constant) & .91 & .54 & & .10 \\
\hline Female & .11 & .12 & .03 & .34 \\
\hline Minority & -.18 & .15 & -.04 & .24 \\
\hline Age & .01 & .01 & .04 & .26 \\
\hline Part-time & .07 & .14 & .02 & .60 \\
\hline Cohort & -.12 & .11 & -.04 & .28 \\
\hline Thesis & -.30 & .14 & -.08 & .04 \\
\hline Mentored & -.01 & .12 & .00 & .91 \\
\hline Multiple Faculty & -.05 & .12 & -.02 & .69 \\
\hline Meeting Often & .11 & .13 & .04 & .38 \\
\hline Funding & .16 & .04 & .19 & .00 \\
\hline Peer Culture & -1.43 & .51 & -.13 & .005 \\
\hline Department Culture & 6.35 & .54 & .63 & .00 \\
\hline Department Climate & .25 & .91 & .01 & .78 \\
\hline
\end{tabular}

$\mathrm{R}^{2}=.46, \mathrm{~F}=27.16, \mathrm{p}<0.001$

Multiple regression was used to test if student satisfaction with their advisers encouragement to make progress on their thesis predicted institutional commitment while 
controlling for student and educational characteristics and culture and climate (See Table 54: Results of regression analysis with student satisfaction with encouraging students to make progress on their thesis with predicting student institutional commitment). The results of the regression indicate that the variable encourage thesis does not predict institutional commitment.

Table 54: Results of regression analysis with student satisfaction with encouraging students to make progress on their thesis with predicting student institutional commitment

\begin{tabular}{|l|l|l|l|l|}
\hline Model & B & Std. Error & Beta & Sig. \\
\hline (Constant) & 3.00 & 1.31 & & 0.02 \\
\hline Female & 0.10 & 0.21 & 0.04 & 0.64 \\
\hline Minority & 0.04 & 0.28 & 0.01 & 0.88 \\
\hline Age & 0.02 & 0.01 & 0.14 & 0.09 \\
\hline Part-time & 0.05 & 0.25 & 0.02 & 0.84 \\
\hline Cohort & -0.10 & 0.20 & -0.04 & 0.62 \\
\hline Mentored & 0.68 & 0.25 & 0.23 & 0.01 \\
\hline Multiple Faculty & -0.36 & 0.25 & -0.11 & 0.16 \\
\hline Meeting Often & 0.22 & 0.36 & 0.05 & 0.54 \\
\hline Encourage Thesis & -0.08 & 0.08 & -0.09 & 0.31 \\
\hline Peer Culture & -2.88 & 0.97 & -0.30 & 0.004 \\
\hline Department Culture & 8.37 & 1.08 & 0.87 & 0.00 \\
\hline Department Climate & -4.35 & 1.88 & -0.18 & 0.02 \\
\hline
\end{tabular}

$\mathrm{R}^{2}=.55, \mathrm{~F}=9.30, \mathrm{p}<0.001$

Multiple regression was used to test if student satisfaction with their adviser knowing them as an individual predicted institutional commitment while controlling for 
student and educational characteristics and culture and climate (See Table 55: Results of regression analysis with student satisfaction with knowing you as an individual with predicting student institutional commitment). The results of the regression indicate that the variable know individual $(\beta=0.13, \mathrm{p}<0.05)$ does predict institutional commitment indicating that as student satisfaction with their adviser knowing them as an individual increases so does satisfaction with institutional commitment.

Table 55: Results of regression analysis with student satisfaction with knowing you as an individual with predicting student institutional commitment

\begin{tabular}{|l|l|l|l|l|}
\hline Model & B & Std. Error & Beta & Sig. \\
\hline Constant) & .96 & .50 & & .05 \\
\hline Female & .09 & .11 & .03 & .42 \\
\hline Minority & -.23 & .14 & -.06 & .11 \\
\hline Age & .01 & .01 & .09 & .02 \\
\hline Part-time & .02 & .12 & .01 & .88 \\
\hline Cohort & -.18 & .11 & -.06 & .09 \\
\hline Thesis & -.17 & .14 & -.04 & .22 \\
\hline Mentored & -.08 & .11 & -.03 & .46 \\
\hline Multiple Faculty & -.01 & .11 & .00 & .95 \\
\hline Meeting Often & .21 & .12 & .07 & .08 \\
\hline Know Individual & .10 & .03 & .13 & .003 \\
\hline Peer Culture & -1.09 & .47 & -.10 & .02 \\
\hline Department Culture & 6.22 & .52 & .62 & .00 \\
\hline Department Climate & -.17 & .87 & -.01 & .85 \\
\hline$R^{2}=41$, F $27.08,0001$ & & & \\
\hline
\end{tabular}

$\mathrm{R}^{2}=.41, \mathrm{~F}=27.08, \mathrm{p}<0.001$ 
Multiple regression was used to test if student satisfaction with their adviser caring about their academic progress predicted institutional commitment while controlling for student and educational characteristics and culture and climate (See Table 56: Results of regression analysis with student satisfaction with caring about your academic progress with predicting student institutional commitment). The results of the regression indicate that the variable care $(\beta=0.11, \mathrm{p}<0.05)$ does predict institutional commitment indicating that as student satisfaction with their adviser caring about their academic progress increases so does satisfaction with institutional commitment.

Table 56: Results of regression analysis with student satisfaction with caring about your academic progress with predicting student institutional commitment

\begin{tabular}{|l|l|l|l|l|}
\hline Model & $\mathrm{B}$ & Std. Error & Beta & Sig. \\
\hline (Constant) & 1.00 & .51 & & .05 \\
\hline Female & .08 & .11 & .03 & .46 \\
\hline Minority & -.22 & .14 & -.05 & .13 \\
\hline Age & .01 & .01 & .09 & .02 \\
\hline Part-time & .02 & .13 & .01 & .88 \\
\hline Cohort & -.19 & .11 & -.06 & .08 \\
\hline Thesis & -.17 & .14 & -.05 & .22 \\
\hline Mentored & -.06 & .11 & -.02 & .62 \\
\hline Multiple Faculty & .00 & .12 & .00 & .98 \\
\hline Meeting Often & .18 & .12 & .06 & .13 \\
\hline Care & .09 & .03 & .11 & .01 \\
\hline Peer Culture & -1.10 & .48 & -.10 & .02 \\
\hline Department Culture & 6.32 & .54 & .62 & .00 \\
\hline Department Climate & -.28 & .88 & -.01 & .75 \\
\hline
\end{tabular}


$\mathrm{R}^{2}=.41, \mathrm{~F}=26.06, \mathrm{p}<0.001$

Institutional integration is linked with student retention (Tinto, 1993). Students who are satisfied with their institution are more likely to finish their degrees. All of the informational advising items were correlated to institutional commitment including educational plan, which captures the written contract students have with the institution to complete their degree. Knowing what they need to do to complete their program correlates with student satisfaction regarding the institutional commitment.

Organizational variables around adviser match are correlated to institutional commitment. Students who have good advisers are more likely to succeed, so it seems logical that they would have a stronger sense of institutional commitment. Students who are satisfied with adviser collaboration and networking help as well as support finding funding and being known as an individual and cared about are more likely to have greater satisfaction regarding their institutional choice. Both administrative and mentoring advising items correlate to institutional commitment.

\section{Advising satisfaction and Program Commitment}

The variable program commitment is defined as "In my program, I am learning the skills and knowledge I need to work in my field." Students indicated their level of agreement on a 6 point Likert-type scale where 1=Strongly Disagree and 6=Strongly Agree. The $\mathrm{R}^{2}$ indicates that the models accounts for $34-46 \%$ of the variance, which indicates that these are strong models. Program commitment is correlated with both administrative and mentoring advising variables. Student satisfaction with information advising variables including help understanding policies and procedures and help forming 
an educational plan as well the organizational advising variables connected with adviser match are correlated to program commitment.

Multiple regression was used to test if student satisfaction with accurate information in advising predicted program commitment while controlling for student and educational characteristics and culture and climate (See Table 57: Results of regression analysis with student satisfaction with accurate information predicting student program commitment). The results of the regression indicate that the variable accurate information does not predict program commitment.

Table 57: Results of regression analysis with student satisfaction with accurate information predicting student program commitment

\begin{tabular}{|l|l|l|l|l|}
\hline Model & B & Std. Error & Beta & Sig. \\
\hline Constant) & 1.53 & 0.44 & & 0.00 \\
\hline Female & 0.01 & 0.09 & 0.00 & 0.90 \\
\hline Minority & 0.04 & 0.12 & 0.01 & 0.74 \\
\hline Age & 0.00 & 0.00 & 0.03 & 0.37 \\
\hline Part-time & 0.04 & 0.10 & 0.01 & 0.71 \\
\hline Cohort & -0.08 & 0.09 & -0.03 & 0.38 \\
\hline Thesis & -0.07 & 0.12 & -0.02 & 0.56 \\
\hline Mentored & 0.04 & 0.09 & 0.02 & 0.66 \\
\hline Multiple Faculty & 0.03 & 0.10 & 0.01 & 0.78 \\
\hline Meeting Often & 0.19 & 0.10 & 0.07 & 0.05 \\
\hline Accurate Information & 0.07 & 0.04 & 0.07 & 0.07 \\
\hline Peer Culture & -0.41 & 0.40 & -0.04 & 0.31 \\
\hline Department Culture & 5.09 & 0.45 & 0.56 & 0.00 \\
\hline Department Climate & 0.00 & 0.75 & 0.00 & 1.00 \\
\hline
\end{tabular}


$\mathrm{R}^{2}=0.35, \mathrm{~F}=24.66, \mathrm{p}<0.001$

Multiple regression was used to test if student satisfaction with help

understanding policies and procedures in advising predicted program commitment while controlling for student and educational characteristics and culture and climate (See Table 58: Results of regression analysis with student satisfaction with policies and procedures predicting student program commitment). The results of the regression indicate that the variable policy and procedure $(\beta=0.11, \mathrm{p}<0.001)$ does predict program commitment indicating that as student satisfaction with faculty help understanding institutional policies and procedures increases so does satisfaction with program commitment.

Table 58: Results of regression analysis with student satisfaction with policies and procedures predicting student program commitment

\begin{tabular}{|l|l|l|l|l|}
\hline Model & B & Std. Error & Beta & Sig. \\
\hline Constant) & 1.58 & 0.43 & & 0.00 \\
\hline Female & -0.01 & 0.09 & 0.00 & 0.89 \\
\hline Minority & 0.04 & 0.12 & 0.01 & 0.74 \\
\hline Age & 0.00 & 0.00 & 0.03 & 0.43 \\
\hline Part-time & 0.04 & 0.10 & 0.01 & 0.72 \\
\hline Cohort & -0.08 & 0.09 & -0.03 & 0.35 \\
\hline Thesis & -0.07 & 0.12 & -0.02 & 0.55 \\
\hline Mentored & 0.04 & 0.09 & 0.01 & 0.70 \\
\hline Multiple Faculty & -0.01 & 0.10 & 0.00 & 0.92 \\
\hline Meeting Often & 0.19 & 0.10 & 0.07 & 0.05 \\
\hline Policy and Procedures & 0.10 & 0.03 & 0.11 & 0.00 \\
\hline Peer Culture & -0.50 & 0.40 & -0.05 & 0.22 \\
\hline
\end{tabular}




\begin{tabular}{|l|l|l|l|l|}
\hline Department Culture & 5.03 & 0.44 & 0.55 & 0.00 \\
\hline Department Climate & -0.05 & 0.75 & 0.00 & 0.94 \\
\hline
\end{tabular}

$\mathrm{R}^{2}=0.35, \mathrm{~F}=25.00, \mathrm{p}<0.001$

Multiple regression was used to test if student satisfaction with help creating an educational plan in advising predicted program commitment while controlling for student and educational characteristics and culture and climate (See Table 59: Results of regression analysis with student satisfaction with help creating an educational plan predicting student program commitment). The results of the regression indicate that the variable ed plan $(\beta=0.23, \mathrm{p}<0.001)$ does predict program commitment indicating that as student satisfaction with faculty help creating an educational plan increases so does satisfaction with program commitment.

Table 59: Results of regression analysis with student satisfaction with help creating an educational plan predicting student program commitment

\begin{tabular}{|l|l|l|l|l|}
\hline Model & B & Std. Error & Beta & Sig. \\
\hline Constant $)$ & 1.47 & 0.44 & & 0.00 \\
\hline Female & -0.01 & 0.09 & 0.00 & 0.90 \\
\hline Minority & 0.05 & 0.12 & 0.01 & 0.71 \\
\hline Age & 0.01 & 0.01 & 0.05 & 0.16 \\
\hline Part-time & 0.05 & 0.11 & 0.02 & 0.61 \\
\hline Cohort & -0.09 & 0.09 & -0.04 & 0.31 \\
\hline Thesis & -0.03 & 0.12 & -0.01 & 0.81 \\
\hline Mentored & 0.00 & 0.10 & 0.00 & 1.00 \\
\hline Multiple Faculty & 0.04 & 0.10 & 0.02 & 0.67 \\
\hline Meeting Often & 0.10 & 0.10 & 0.04 & 0.30 \\
\hline
\end{tabular}




\begin{tabular}{|l|l|l|l|l|}
\hline Ed Plan & 0.18 & 0.03 & 0.23 & 0.00 \\
\hline Peer Culture & -0.47 & 0.41 & -0.05 & 0.25 \\
\hline Department Culture & 4.58 & 0.46 & 0.50 & 0.00 \\
\hline Department Climate & -0.16 & 0.76 & -0.01 & 0.84 \\
\hline
\end{tabular}

$\mathrm{R}^{2}=.40, \mathrm{~F}=27.72, \mathrm{p}<0.001$

Multiple regression was used to test if student satisfaction with his/her advisers accessibility predicted program commitment while controlling for student and educational characteristics and culture and climate (See Table 60: Results of regression analysis with student satisfaction with adviser accessibility predicting student program commitment). The results of the regression indicate that the variable adviser accessibility does not predict program commitment.

Table 60: Results of regression analysis with student satisfaction with adviser accessibility predicting student program commitment

\begin{tabular}{|l|l|l|l|l|}
\hline Model & B & Std. Error & Beta & Sig. \\
\hline Constant) & 1.74 & 0.44 & & 0.00 \\
\hline Female & 0.01 & 0.09 & 0.00 & 0.91 \\
\hline Minority & 0.07 & 0.12 & 0.02 & 0.55 \\
\hline Age & 0.01 & 0.00 & 0.04 & 0.21 \\
\hline Part-time & 0.03 & 0.10 & 0.01 & 0.75 \\
\hline Cohort & -0.10 & 0.09 & -0.04 & 0.28 \\
\hline Thesis & -0.09 & 0.12 & -0.03 & 0.44 \\
\hline Mentored & 0.03 & 0.09 & 0.01 & 0.71 \\
\hline Multiple Faculty & 0.03 & 0.10 & 0.01 & 0.77 \\
\hline Meeting Often & 0.18 & 0.10 & 0.07 & 0.08 \\
\hline
\end{tabular}




\begin{tabular}{|l|l|l|l|l|}
\hline Adviser Accessibility & 0.01 & 0.03 & 0.02 & 0.62 \\
\hline Peer Culture & -0.42 & 0.41 & -0.05 & 0.30 \\
\hline Department Culture & 5.36 & 0.45 & 0.59 & 0.00 \\
\hline Department Climate & -0.27 & 0.76 & -0.01 & 0.72 \\
\hline
\end{tabular}

$\mathrm{R}^{2}=.34, \mathrm{~F}=23.57, \mathrm{p}<0.001$

Multiple regression was used to test if student satisfaction with the amount of

time students spend with their advisers predicted program commitment while controlling for student and educational characteristics and culture and climate (See Table 61: Results of regression analysis with student satisfaction with adviser time predicting student program commitment). The results of the regression indicate that the variable adviser time does not predict program commitment.

Table 61: Results of regression analysis with student satisfaction with adviser time predicting student program commitment

\begin{tabular}{|l|l|l|l|l|}
\hline Model & B & Std. Error & Beta & Sig. \\
\hline Constant $)$ & 1.68 & 0.43 & & 0.00 \\
\hline Female & 0.01 & 0.09 & 0.00 & 0.95 \\
\hline Minority & 0.06 & 0.12 & 0.02 & 0.62 \\
\hline Age & 0.01 & 0.00 & 0.04 & 0.24 \\
\hline Part-time & 0.02 & 0.10 & 0.01 & 0.86 \\
\hline Cohort & -0.09 & 0.09 & -0.03 & 0.33 \\
\hline Thesis & -0.10 & 0.12 & -0.03 & 0.40 \\
\hline Mentored & 0.03 & 0.09 & 0.01 & 0.77 \\
\hline Multiple Faculty & 0.03 & 0.10 & 0.01 & 0.72 \\
\hline Meeting Often & 0.13 & 0.10 & 0.05 & 0.20 \\
\hline
\end{tabular}




\begin{tabular}{|l|l|l|l|l|}
\hline Adviser Time & 0.05 & 0.03 & 0.07 & 0.07 \\
\hline Peer Culture & -0.37 & 0.40 & -0.04 & 0.36 \\
\hline Department Culture & 5.18 & 0.45 & 0.57 & 0.00 \\
\hline Department Climate & -0.21 & 0.76 & -0.01 & 0.78 \\
\hline
\end{tabular}

$\mathrm{R}^{2}=0.35, \mathrm{~F}=24.60, \mathrm{p}<0.001$

Multiple regression was used to test if student agreement with how advisers are assigned predicted program commitment while controlling for student and educational characteristics and culture and climate (See Table 62: Results of regression analysis with student satisfaction with adviser assigned predicting student program commitment). The results of the regression indicate that the variable adviser assigned $(\beta=0.16, p<0.001)$ does predict program commitment indicating that as student agreement with how faculty are assigned increases so does satisfaction with program commitment.

Table 62: Results of regression analysis with student satisfaction with adviser assigned predicting student program commitment

\begin{tabular}{|l|l|l|l|l|}
\hline Model & B & Std. Error & Beta & Sig. \\
\hline Constant) & 1.72 & 0.43 & & 0.00 \\
\hline Female & 0.02 & 0.09 & 0.01 & 0.80 \\
\hline Minority & 0.05 & 0.12 & 0.01 & 0.66 \\
\hline Age & 0.00 & 0.00 & 0.02 & 0.47 \\
\hline Part-time & 0.03 & 0.10 & 0.01 & 0.78 \\
\hline Cohort & -0.11 & 0.09 & -0.04 & 0.23 \\
\hline Thesis & -0.08 & 0.11 & -0.02 & 0.50 \\
\hline Mentored & 0.08 & 0.09 & 0.03 & 0.38 \\
\hline Multiple Faculty & 0.03 & 0.09 & 0.01 & 0.78 \\
\hline
\end{tabular}




\begin{tabular}{|l|l|l|l|l|}
\hline Meeting Often & 0.12 & 0.10 & 0.04 & 0.23 \\
\hline Adviser Assigned & 0.10 & 0.02 & 0.16 & 0.00 \\
\hline Peer Culture & -0.28 & 0.40 & -0.03 & 0.49 \\
\hline Department Culture & 4.82 & 0.44 & 0.53 & 0.00 \\
\hline Department Climate & -0.34 & 0.75 & -0.02 & 0.65 \\
\hline
\end{tabular}

$\mathrm{R}^{2}=.36, \mathrm{~F}=26.43, \mathrm{p}<0.001$

Multiple regression was used to test if student agreement with wishing for another adviser in their department predicted program commitment while controlling for student and educational characteristics and culture and climate (See Table 63: Results of regression analysis with student satisfaction with adviser wish predicting student program commitment). The results of the regression indicate that the variable adviser wish $(B=-$ 0.09, $\mathrm{p}<0.05)$ does predict program commitment indicating that as student agreement with wishing for another faculty member in their department to be their adviser decreases satisfaction with program commitment increases.

Table 63: Results of regression analysis with student satisfaction with adviser wish predicting student program commitment

\begin{tabular}{|l|l|l|l|l|}
\hline Model & B & Std. Error & Beta & Sig. \\
\hline Constant $)$ & 2.03 & 0.46 & & 0.00 \\
\hline Female & 0.01 & 0.09 & 0.00 & 0.90 \\
\hline Minority & 0.04 & 0.12 & 0.01 & 0.73 \\
\hline Age & 0.00 & 0.00 & 0.03 & 0.39 \\
\hline Part-time & 0.05 & 0.10 & 0.02 & 0.61 \\
\hline Cohort & -0.09 & 0.09 & -0.03 & 0.34 \\
\hline Thesis & -0.09 & 0.12 & -0.03 & 0.44 \\
\hline
\end{tabular}




\begin{tabular}{|l|l|l|l|l|}
\hline Mentored & 0.05 & 0.09 & 0.02 & 0.58 \\
\hline Multiple Faculty & 0.06 & 0.10 & 0.02 & 0.56 \\
\hline Meeting Often & 0.15 & 0.10 & 0.06 & 0.13 \\
\hline Adviser Wish & -0.06 & 0.03 & -0.09 & 0.01 \\
\hline Peer Culture & -0.30 & 0.40 & -0.03 & 0.47 \\
\hline Department Culture & 5.10 & 0.44 & 0.56 & 0.00 \\
\hline Department Climate & -0.14 & 0.75 & -0.01 & 0.86 \\
\hline
\end{tabular}

$\mathrm{R}^{2}=.35, \mathrm{~F}=24.92, \mathrm{p}<0.001$

Multiple regression was used to test if student satisfaction with advisers feedback regarding their work predicted program commitment while controlling for student and educational characteristics and culture and climate (See Table 64: Results of regression analysis with student satisfaction good feedback with predicting student program commitment). The results of the regression indicate that the variable good feedback $(ß=0.12, \mathrm{p}<0.05)$ does predict program commitment indicating that as student satisfaction with their advisers' feedback increases satisfaction with program commitment increases.

Table 64: Results of regression analysis with student satisfaction good feedback with predicting student program commitment

\begin{tabular}{|l|l|l|l|l|}
\hline Model & B & Std. Error & Beta & Sig. \\
\hline (Constant) & 1.50 & 0.53 & & 0.01 \\
\hline Female & 0.00 & 0.11 & 0.00 & 1.00 \\
\hline Minority & -0.05 & 0.15 & -0.01 & 0.76 \\
\hline Age & 0.00 & 0.01 & 0.02 & 0.55 \\
\hline Part-time & 0.05 & 0.13 & 0.02 & 0.71 \\
\hline Cohort & -0.08 & 0.11 & -0.03 & 0.49 \\
\hline
\end{tabular}




\begin{tabular}{|l|l|l|l|l|}
\hline Thesis & -0.07 & 0.14 & -0.02 & 0.60 \\
\hline Mentored & -0.08 & 0.12 & -0.03 & 0.50 \\
\hline Multiple Faculty & 0.08 & 0.12 & 0.03 & 0.49 \\
\hline Meeting Often & 0.25 & 0.12 & 0.09 & 0.04 \\
\hline Good Feedback & 0.09 & 0.04 & 0.12 & 0.02 \\
\hline Peer Culture & -0.37 & 0.48 & -0.04 & 0.45 \\
\hline Department Culture & 4.90 & 0.54 & 0.53 & 0.00 \\
\hline Department Climate & 0.13 & 0.91 & 0.01 & 0.88 \\
\hline
\end{tabular}

$\mathrm{R}^{2}=.36, \mathrm{~F}=18.65, \mathrm{p}<0.001$

Multiple regression was used to test if student satisfaction with his/her advisers collaboration predicted program commitment while controlling for student and educational characteristics and culture and climate (See Table 65: Results of regression analysis with student satisfaction with faculty collaboration with predicting student program commitment). The results of the regression indicate that the variable collaboration $(\beta=0.13, \mathrm{p}<0.05)$ does predict program commitment indicating that as student agreement with how faculty collaborate with them increases so does satisfaction with program commitment.

Table 65: Results of regression analysis with student satisfaction with faculty collaboration with predicting student program commitment

\begin{tabular}{|l|l|l|l|l|}
\hline Model & B & Std. Error & Beta & Sig. \\
\hline (Constant) & 1.23 & 0.56 & & 0.03 \\
\hline Female & 0.01 & 0.12 & 0.00 & 0.91 \\
\hline Minority & 0.04 & 0.16 & 0.01 & 0.79 \\
\hline Age & 0.01 & 0.01 & 0.07 & 0.13 \\
\hline
\end{tabular}




\begin{tabular}{|l|l|l|l|l|}
\hline Part-time & 0.02 & 0.15 & 0.01 & 0.87 \\
\hline Cohort & -0.06 & 0.12 & -0.02 & 0.64 \\
\hline Thesis & -0.16 & 0.15 & -0.05 & 0.29 \\
\hline Mentored & -0.13 & 0.13 & -0.05 & 0.33 \\
\hline Multiple Faculty & 0.15 & 0.13 & 0.05 & 0.26 \\
\hline Meeting Often & 0.19 & 0.13 & 0.07 & 0.14 \\
\hline Collaboration & 0.10 & 0.04 & 0.13 & 0.01 \\
\hline Peer Culture & -0.69 & 0.51 & -0.07 & 0.18 \\
\hline Department Culture & 5.10 & 0.57 & 0.55 & 0.00 \\
\hline Department Climate & 0.37 & 0.94 & 0.02 & 0.69 \\
\hline
\end{tabular}

$\mathrm{R}^{2}=.36, \mathrm{~F}=16.15, \mathrm{p}<0.001$

Multiple regression was used to test if student satisfaction with his/her advisers help with networking predicted program commitment while controlling for student and educational characteristics and culture and climate (See Table 66: Results of regression analysis with student satisfaction with faculty networking with predicting student program commitment). The results of the regression indicate that the variable networking $(ß=0.16, \mathrm{p}<0.001)$ does predict program commitment indicating that as student agreement with how faculty help them network increases so does satisfaction with program commitment.

Table 66: Results of regression analysis with student satisfaction with faculty networking with predicting student program commitment

\begin{tabular}{|l|l|l|l|l|}
\hline Model & B & Std. Error & Beta & Sig. \\
\hline (Constant) & 1.80 & 0.51 & & 0.00 \\
\hline Female & 0.00 & 0.11 & 0.00 & 0.97 \\
\hline
\end{tabular}




\begin{tabular}{|l|l|l|l|l|}
\hline Minority & -0.01 & 0.14 & 0.00 & 0.92 \\
\hline Age & 0.00 & 0.01 & 0.03 & 0.50 \\
\hline Part-time & -0.03 & 0.13 & -0.01 & 0.84 \\
\hline Cohort & -0.09 & 0.11 & -0.04 & 0.39 \\
\hline Thesis & -0.10 & 0.14 & -0.03 & 0.47 \\
\hline Mentored & -0.20 & 0.12 & -0.08 & 0.09 \\
\hline Multiple Faculty & 0.09 & 0.12 & 0.03 & 0.43 \\
\hline Meeting Often & 0.25 & 0.12 & 0.09 & 0.04 \\
\hline Networking & 0.12 & 0.03 & 0.16 & 0.00 \\
\hline Peer Culture & -0.69 & 0.47 & -0.07 & 0.14 \\
\hline Department Culture & 5.08 & 0.53 & 0.55 & 0.00 \\
\hline Department Climate & -0.30 & 0.86 & -0.02 & 0.73 \\
\hline
\end{tabular}

$\mathrm{R}^{2}=.37, \mathrm{~F}=19.64, \mathrm{p}<0.001$

Multiple regression was used to test if student satisfaction with his/her advisers referral to academic support when needed predicted program commitment while controlling for student and educational characteristics and culture and climate (See Table 67: Results of regression analysis with student satisfaction with referral to academic support with predicting student program commitment). The results of the regression indicate that the variable academic support does not predict program commitment.

Table 67: Results of regression analysis with student satisfaction with referral to academic support with predicting student program commitment

\begin{tabular}{|l|l|l|l|l|}
\hline Model & B & Std. Error & Beta & Sig. \\
\hline (Constant) & 1.51 & 0.57 & & 0.01 \\
\hline Female & 0.05 & 0.13 & 0.02 & 0.72 \\
\hline
\end{tabular}




\begin{tabular}{|l|l|l|l|l|}
\hline Minority & -0.05 & 0.16 & -0.01 & 0.77 \\
\hline Age & 0.01 & 0.01 & 0.03 & 0.48 \\
\hline Part-time & 0.17 & 0.15 & 0.06 & 0.26 \\
\hline Cohort & -0.17 & 0.13 & -0.06 & 0.19 \\
\hline Thesis & -0.19 & 0.17 & -0.05 & 0.27 \\
\hline Mentored & -0.18 & 0.14 & -0.07 & 0.19 \\
\hline Multiple Faculty & 0.15 & 0.14 & 0.05 & 0.30 \\
\hline Meeting Often & 0.31 & 0.14 & 0.12 & 0.03 \\
\hline Academic Support & 0.05 & 0.04 & 0.06 & 0.23 \\
\hline Peer Culture & -0.45 & 0.56 & -0.05 & 0.42 \\
\hline Department Culture & 5.62 & 0.58 & 0.62 & 0.00 \\
\hline Department Climate & -0.40 & 0.99 & -0.02 & 0.69 \\
\hline
\end{tabular}

$\mathrm{R}^{2}=.39, \mathrm{~F}=15.42, \mathrm{p}<0.001$

Multiple regression was used to test if student satisfaction with his/her advisers referral to non-academic support when needed predicted program commitment while controlling for student and educational characteristics and culture and climate (See Table 68: Results of regression analysis with student satisfaction with referral to non-academic support with predicting student program commitment). The results of the regression indicate that the variable non-academic support does not predict program commitment.

Table 68: Results of regression analysis with student satisfaction with referral to non-academic support with predicting student program commitment

\begin{tabular}{|l|l|l|l|l|}
\hline Model & B & Std. Error & Beta & Sig. \\
\hline (Constant) & 1.68 & 0.60 & & 0.01 \\
\hline Female & -0.06 & 0.14 & -0.02 & 0.67 \\
\hline
\end{tabular}




\begin{tabular}{|l|l|l|l|l|}
\hline Minority & 0.07 & 0.17 & 0.02 & 0.68 \\
\hline Age & 0.01 & 0.01 & 0.07 & 0.21 \\
\hline Part-time & 0.11 & 0.16 & 0.04 & 0.51 \\
\hline Cohort & -0.11 & 0.14 & -0.04 & 0.42 \\
\hline Thesis & -0.24 & 0.19 & -0.07 & 0.20 \\
\hline Mentored & -0.13 & 0.15 & -0.05 & 0.40 \\
\hline Multiple Faculty & 0.11 & 0.16 & 0.04 & 0.48 \\
\hline Meeting Often & 0.16 & 0.15 & 0.06 & 0.28 \\
\hline Non-Academic Support & 0.04 & 0.04 & 0.06 & 0.33 \\
\hline Peer Culture & -0.79 & 0.59 & -0.08 & 0.18 \\
\hline Department Culture & 5.39 & 0.61 & 0.60 & 0.00 \\
\hline Department Climate & -0.15 & 1.02 & -0.01 & 0.89 \\
\hline
\end{tabular}

$\mathrm{R}^{2}=.35, \mathrm{~F}=11.55, \mathrm{p}<0.001$

Multiple regression was used to test if student satisfaction with his/her advisers help identifying funding predicted program commitment while controlling for student and educational characteristics and culture and climate (See Table 69: Results of regression analysis with student satisfaction with help identifying funding with predicting student program commitment). The results of the regression indicate that the variable funding $(ß=0.17, \mathrm{p}<0.001)$ does predict program commitment indicating that as student satisfaction with his/her advisers help identifying funding increases so does satisfaction with program commitment.

Table 69: Results of regression analysis with student satisfaction with help identifying funding with predicting student program commitment

\begin{tabular}{|l|l|l|l|l|}
\hline Model & B & Std. Error & Beta & Sig. \\
\hline
\end{tabular}




\begin{tabular}{|l|l|l|l|l|}
\hline (Constant) & 1.65 & 0.51 & & 0.00 \\
\hline Female & -0.04 & 0.11 & -0.01 & 0.71 \\
\hline Minority & 0.04 & 0.14 & 0.01 & 0.75 \\
\hline Age & 0.00 & 0.01 & 0.02 & 0.68 \\
\hline Part-time & 0.06 & 0.13 & 0.02 & 0.62 \\
\hline Cohort & -0.12 & 0.11 & -0.05 & 0.24 \\
\hline Thesis & -0.22 & 0.13 & -0.07 & 0.10 \\
\hline Mentored & -0.11 & 0.11 & -0.04 & 0.32 \\
\hline Multiple Faculty & 0.11 & 0.12 & 0.04 & 0.33 \\
\hline Meeting Often & 0.17 & 0.12 & 0.06 & 0.16 \\
\hline Funding & 0.12 & 0.03 & 0.17 & 0.00 \\
\hline Peer Culture & -0.72 & 0.47 & -0.07 & 0.13 \\
\hline Department Culture & 4.95 & 0.50 & 0.55 & 0.00 \\
\hline Department Climate & 0.37 & 0.86 & 0.02 & 0.67 \\
\hline
\end{tabular}

$\mathrm{R}^{2}=.39, \mathrm{~F}=20.81, \mathrm{p}<0.001$

Multiple regression was used to test if student satisfaction with their advisers encouragement to make progress on their thesis predicted program commitment while controlling for student and educational characteristics and culture and climate (See Table 70: Results of regression analysis with student satisfaction with encouraging students to make progress on their thesis with predicting student program commitment). The results of the regression indicate that the variable encourage thesis $(\beta=0.20, \mathrm{p}<0.05)$ does predict program commitment indicating that as student satisfaction with their advisers encouragement increases so does satisfaction with program commitment. 
FACILITATING MASTER'S STUDENT SUCCESS

Table 70: Results of regression analysis with student satisfaction with encouraging students to make progress on their thesis with predicting student program commitment

\begin{tabular}{|l|l|l|l|l|}
\hline Model & B & Std. Error & Beta & Sig. \\
\hline Constant) & 1.52 & 1.47 & & 0.31 \\
\hline Female & -0.27 & 0.23 & -0.10 & 0.25 \\
\hline Minority & 0.07 & 0.32 & 0.02 & 0.83 \\
\hline Age & 0.03 & 0.01 & 0.18 & 0.04 \\
\hline Part-time & 0.00 & 0.28 & 0.00 & 1.00 \\
\hline Cohort & -0.31 & 0.22 & -0.11 & 0.17 \\
\hline Mentored & 0.42 & 0.28 & 0.14 & 0.14 \\
\hline Multiple Faculty & 0.00 & 0.28 & 0.00 & 0.99 \\
\hline Meeting Often & 0.50 & 0.40 & 0.11 & 0.22 \\
\hline Encourage Thesis & 0.18 & 0.09 & 0.20 & 0.04 \\
\hline Peer Culture & 0.27 & 1.09 & 0.03 & 0.80 \\
\hline Department Culture & 4.78 & 1.21 & 0.48 & 0.00 \\
\hline Department Climate & -3.37 & 2.11 & -0.14 & 0.11 \\
\hline
\end{tabular}

$\mathrm{R}^{2}=.46, \mathrm{~F}=6.55, \mathrm{p}<0.001$

Multiple regression was used to test if student satisfaction with their adviser knowing them as an individual predicted program commitment while controlling for student and educational characteristics and culture and climate (See Table 71: Results of regression analysis with student satisfaction with knowing you as an individual with predicting student program commitment). The results of the regression indicate that the variable know individual $(\beta=0.11, \mathrm{p}<0.05)$ does predict program commitment indicating 
that as student satisfaction with their adviser knowing them as an individual increases so does satisfaction with program commitment.

Table 71: Results of regression analysis with student satisfaction with knowing you as an individual with predicting student program commitment

\begin{tabular}{|l|l|l|l|l|}
\hline Model & B & Std. Error & Beta & Sig. \\
\hline Constant) & 1.61 & 0.47 & & 0.00 \\
\hline Female & 0.00 & 0.10 & 0.00 & 0.98 \\
\hline Minority & -0.03 & 0.13 & -0.01 & 0.84 \\
\hline Age & 0.00 & 0.01 & 0.03 & 0.45 \\
\hline Part-time & 0.02 & 0.12 & 0.01 & 0.86 \\
\hline Cohort & -0.07 & 0.10 & -0.03 & 0.46 \\
\hline Thesis & -0.12 & 0.13 & -0.04 & 0.34 \\
\hline Mentored & -0.12 & 0.11 & -0.05 & 0.26 \\
\hline Multiple Faculty & 0.06 & 0.11 & 0.02 & 0.59 \\
\hline Meeting Often & 0.23 & 0.11 & 0.09 & 0.04 \\
\hline Know Individual & 0.08 & 0.03 & 0.11 & 0.02 \\
\hline Peer Culture & -0.57 & 0.44 & -0.06 & 0.20 \\
\hline Department Culture & 4.94 & 0.50 & 0.54 & 0.00 \\
\hline Department Climate & 0.28 & 0.82 & 0.01 & 0.34 \\
\hline
\end{tabular}

$\mathrm{R}^{2}=.34, \mathrm{~F}=20.45, \mathrm{p}<0.001$

Multiple regression was used to test if student satisfaction with their adviser

caring about their academic progress predicted program commitment while controlling for student and educational characteristics and culture and climate (See Table 72: Results of regression analysis with student satisfaction with caring about your academic progress 
with predicting student program commitment). The results of the regression indicate that the variable care $(\beta=0.10, \mathrm{p}<0.05)$ does predict program commitment indicating that as student satisfaction with their adviser caring about their academic progress increases so does satisfaction with program commitment.

Table 72: Results of regression analysis with student satisfaction with caring about your academic progress with predicting student program commitment

\begin{tabular}{|l|l|l|l|l|}
\hline Model & B & Std. Error & Beta & Sig. \\
\hline Constant) & 1.66 & 0.48 & & 0.00 \\
\hline Female & -0.01 & 0.10 & 0.00 & 0.94 \\
\hline Minority & -0.03 & 0.14 & -0.01 & 0.80 \\
\hline Age & 0.00 & 0.01 & 0.03 & 0.44 \\
\hline Part-time & 0.02 & 0.12 & 0.01 & 0.90 \\
\hline Cohort & -0.07 & 0.10 & -0.03 & 0.48 \\
\hline Thesis & -0.11 & 0.13 & -0.03 & 0.39 \\
\hline Mentored & -0.11 & 0.11 & -0.04 & 0.32 \\
\hline Multiple Faculty & 0.04 & 0.11 & 0.02 & 0.70 \\
\hline Meeting Often & 0.22 & 0.11 & 0.08 & 0.05 \\
\hline Care & 0.07 & 0.03 & 0.10 & 0.02 \\
\hline Peer Culture & -0.57 & 0.45 & -0.06 & 0.20 \\
\hline Department Culture & 5.03 & 0.51 & 0.55 & 0.00 \\
\hline Department Climate & 0.10 & 0.83 & 0.01 & 0.90 \\
\hline
\end{tabular}

$\mathrm{R}^{2}=.35, \mathrm{~F}=20.08, \mathrm{p}<0.001$

Nearly all the mentoring advising variables - except for academic and nonacademic referral — are positively correlated to program commitment. Students may see accuracy of information, adviser accessibility, time spent with adviser, and the referral 
functions as not being related to their program, which may account for why these variables were not significant.

\section{Advising Satisfaction and Degree Commitment}

The variable degree commitment is defined as, "My graduate degree will help me advance professionally." Students indicated their level of agreement on a 6 point Likert-type scale where $1=$ Strongly Disagree and $6=$ Strongly Agree. The $\mathrm{R}^{2}$ indicates the models account for $21-31 \%$ of the variance. These models are not as strong as the institutional and program commitment models.

Multiple regression was used to test if student satisfaction with accurate information in advising predicted degree commitment while controlling for student and educational characteristics and culture and climate (See Table 73: Results of regression analysis with student satisfaction with accurate information predicting student degree commitment). The results of the regression indicate that the variable accurate information does not predict degree commitment.

Table 73: Results of regression analysis with student satisfaction with accurate information predicting student degree commitment

\begin{tabular}{|l|l|l|l|l|}
\hline Model & B & Std. Error & Beta & Sig. \\
\hline (Constant) & 3.01 & 0.42 & & 0.00 \\
\hline Female & -0.05 & 0.09 & -0.02 & 0.60 \\
\hline Minority & -0.05 & 0.12 & -0.02 & 0.68 \\
\hline Age & 0.00 & 0.00 & 0.02 & 0.66 \\
\hline Part-time & 0.15 & 0.10 & 0.06 & 0.13 \\
\hline
\end{tabular}




\begin{tabular}{|l|l|l|l|l|}
\hline Cohort & 0.08 & 0.09 & 0.04 & 0.35 \\
\hline Thesis & -0.01 & 0.11 & 0.00 & 0.92 \\
\hline Mentored & 0.01 & 0.09 & 0.00 & 0.94 \\
\hline Multiple Faculty & -0.05 & 0.09 & -0.02 & 0.60 \\
\hline Meeting Often & 0.12 & 0.09 & 0.05 & 0.20 \\
\hline Accurate Information & 0.06 & 0.04 & 0.07 & 0.11 \\
\hline Peer Culture & 0.12 & 0.39 & 0.02 & 0.75 \\
\hline Department Culture & 3.47 & 0.44 & 0.43 & 0.00 \\
\hline Department Climate & -0.67 & 0.73 & -0.04 & 0.36 \\
\hline
\end{tabular}

$\mathrm{R}^{2}=0.22, \mathrm{~F}=12.87, \mathrm{p}<0.001$

Multiple regression was used to test if student satisfaction with help

understanding policies and procedures in advising predicted degree commitment while controlling for student and educational characteristics and culture and climate (See Table 74: Results of regression analysis with student satisfaction with policies and procedures predicting student degree commitment). The results of the regression indicate that the variable policy and procedure $(\beta=0.12, \mathrm{p}<0.001)$ does predict degree commitment indicating that as student satisfaction with faculty help understanding institutional policies and procedures increases so does satisfaction with degree commitment.

Table 74: Results of regression analysis with student satisfaction with policies and procedures predicting student degree commitment

\begin{tabular}{|l|l|l|l|l|}
\hline Model & B & Std. Error & Beta & Sig. \\
\hline (Constant) & 3.08 & .42 & & .00 \\
\hline Female & -.07 & .09 & -.03 & .44 \\
\hline Minority & -.05 & .12 & -.02 & .68 \\
\hline
\end{tabular}


FACILITATING MASTER'S STUDENT SUCCESS

\begin{tabular}{|l|l|l|l|l|}
\hline Age & .00 & .00 & .01 & .76 \\
\hline Part-time & .15 & .10 & .06 & .14 \\
\hline Cohort & .08 & .09 & .03 & .38 \\
\hline Thesis & -.01 & .11 & .00 & .90 \\
\hline Mentored & .00 & .09 & .00 & 1.00 \\
\hline Multiple Faculty & -.07 & .09 & -.03 & .45 \\
\hline Meeting Often & .12 & .09 & .05 & .22 \\
\hline Policy and Procedures & .09 & .03 & .12 & .00 \\
\hline Peer Culture & .04 & .39 & .00 & .93 \\
\hline Department Culture & 3.37 & .43 & .42 & .00 \\
\hline Department Climate & -.74 & .73 & -.04 & .31 \\
\hline
\end{tabular}

$\mathrm{R}^{2}=0.22, \mathrm{~F}=13.08, \mathrm{p}<0.001$

Multiple regression was used to test if student satisfaction with help creating an educational plan in advising predicted degree commitment while controlling for student and educational characteristics and culture and climate (See Table 75: Results of regression analysis with student satisfaction with help creating an educational plan predicting student degree commitment). The results of the regression indicate that the variable ed plan $(\beta=0.12, \mathrm{p}<0.05)$ does predict degree commitment indicating that as student satisfaction with faculty help creating an educational plan increases so does satisfaction with degree commitment.

Table 75: Results of regression analysis with student satisfaction with help creating an educational plan predicting student degree commitment

\begin{tabular}{|l|l|l|l|l|}
\hline Model & B & Std. Error & Beta & Sig. \\
\hline (Constant) & 2.94 & 0.44 & & 0.00 \\
\hline
\end{tabular}




\begin{tabular}{|l|l|l|l|l|}
\hline Female & -0.07 & 0.09 & -0.03 & 0.47 \\
\hline Minority & -0.01 & 0.12 & 0.00 & 0.91 \\
\hline Age & 0.00 & 0.01 & 0.02 & 0.56 \\
\hline Part-time & 0.15 & 0.11 & 0.06 & 0.17 \\
\hline Cohort & 0.10 & 0.09 & 0.04 & 0.28 \\
\hline Thesis & 0.08 & 0.12 & 0.03 & 0.49 \\
\hline Mentored & -0.06 & 0.10 & -0.02 & 0.56 \\
\hline Multiple Faculty & -0.05 & 0.10 & -0.02 & 0.61 \\
\hline Meeting Often & 0.02 & 0.10 & 0.01 & 0.83 \\
\hline Ed Plan & 0.09 & 0.03 & 0.12 & 0.01 \\
\hline Peer Culture & 0.27 & 0.41 & 0.03 & 0.51 \\
\hline Department Culture & 3.40 & 0.46 & 0.42 & 0.00 \\
\hline Department Climate & -0.72 & 0.77 & -0.04 & 0.35 \\
\hline
\end{tabular}

$\mathrm{R}^{2}=.24, \mathrm{~F}=13.32, \mathrm{p}<0.001$

Multiple regression was used to test if student satisfaction with his/her advisers accessibility predicted degree commitment while controlling for student and educational characteristics and culture and climate (See Table 76: Results of regression analysis with student satisfaction with adviser accessibility predicting student degree commitment).

The results of the regression indicate that the variable adviser accessibility does not predict degree commitment.

Table 76: Results of regression analysis with student satisfaction with adviser accessibility predicting student degree commitment

\begin{tabular}{|l|l|l|l|l|}
\hline Model & B & Std. Error & Beta & Sig. \\
\hline (Constant) & 3.19 & 0.42 & & 0.00 \\
\hline
\end{tabular}




\begin{tabular}{|l|l|l|l|l|}
\hline Female & -0.09 & 0.09 & -0.04 & 0.32 \\
\hline Minority & -0.04 & 0.12 & -0.01 & 0.74 \\
\hline Age & 0.00 & 0.00 & 0.02 & 0.58 \\
\hline Part-time & 0.15 & 0.10 & 0.06 & 0.13 \\
\hline Cohort & 0.05 & 0.09 & 0.02 & 0.54 \\
\hline Thesis & -0.03 & 0.11 & -0.01 & 0.79 \\
\hline Mentored & 0.02 & 0.09 & 0.01 & 0.85 \\
\hline Multiple Faculty & -0.04 & 0.09 & -0.02 & 0.65 \\
\hline Meeting Often & 0.12 & 0.10 & 0.05 & 0.24 \\
\hline Adviser Accessibility & 0.01 & 0.03 & 0.02 & 0.68 \\
\hline Peer Culture & 0.28 & 0.39 & 0.03 & 0.47 \\
\hline Department Culture & 3.60 & 0.44 & 0.45 & 0.00 \\
\hline Department Climate & -0.86 & 0.73 & -0.05 & 0.24 \\
\hline
\end{tabular}

$\mathrm{R}^{2}=.22, \mathrm{~F}=12.35, \mathrm{p}<0.001$

Multiple regression was used to test if student satisfaction with the amount of time students spend with their advisers predicted degree commitment while controlling for student and educational characteristics and culture and climate (See Table 77: Results of regression analysis with student satisfaction with adviser time predicting student degree commitment). The results of the regression indicate that the variable adviser time does not predict degree commitment.

Table 77: Results of regression analysis with student satisfaction with adviser time predicting student degree commitment

\begin{tabular}{|l|l|l|l|l|}
\hline Model & B & Std. Error & Beta & Sig. \\
\hline
\end{tabular}




\begin{tabular}{|l|l|l|l|l|}
\hline (Constant) & 3.13 & 0.42 & & 0.00 \\
\hline Female & -0.08 & 0.09 & -0.03 & 0.38 \\
\hline Minority & -0.04 & 0.12 & -0.01 & 0.73 \\
\hline Age & 0.00 & 0.00 & 0.02 & 0.60 \\
\hline Part-time & 0.15 & 0.10 & 0.06 & 0.14 \\
\hline Cohort & 0.07 & 0.09 & 0.03 & 0.42 \\
\hline Thesis & -0.02 & 0.11 & -0.01 & 0.83 \\
\hline Mentored & 0.00 & 0.09 & 0.00 & 0.98 \\
\hline Multiple Faculty & -0.04 & 0.09 & -0.02 & 0.63 \\
\hline Meeting Often & 0.08 & 0.10 & 0.04 & 0.42 \\
\hline Adviser Time & 0.03 & 0.03 & 0.05 & 0.25 \\
\hline Peer Culture & 0.27 & 0.39 & 0.03 & 0.49 \\
\hline Department Culture & 3.56 & 0.44 & 0.44 & 0.00 \\
\hline Department Climate & -0.83 & 0.74 & -0.05 & 0.26 \\
\hline
\end{tabular}

$\mathrm{R}^{2}=0.22, \mathrm{~F}=12.87, \mathrm{p}<0.001$

Multiple regression was used to test if student agreement with how advisers are assigned predicted degree commitment while controlling for student and educational characteristics and culture and climate (See Table 78: Results of regression analysis with student satisfaction with adviser assigned predicting student degree commitment). The results of the regression indicate that the variable adviser assigned $(\beta=0.14, p<0.001)$ does predict degree commitment indicating that as student agreement with how faculty are assigned increases so does satisfaction with degree commitment.

Table 78: Results of regression analysis with student satisfaction with adviser assigned predicting student degree commitment 


\begin{tabular}{|l|l|l|l|l|}
\hline Model & B & Std. Error & Beta & Sig. \\
\hline Constant) & 3.17 & 0.42 & & 0.00 \\
\hline Female & -0.03 & 0.09 & -0.01 & 0.70 \\
\hline Minority & -0.04 & 0.11 & -0.01 & 0.73 \\
\hline Age & 0.00 & 0.00 & 0.01 & 0.80 \\
\hline Part-time & 0.14 & 0.10 & 0.06 & 0.16 \\
\hline Cohort & 0.06 & 0.09 & 0.03 & 0.51 \\
\hline Thesis & -0.02 & 0.11 & -0.01 & 0.86 \\
\hline Mentored & 0.03 & 0.09 & 0.01 & 0.71 \\
\hline Multiple Faculty & -0.05 & 0.09 & -0.02 & 0.61 \\
\hline Meeting Often & 0.07 & 0.09 & 0.03 & 0.48 \\
\hline Adviser Assigned & 0.08 & 0.02 & 0.14 & 0.00 \\
\hline Peer Culture & 0.22 & 0.39 & 0.03 & 0.57 \\
\hline Department Culture & 3.30 & 0.43 & 0.41 & 0.00 \\
\hline Department Climate & -0.93 & 0.73 & -0.05 & 0.20 \\
\hline
\end{tabular}

$\mathrm{R}^{2}=.23, \mathrm{~F}=13.80, \mathrm{p}<0.001$

Multiple regression was used to test if student agreement with wishing for another adviser in their department predicted degree commitment while controlling for student and educational characteristics and culture and climate (See Table 79: Results of regression analysis with student satisfaction with adviser wish predicting student degree commitment). The results of the regression indicate that the variable adviser wish does not predict degree commitment.

Table 79: Results of regression analysis with student satisfaction with adviser wish predicting student degree commitment 


\begin{tabular}{|l|l|l|l|l|}
\hline Model & B & Std. Error & Beta & Sig. \\
\hline Constant) & 3.35 & 0.44 & & 0.00 \\
\hline Female & -0.05 & 0.09 & -0.02 & 0.60 \\
\hline Minority & -0.04 & 0.12 & -0.01 & 0.70 \\
\hline Age & 0.00 & 0.00 & 0.02 & 0.69 \\
\hline Part-time & 0.16 & 0.10 & 0.06 & 0.11 \\
\hline Cohort & 0.07 & 0.09 & 0.03 & 0.40 \\
\hline Thesis & -0.02 & 0.11 & -0.01 & 0.83 \\
\hline Mentored & 0.01 & 0.09 & 0.00 & 0.92 \\
\hline Multiple Faculty & -0.03 & 0.09 & -0.01 & 0.79 \\
\hline Meeting Often & 0.10 & 0.10 & 0.04 & 0.31 \\
\hline Adviser Wish & -0.04 & 0.03 & -0.06 & 0.12 \\
\hline Peer Culture & 0.19 & 0.39 & 0.02 & 0.63 \\
\hline Department Culture & 3.55 & 0.42 & 0.44 & 0.00 \\
\hline Department Climate & -0.75 & 0.73 & -0.04 & 0.31 \\
\hline
\end{tabular}

$\mathrm{R}^{2}=.22, \mathrm{~F}=12.82, \mathrm{p}<0.001$

Multiple regression was used to test if student satisfaction with advisers feedback regarding their work predicted degree commitment while controlling for student and educational characteristics and culture and climate (See Table 80: Results of regression analysis with student satisfaction good feedback with predicting student degree commitment). The results of the regression indicate that the variable good feedback does not predict degree commitment.

Table 80: Results of regression analysis with student satisfaction good feedback with predicting student degree commitment 


\begin{tabular}{|l|l|l|l|l|}
\hline Model & B & Std. Error & Beta & Sig. \\
\hline (Constant) & 3.02 & 0.53 & & 0.00 \\
\hline Female & -0.04 & 0.11 & -0.02 & 0.69 \\
\hline Minority & 0.01 & 0.15 & 0.00 & 0.95 \\
\hline Age & 0.00 & 0.01 & 0.02 & 0.62 \\
\hline Part-time & 0.14 & 0.13 & 0.05 & 0.28 \\
\hline Cohort & 0.02 & 0.11 & 0.01 & 0.89 \\
\hline Thesis & 0.07 & 0.14 & 0.02 & 0.62 \\
\hline Mentored & -0.06 & 0.12 & -0.02 & 0.64 \\
\hline Multiple Faculty & -0.02 & 0.12 & -0.01 & 0.86 \\
\hline Meeting Often & 0.01 & 0.12 & 0.00 & 0.94 \\
\hline Good Feedback & 0.05 & 0.04 & 0.08 & 0.13 \\
\hline Peer Culture & 0.21 & 0.47 & 0.03 & 0.65 \\
\hline Department Culture & 3.46 & 0.54 & 0.42 & 0.00 \\
\hline Department Climate & -0.61 & 0.90 & -0.03 & 0.50 \\
\hline
\end{tabular}

$\mathrm{R}^{2}=.22, \mathrm{~F}=9.00, \mathrm{p}<0.001$

Multiple regression was used to test if student satisfaction with his/her advisers collaboration predicted degree commitment while controlling for student and educational characteristics and culture and climate (See Table 81: Results of regression analysis with student satisfaction with faculty collaboration with predicting student degree commitment). The results of the regression indicate that the variable collaboration $(ß=0.14, \mathrm{p}<0.05)$ does predict degree commitment indicating that as student agreement with how faculty collaborate with them increases so does satisfaction with degree commitment. 
FACILITATING MASTER'S STUDENT SUCCESS

Table 81: Results of regression analysis with student satisfaction with faculty collaboration with predicting student degree commitment

\begin{tabular}{|l|l|l|l|l|}
\hline Model & B & Std. Error & Beta & Sig. \\
\hline Constant) & 2.76 & 0.55 & & 0.00 \\
\hline Female & -0.06 & 0.12 & -0.02 & 0.62 \\
\hline Minority & 0.08 & 0.15 & 0.03 & 0.59 \\
\hline Age & 0.01 & 0.01 & 0.06 & 0.26 \\
\hline Part-time & 0.06 & 0.14 & 0.02 & 0.65 \\
\hline Cohort & 0.05 & 0.12 & 0.02 & 0.68 \\
\hline Thesis & -0.03 & 0.15 & -0.01 & 0.84 \\
\hline Mentored & -0.07 & 0.13 & -0.03 & 0.60 \\
\hline Multiple Faculty & 0.05 & 0.13 & 0.02 & 0.67 \\
\hline Meeting Often & -0.01 & 0.13 & -0.01 & 0.92 \\
\hline Collaboration & 0.09 & 0.04 & 0.14 & 0.01 \\
\hline Peer Culture & 0.13 & 0.50 & 0.02 & 0.79 \\
\hline Department Culture & 3.12 & 0.56 & 0.38 & 0.00 \\
\hline Department Climate & -0.20 & 0.92 & -0.01 & 0.83 \\
\hline R & & & & \\
\hline
\end{tabular}

$\mathrm{R}^{2}=.22, \mathrm{~F}=8.10, \mathrm{p}<0.001$

Multiple regression was used to test if student satisfaction with his/her advisers help with networking predicted degree commitment while controlling for student and educational characteristics and culture and climate (See Table 82: Results of regression analysis with student satisfaction with faculty networking with predicting student degree commitment). The results of the regression indicate that the variable networking $(\beta=0.14$, $\mathrm{p}<0.05)$ does predict degree commitment indicating that as student agreement with how faculty help them network increases so does satisfaction with degree commitment. 
FACILITATING MASTER'S STUDENT SUCCESS

Table 82: Results of regression analysis with student satisfaction with faculty networking with predicting student degree commitment

\begin{tabular}{|l|l|l|l|l|}
\hline Model & B & Std. Error & Beta & Sig. \\
\hline (Constant) & 3.17 & 0.51 & & 0.00 \\
\hline Female & -0.06 & 0.11 & -0.02 & 0.57 \\
\hline Minority & -0.05 & 0.14 & -0.02 & 0.72 \\
\hline Age & 0.00 & 0.01 & 0.02 & 0.71 \\
\hline Part-time & 0.12 & 0.13 & 0.05 & 0.34 \\
\hline Cohort & 0.10 & 0.11 & 0.04 & 0.36 \\
\hline Thesis & 0.02 & 0.14 & 0.01 & 0.87 \\
\hline Mentored & -0.06 & 0.12 & -0.03 & 0.61 \\
\hline Multiple Faculty & 0.00 & 0.12 & 0.00 & 0.98 \\
\hline Meeting Often & 0.02 & 0.12 & 0.01 & 0.86 \\
\hline Networking & 0.09 & 0.03 & 0.14 & 0.01 \\
\hline Peer Culture & -0.08 & 0.47 & -0.01 & 0.86 \\
\hline Department Culture & 3.17 & 0.53 & 0.39 & 0.00 \\
\hline Department Climate & -0.49 & 0.86 & -0.03 & 0.57 \\
\hline
\end{tabular}

$\mathrm{R}^{2}=.21, \mathrm{~F}=8.64, \mathrm{p}<0.001$

Multiple regression was used to test if student satisfaction with his/her advisers

referral to academic support when needed predicted degree commitment while

controlling for student and educational characteristics and culture and climate (See Table

83: Results of regression analysis with student satisfaction with referral to academic

support with predicting student degree commitment). The results of the regression

indicate that the variable academic support does not predict degree commitment. 
FACILITATING MASTER'S STUDENT SUCCESS

Table 83: Results of regression analysis with student satisfaction with referral to academic support with predicting student degree commitment

\begin{tabular}{|l|l|l|l|l|}
\hline Model & B & Std. Error & Beta & Sig. \\
\hline Constant) & 3.03 & 0.55 & & 0.00 \\
\hline Female & -0.01 & 0.12 & 0.00 & 0.95 \\
\hline Minority & 0.01 & 0.15 & 0.00 & 0.93 \\
\hline Age & 0.01 & 0.01 & 0.06 & 0.23 \\
\hline Part-time & 0.31 & 0.15 & 0.12 & 0.03 \\
\hline Cohort & 0.03 & 0.13 & 0.01 & 0.79 \\
\hline Thesis & -0.02 & 0.17 & -0.01 & 0.91 \\
\hline Mentored & -0.11 & 0.13 & -0.05 & 0.41 \\
\hline Multiple Faculty & 0.10 & 0.14 & 0.04 & 0.46 \\
\hline Meeting Often & 0.17 & 0.13 & 0.07 & 0.19 \\
\hline Academic Support & 0.04 & 0.04 & 0.05 & 0.35 \\
\hline Peer Culture & -0.12 & 0.53 & -0.01 & 0.82 \\
\hline Department Culture & 4.27 & 0.56 & 0.53 & 0.00 \\
\hline Department Climate & -1.69 & 0.95 & -0.10 & 0.07 \\
\hline
\end{tabular}

$\mathrm{R}^{2}=.29, \mathrm{~F}=9.62, \mathrm{p}<0.001$

Multiple regression was used to test if student satisfaction with his/her advisers

referral to non-academic support when needed predicted degree commitment while controlling for student and educational characteristics and culture and climate (See Table 84: Results of regression analysis with student satisfaction with referral to non-academic support with predicting student degree commitment). The results of the regression indicate that the variable non-academic support does not predict degree commitment. 
FACILITATING MASTER'S STUDENT SUCCESS

Table 84: Results of regression analysis with student satisfaction with referral to non-academic support with predicting student degree commitment

\begin{tabular}{|l|l|l|l|l|}
\hline Model & B & Std. Error & Beta & Sig. \\
\hline Constant) & 2.86 & 0.59 & & 0.00 \\
\hline Female & 0.04 & 0.14 & 0.02 & 0.76 \\
\hline Minority & 0.11 & 0.17 & 0.04 & 0.51 \\
\hline Age & 0.01 & 0.01 & 0.09 & 0.10 \\
\hline Part-time & 0.30 & 0.16 & 0.11 & 0.06 \\
\hline Cohort & 0.08 & 0.14 & 0.03 & 0.55 \\
\hline Thesis & -0.11 & 0.18 & -0.03 & 0.56 \\
\hline Mentored & -0.01 & 0.14 & -0.01 & 0.92 \\
\hline Multiple Faculty & 0.01 & 0.15 & 0.00 & 0.95 \\
\hline Meeting Often & 0.18 & 0.14 & 0.08 & 0.20 \\
\hline Non-Academic Support & 0.02 & 0.04 & 0.03 & 0.60 \\
\hline Peer Culture & -0.44 & 0.57 & -0.05 & 0.45 \\
\hline Department Culture & 4.13 & 0.59 & 0.51 & 0.00 \\
\hline Department Climate & -1.21 & 0.99 & -0.07 & 0.22 \\
\hline
\end{tabular}

$\mathrm{R}^{2}=.25, \mathrm{~F}=7.31, \mathrm{p}<0.001$

Multiple regression was used to test if student satisfaction with his/her advisers

help identifying funding predicted degree commitment while controlling for student and educational characteristics and culture and climate (See Table 85: Results of regression analysis with student satisfaction with help identifying funding with predicting student degree commitment). The results of the regression indicate that the variable funding $(ß=0.22, \mathrm{p}<0.001)$ does predict degree commitment indicating that as student satisfaction 
with his/her advisers help identifying funding increases so does satisfaction with degree commitment.

Table 85: Results of regression analysis with student satisfaction with help identifying funding with predicting student degree commitment

\begin{tabular}{|l|l|l|l|l|}
\hline Model & B & Std. Error & Beta & Sig. \\
\hline Constant) & 3.64 & 0.51 & & 0.00 \\
\hline Female & -0.08 & 0.11 & -0.03 & 0.48 \\
\hline Minority & 0.10 & 0.14 & 0.03 & 0.46 \\
\hline Age & 0.00 & 0.01 & -0.02 & 0.64 \\
\hline Part-time & 0.18 & 0.13 & 0.07 & 0.16 \\
\hline Cohort & 0.04 & 0.11 & 0.02 & 0.71 \\
\hline Thesis & 0.00 & 0.13 & 0.00 & 0.99 \\
\hline Mentored & -0.17 & 0.11 & -0.07 & 0.13 \\
\hline Multiple Faculty & 0.06 & 0.12 & 0.02 & 0.60 \\
\hline Meeting Often & -0.03 & 0.12 & -0.01 & 0.82 \\
\hline Funding & 0.14 & 0.03 & 0.22 & 0.00 \\
\hline Peer Culture & -0.25 & 0.47 & -0.03 & 0.59 \\
\hline Department Culture & 3.17 & 0.50 & 0.40 & 0.00 \\
\hline Department Climate & -1.03 & 0.85 & -0.06 & 0.23 \\
\hline
\end{tabular}

$\mathrm{R}^{2}=.24, \mathrm{~F}=10.28, \mathrm{p}<0.001$

Multiple regression was used to test if student satisfaction with their advisers encouragement to make progress on their thesis predicted degree commitment while controlling for student and educational characteristics and culture and climate (See Table 86: Results of regression analysis with student satisfaction with encouraging students to make progress on their thesis with predicting student degree commitment). The results of 
the regression indicate that the variable encourage thesis does not predict degree commitment.

Table 86: Results of regression analysis with student satisfaction with encouraging students to make progress on their thesis with predicting student degree commitment

\begin{tabular}{|l|l|l|l|l|}
\hline Model & B & Std. Error & Beta & Sig. \\
\hline (Constant) & 5.46 & 1.35 & & 0.00 \\
\hline Female & -0.48 & 0.22 & -0.21 & 0.03 \\
\hline Minority & -0.50 & 0.29 & -0.16 & 0.09 \\
\hline Age & 0.01 & 0.01 & 0.06 & 0.57 \\
\hline Part-time & -0.30 & 0.26 & -0.12 & 0.25 \\
\hline Cohort & 0.03 & 0.21 & 0.01 & 0.89 \\
\hline Mentored & 0.00 & 0.26 & 0.00 & 1.00 \\
\hline Multiple Faculty & -0.32 & 0.26 & -0.12 & 0.23 \\
\hline Meeting Often & -0.21 & 0.37 & -0.06 & 0.57 \\
\hline Encourage Thesis & 0.07 & 0.08 & 0.10 & 0.38 \\
\hline Peer Culture & 0.41 & 1.00 & 0.05 & 0.68 \\
\hline Department Culture & 3.43 & 1.11 & 0.43 & 0.00 \\
\hline Department Climate & -4.35 & 1.88 & -0.18 & .041 \\
\hline$R^{2}=31$, F $3.46, p<0.001$ & & & & \\
\hline
\end{tabular}

$\mathrm{R}^{2}=.31, \mathrm{~F}=3.46, \mathrm{p}<0.001$

Multiple regression was used to test if student satisfaction with their adviser knowing them as an individual predicted degree commitment while controlling for student and educational characteristics and culture and climate (See Table 87: Results of regression analysis with student satisfaction with knowing you as an individual with predicting student degree commitment). The results of the regression indicate that the 
variable know individual $(\beta=0.18, \mathrm{p}<0.001)$ does predict degree commitment indicating that as student satisfaction with their adviser knowing them as an individual increases so does satisfaction with degree commitment.

Table 87: Results of regression analysis with student satisfaction with knowing you as an individual with predicting student degree commitment

\begin{tabular}{|l|l|l|l|l|}
\hline Model & B & Std. Error & Beta & Sig. \\
\hline (Constant) & 3.03 & 0.45 & & 0.00 \\
\hline Female & -0.04 & 0.10 & -0.02 & 0.70 \\
\hline Minority & -0.08 & 0.13 & -0.03 & 0.53 \\
\hline Age & 0.00 & 0.01 & 0.02 & 0.71 \\
\hline Part-time & 0.17 & 0.11 & 0.07 & 0.13 \\
\hline Cohort & 0.06 & 0.10 & 0.02 & 0.56 \\
\hline Thesis & -0.01 & 0.12 & 0.00 & 0.94 \\
\hline Mentored & -0.08 & 0.10 & -0.04 & 0.41 \\
\hline Multiple Faculty & -0.02 & 0.10 & -0.01 & 0.82 \\
\hline Meeting Often & 0.06 & 0.11 & 0.03 & 0.56 \\
\hline Know Individual & 0.11 & 0.03 & 0.18 & 0.00 \\
\hline Peer Culture & -0.02 & 0.43 & 0.00 & 0.96 \\
\hline Department Culture & 3.10 & 0.48 & 0.38 & 0.00 \\
\hline Department Climate & -0.42 & 0.79 & -0.02 & 0.59 \\
\hline
\end{tabular}

$\mathrm{R}^{2}=.23, \mathrm{~F}=11.63, \mathrm{p}<0.001$

Multiple regression was used to test if student satisfaction with their adviser caring about their academic progress predicted degree commitment while controlling for student and educational characteristics and culture and climate (See Table 88: Results of regression analysis with student satisfaction with caring about your academic progress 
with predicting student degree commitment). The results of the regression indicate that the variable care $(\beta=0.13, \mathrm{p}<0.05)$ does predict degree commitment indicating that as student satisfaction with their adviser caring about their academic progress increases so does satisfaction with degree commitment.

Table 88: Results of regression analysis with student satisfaction with caring about your academic progress with predicting student degree commitment

\begin{tabular}{|l|l|l|l|l|}
\hline Model & B & Std. Error & Beta & Sig. \\
\hline (Constant) & 3.06 & 0.46 & & 0.00 \\
\hline Female & -0.05 & 0.10 & -0.02 & 0.63 \\
\hline Minority & -0.08 & 0.13 & -0.02 & 0.57 \\
\hline Age & 0.00 & 0.01 & 0.02 & 0.64 \\
\hline Part-time & 0.19 & 0.11 & 0.07 & 0.10 \\
\hline Cohort & 0.07 & 0.10 & 0.03 & 0.44 \\
\hline Thesis & 0.00 & 0.13 & 0.00 & 0.97 \\
\hline Mentored & -0.07 & 0.10 & -0.03 & 0.51 \\
\hline Multiple Faculty & 0.00 & 0.11 & 0.00 & 1.00 \\
\hline Meeting Often & 0.04 & 0.11 & 0.02 & 0.68 \\
\hline Care & 0.08 & 0.03 & 0.13 & 0.01 \\
\hline Peer Culture & 0.01 & 0.44 & 0.00 & 0.99 \\
\hline Department Culture & 3.31 & 0.50 & 0.41 & 0.00 \\
\hline Department Climate & -0.62 & 0.80 & -0.04 & 0.44 \\
\hline
\end{tabular}

$\mathrm{R}^{2}=.22, \mathrm{~F}=11.00, \mathrm{p}<0.001$

Only half of the advising variables correlate to degree commitment. Student satisfaction with adviser help with understanding policies and procedures and help 
forming an educational plan from informational advising correlate to degree commitment. Student agreement with how advisers are assigned also positively correlates to degree commitment for organizational advising. From relational advising, help finding funding and being known as an individual and adviser care correlate to degree commitment. From educational advising, student satisfaction with faculty collaboration and help with networking correlate to degree commitment. Student satisfaction with accurate information, wishing for another adviser, time spent with adviser, accessibility of adviser, good feedback, academic and non-academic referral, and encouragement on thesis progress are not correlated to degree commitment.

The student success outcome degree commitment, "my graduate degree will help me advance professionally," is facilitated by knowing policies and procedures, being satisfied with your adviser, adviser collaboration, adviser help with networking in the field, help finding funding, being known as an individual and having an adviser care about you progress.

Master's student GPA and student commitment to institution, program, and degree are facilitated by administrative and mentoring advising (See Table 89: Results of regression analysis with student satisfaction with advising predicting GPA, institutional commitment, program commitment, and degree commitment summary). All but three of the advising variables correlate to one of the success outcomes. The organizational advising variables time spent with adviser and adviser accessibility, and the relational advising item non-academic referral are not correlated to a success outcome. 


\section{Table 89: Results of regression analysis with student satisfaction with advising predicting GPA, institutional commitment, program commitment, and degree commitment summary}

\begin{tabular}{|c|c|c|c|c|}
\hline Advising $[ß]$ & GPA & Institution & Program & Degree \\
\hline Accurate Information & & $0.16 * *$ & & \\
\hline Policies \& Procedures & & $0.11 *$ & $0.11 * *$ & $0.12 * *$ \\
\hline Educational Plan & & $0.21 * *$ & $0.23 * *$ & $0.12 *$ \\
\hline \multicolumn{5}{|l|}{ Accessibility } \\
\hline \multicolumn{5}{|l|}{ Adviser Time } \\
\hline Adviser Assigned & & $0.10^{*}$ & $0.16 * *$ & $0.14 * *$ \\
\hline Adviser Wish & & $-0.08 *$ & $-0.09 *$ & \\
\hline Feedback & & & $0.12 *$ & \\
\hline Collaborate & & $0.13 * *$ & $0.13^{*}$ & $0.14^{*}$ \\
\hline Networking & & $0.10 *$ & $0.16^{* *}$ & $0.14 *$ \\
\hline Encourage Thesis & & & $0.20 *$ & \\
\hline Referral Academic & $-0.15^{*}$ & & & \\
\hline \multicolumn{5}{|l|}{ Referral Non-academic } \\
\hline Funding & & $0.19 * *$ & $0.17 * *$ & $0.22 * *$ \\
\hline Individual & & $0.13 *$ & $0.11 *$ & $0.18 * *$ \\
\hline Care & & $0.11 *$ & $0.10^{*}$ & $0.13 *$ \\
\hline
\end{tabular}

$\overline{(* * \mathrm{p}<0.001, * \mathrm{p}<0.05)}$

GPA has only one significant advising variable. Institutional commitment has 10 out of 16 significant advising variables. Program commitment has 11 out of 16 significant advising variables. Half of the advising variables, 8 out of 16, are significant for degree commitment. In informational advising accurate information is only significant to institutional commitment, but help navigating policies and procedures and creating an educational plan are significant for all three kinds of commitment. In organizational advising, how advisers are assigned and student satisfaction with their adviser were significant for student commitment. Adviser accessibility and time spent with their adviser were not significant for commitment. In educational advising, collaboration and networking were significant for all three kinds of commitment, while good feedback and encouraging thesis were significant for program commitment. In relational advising, referral academic was significant for GPA, referral non-academic was 
not significant and help with funding, knowing students as individuals, and adviser care were significant for all three kinds of commitment.

On the whole, then, institutions should consider informational, organizational, educational, and relational advising in master's student success these four advising concepts will be fully explored and explicated in chapter five. 


\section{Chapter 5: Implications}

The positive relationship between advising and the success of undergraduate and doctoral students is well established in the literature. This study was motivated by the desire to understand the correlation between advising and student success for the lessstudied population of master's students. This dissertation is consistent with the literature in showing that good advising facilitates master's student success. This is an important finding because master's students are growing in enrollment, and the master's degree is a critical credential for many fields. This study delves into the general connection between advising and success by showing a connection between student satisfaction with administrative and mentoring advising and student success measured by graduate GPA and student commitment.

In order to explore the connection between advising satisfaction and success, a system for measuring master's student advising, satisfaction, and success had to be created. Advising was divided into two dimensions: administrative and mentoring advising. The category administrative advising included all the informational and organizational aspects of advising found in the literature and the category mentoring advising included all the educational and relational aspects of advising found in the literature. Altogether, 16 advising variables were identified and used in the survey for this study.

The major findings of this study include the educational characteristics that are associated with higher satisfaction with advising: frequency of adviser interaction, 
multiple faculty contacts, and having a mentor. Students with these characteristics were more satisfied with advising.

Student satisfaction with informational advising - information about policies and procedures and help forming an educational plan—was correlated with institutional, program, and degree commitment. Also, accurate information was correlated to institutional commitment. Students are more likely to be satisfied with their choice to attend this institution and believe that their program and degree will help them succeed if they are satisfied with informational advising, which provides the tools for graduate school success. Technology may assist faculty in providing accurate and up-to-date information regarding degree requirements and campus policies and procedures. Technology may also support electronic educational planning.

Student satisfaction with organizational advising — how advisers are assignedwas positively correlated with institutional, program, and degree commitment. Not wishing for another adviser was correlated to institutional and program commitment. Students who are satisfied with how advisers are assigned are likely to feel positively about their particular adviser. So this suggests that good advising supports graduation and provides a sense that the institution, program, and degree will help the student succeed. Transparency in institutional policy regarding adviser matching as well as nofault systems for students to switch advisers could support student commitment.

Student satisfaction with relational advising - faculty care, and being known as an individual, and help identifying funding — was positively correlated with institutional, program, and degree commitment. Referral to academic and non-academic support was 
not correlated to commitment. However, satisfaction with referral to academic support was correlated to higher GPA. The referral functions are likely to be very important for the students who really need them. Students who do not need referral to services may have opted out of these survey items.

Impediments to faculty-student relationships may include large advising loads and faculty workloads. Technology may be a way for faculty to address large advising loads as well as students who are part-time or non-residential. Offering targeted group advising may allow faculty to meet more regularly with advisees and address specific concerns regarding registration, thesis research, graduation, etc. Rather than having short, infrequent, individual appointments.

Student satisfaction with educational advising — faculty collaboration and help with networking — was positively correlated with institutional, program, and degree commitment. Good feedback and encouragement on thesis writing were positively correlated to program commitment, but not institutional or degree commitment. Students with access to multiple faculty through advising and courses many have more opportunities to develop mentors and find faculty to help them develop as scholars.

While having a mentor was significant for advising satisfaction, both administrative and mentoring advising elements are significant for master's student success. Similar to undergraduates (Smith \& Allen, 2006), master's students need holistic advising. Beneficial educational characteristics included having a mentor, relying upon multiple faculty members for information, and meeting with one's adviser at least once per term. Surprisingly, students who attend their graduate program part-time did 
not differ from students who attended full-time in their satisfaction with advising. According to the literature, part-time students in doctoral students have felt a sense of alienation (Gardner \& Gopaul, 2012), but perhaps the nature of master's education works better for part-time students, especially those in professional programs like education and business where part-time attendance may be the norm. Students in a cohort were negatively correlated with having access to accurate information. This finding was surprising and may say more about the specific programs that are cohort based or it may indicate that group advising needs to pay particular attention to accurate information for individual students.

\section{Recommendations}

The findings of this study suggest practices that master's level programs can use to improve student satisfaction with advising and, therefore, student success and retention. The similarities of some of these recommendations with existing recommendations for doctoral students suggests that master's student advising may align more closely with doctoral student advising. However, it is likely that master's student advising loads for faculty are much higher than doctoral advising loads. This may explain the low number of students who identified as having a mentor, who was also their faculty adviser (24\%). Unlike doctoral students, who may only be accepted into their program if an adviser agrees to work with them, master's students may be one of a few or one of fifty master's students assigned to a single faculty adviser. Thus, these recommendations must take into consideration the large advising load a faculty member may have in addition to their teaching and research agenda. Also, departments may take 
on many more master's students than doctoral students. Master's student enrollment is growing and new master's degree programs are being created. These programs and departments would benefit by thinking about the potential advising needs of their students and innovative ways to meet those needs recognizing the limits of time and faculty advisers. These recommendations are made with the understanding that the findings from this study may be considered preliminary and still in need of further research. Nevertheless, the study presents enough data to suggest ways that programs may improve master's student satisfaction with advising.

\section{Create interactive, online degree maps and education plans}

Students need to know what is expected of them in their master's programs. The results of the study show that satisfaction with their advisers help forming an educational plan or program of study correlates statistically to all of the commitment success factors. One recommendation is to use degree maps (Di Pierro, 2007, 2010), which provide information for how students traverse their graduate program. Such maps can be primarily visual, thus supporting English language learners and visual learners. They can embed information relevant to students at critical points in their degree program, recommending reentry points for students who fall off-track or stop-out of their program for a while. They are beneficial to both prospective students and current students, and can improve student and faculty communication regarding requirements and milestones and transmit accurate information regarding program policy.

In tandem with degree maps, online degree tracking provides an interactive way to help students track their degree progress. One of the Council of Graduate School's 
promising practices in promoting student success and $\mathrm{Ph} . \mathrm{D}$. completion is to "enhance online mechanisms so students and faculty can track progress" (CGS, 2010, p. 35). Students using online degree tracking can see how their courses fit into their program of study electronically. It provides a clear pathway for students through the degree, immediate feedback on where they are in their program of study, and lays out future courses requirements and milestones. This is a tool that students and faculty can use together to help the student plan their course work.

\section{Transparent adviser matching process}

The system for matching students and advisers should be clear to students prior to beginning their master's program. Student satisfaction with how advisers are assigned was found to be significant for all of the commitment success factors. Adviser match is critical for doctoral students (Golde \& Dore, 2001; Zhao et al., 2007) especially because adviser mismatch has been cited as a reason for doctoral student attrition (Golde, 1998, 2000). Policy should be written into department handbooks regarding this process and also the system for addressing adviser mismatch. Recognizing the varying styles of advisers, the fact that students' research interests may change, that faculty may leave universities for new positions, and that some personalities just do not work well together, it is important to create a system or policy that allows students to change advisers without fear of retribution or penalty.

\section{Offer group advising or multiple orientations}

While frequent meetings with an adviser or mentor are shown to improve student satisfaction with advising, this may not be feasible with faculty members' current 
advising loads. Advisers may simply not have the capacity to meet with their advisees every term or multiple times per term one on one. Advising is often one part of faculty members' workload and is one that is often not rewarded in promotion and tenure (Fairweather, 1993). This points to part of the larger problem, which is an incentive system that does not promote investing time in advising.

CGS (2010) finds that "a comprehensive orientation can prepare students for graduate school" (p. 34). A potential solution would be to offer group advising to students at similar points in their graduate program. One example would be to offer multiple orientations, one on entrance to the program and another orientation prior to a significant program milestone such as taking exams or writing a thesis. Group advising may benefit students in providing opportunities for peer interaction. This recommendation may be more easily implemented in cohort programs. However, this solution needs to take into consideration cohort students' dissatisfaction with accuracy of the information they receive. A more formalized orientation system for giving students information could solve the problem of inaccurate information as could the implementation of degree maps and online degree tracking to give clear pathways to graduation and individualized feedback on degree progress.

\section{Multiple faculty}

The traditional model of faculty advising has been a one-to-one advising relationship. Students may benefit from a system that promotes access to multiple mentors. Students who relied on more than one faculty member for information were more satisfied with all the informational advising items, the feedback they got from their 
adviser, and most of the relational advising items. Encouraging students to interact with multiple faculty supports student satisfaction with advising. Multiple faculty connections may allow students to seek out different characteristics and advising supports inside and outside of their departments.

This study identifies 16 advising functions and it may be unrealistic to expect faculty members to provide support on all 16 functions to all the students in their advising load, especially for faculty with large advising loads. A more beneficial model may be to have faculty provide group advising in areas of strength. An example may be that if a faculty member has a strong connection to a national conference then s/he could advise a group of students on conference presentation and attendance. Another faculty member may have extensive knowledge of university resources and could offer orientation information to students regarding campus services. A third option would be to partner with university resources to advise students in orientations or group advising session on specific services such as career advising or help identifying funding. It might be beneficial to explore utilizing faculty strengths in combination with group advising, well-timed orientations, and utilizing technology like degree maps and online degree tracking.

\section{Mentors}

Students who reported having a mentor showed higher levels of satisfaction with advising than students who did not have a mentor. However, the majority of students reported not having a mentor. Faculty may not see themselves as mentors, and students may not know how to find a mentor. It is unrealistic to assume that all faculty members 
know how to be mentors. Mentoring tends to be a private business, and often the only model available is an adviser's own experience of having been advised. If it was good, they decide to copy that style and methodology; if it was bad, they do the opposite (Kearns \& Gardiner, 2011). In other words, advising and mentoring are parts of the faculty job description for which there is little formal preparation or training, and consequently, quality and styles of advising vary widely. Because the relationship between advising and student success is well-established in the literature and is confirmed in this study, graduate schools and departments would be well advised to invest in opportunities for faculty to develop their advising and mentoring skills. The benefits to students' overall satisfaction with advising and success are significant and compelling.

\section{Future Research}

This study was conducted at a single urban institution, and the results may not be generalizable to more traditional research universities. Future research could replicate this study to see if the advising satisfaction of master's students at other institutions is consistent. This dissertation does not use all the data collected with the Graduate advising survey: Master's student version. This additional data can be explored in possible future studies including a qualitative study of the student responses to the openended questions regarding advising experiences, quantitative studies looking at the role of discipline in advising satisfaction, the role of race and gender in advising pairs, the influence of work and family responsibilities on student advising and success, and student collaboration and professional development through writing, publishing and 
conference presentations. Also, additional enrollment data can be added to the current study to explore time-to-degree and to reevaluate graduation and student success after two and three years.

\section{Conclusion}

Faculty advising is crucial for student success and previously little was known about master's student experiences with advising. This quantitative study investigated nearly 1,000 master's students' experiences. It deconstructed advising into two primary types of advising — administrative and mentoring advising — and into the four concepts that make up these two types - informational and organizational advising and educational and relational advising.

This study looked at multiple proxies of student success (e.g., GPA, program, institutional, and degree commitment), and found that student satisfaction with advising correlates to commitment. Student satisfaction with administrative advising, which communicates accurate policies and helps students form educational plans, increased student success. Student satisfaction with mentoring advising, which emphasizes individualized professional support (e.g., feedback on thesis writing) was also shown to facilitate master's student success.

Master's students may be similar to doctoral students in their need for mentoring, but the resources for mentoring advising in the form of individual relationships, collaboration, feedback, and help with networking may be challenging for faculty with large advising loads. Providing mentoring and holistic advising to this growing 
population may require innovative solutions including the use of technology, targeted advising, multiple advisers, and developing faculty and staff mentoring skills. 


\section{References}

Allum, J., Bell, N. E., \& Sowell, R. (2012). Graduate enrollment and degrees: 2001 to 2011. Washington, DC.

American Council on Education. (2008). Minorities in higher education 2008: TwentyThird status report. Washington DC.

Anderson, M. S., \& Swazey, J. P. (1998). Reflections on the graduate student experience: An overview. New Directions for Higher Education, 101, 3-13. doi:10.1002/he.10101

Astin, A. W. (1984). Student involvement: A developmental theory for higher education. Journal of College Student Development, 25, 297-308.

Austin, A. E. (2002). Preparing the next generation of Faculty: Graduate school as socialization to the academic career. The Journal of Higher Education, 73(1), 94122.

Bair, C. R., \& Haworth, J. G. (1993). Doctoral student attrition and persistence: A metasynthesis of research. In J. C. Smart (Ed.), Higher Education: Handbook of theory and research (Vol. XIX., Vol. XIX, pp. 481-533).

Barker, M. (2011). Racial context, currency, and connections: Black doctoral student and white advisor perspectives on cross-race advising. Innovations in Higher Education and Teaching International, 48(4), 387-400. 
FACILITATING MASTER'S STUDENT SUCCESS

Barnes, B. J., \& Austin, A. E. (2009). The role of doctoral advisors: A look at advising from the advisor's perspective. Innovative Higher Education, 33, 297-315. doi:10.1007/s10755-008-9084-x

Barnes, B. J., Williams, E. A., \& Archer, S. A. (2010). Characteristics that matter most: Doctoral students' perceptions of positive and negative advisor attributes. NACADA Journal, 30(1), 34-46.

Barnes, B. J., Williams, E. A., \& Stassen, M. L. A. (2011). Dissecting doctoral advising: A comparison of students' experiences across disciplines. Journal of Further and Higher Education, 1-23. doi:10.1080/0309877x.2011.614933

Barr, R. B., \& Tagg, J. (1995). From teaching to learning: A new paradigm for undergraduate education. Change, 27(6), 12-25.

Bell, N. E. (2009). Data sources: How graduate students finance their education. Washington DC.

Boyle, P., \& Boice, B. (1998). Best practices for enculturation: Collegiality, mentoring, and structure. In M.S. Anderson (Ed.), The experience of being in graduate school: An exploration. (pp. 87-94).

CGS (Council of Graduate Schools). (2010). PH.D. completion and attrition: Policies and practices to promote student success (pp. 1-76). Washington, DC.

Choy, S. P., \& Geis, S. (2002). Student financing of graduate and education, $1999-$ 2000. Profiles of students in selected degree programs and their use of assistantships. (pp. 1999-2000). Washington D.C. 
Conrad, C. F., Duren, K. M., \& Haworth, J. G. (1998). Students' perspectives on their master's degree experiences: Disturbing the conventional wisdom. New Directions for Higher Education, 1998(101), 65-76. doi:10.1002/he.10106

Cooke, D. K. (1995). The relationship between graduate student attitudes and attrition. Journal of Psychology, 129(6), 677-688.

Council of Graduate Schools. (2008). Ph.D. completion and attrition: Analysis of baseline program data from the Ph.D. completion project. Washington DC.

Council of Graduate Schools. (2009). Broadening participation in graduate education. Washington DC.

Crookston, B. B. (1994). A developmental view of academic advising as teaching. NACADA Journal, 14(2), 5-9.

Di Pierro, M. (2007). Excellence in doctoral education: Defining best practices. College Student Journal, 41(2), 368-375.

Di Pierro, M. (2010). Doctoral process flowcharts: Charting for success (pp. 1-4). Retrieved from www.asq.org

Dowd, A. C., Swatzky, M., \& Korn, R. (2011). Theoretical foundations and a research agenda to validate measures of intercultural effort. The Review of Higher Education, $35(1), 17-44$.

Fairweather, J. S. (1993). Academic values and faculty rewards. Review of Higher Education, 17(1), 43-68.

Field, A. (2009). Discovery statistics using SPSS (3rd ed.). London: Sage. 
Fisher, D. G., \& Reynolds, G. L. (2012). Time to graduation of three different master's degrees in psychology at a public university. In V. C. X. Wang (Ed.), Encyclopedia of E-Leadership, Counseling and Training (pp. 808-818). Hershey: IGI Global. doi:10.4018/978-1-61350-068-2

Gardner, S. K. (2008a). Fitting the mold of graduate school: A qualitative study of socialization in doctoral education. Innovative Higher Education, 33(2), 125-138. doi:10.1007/s10755-008-9068-х

Gardner, S. K. (2008b). “What's too much and what's too little?”: The process of becoming an independent researcher in doctoral education. The Journal of Higher Education, 79(3), 326-350.

Gardner, S. K. (2009). Conceptualizing success in doctoral education: Perspectives of faculty in seven disciplines. The Review of Higher Education, 32(3), 383-406. doi:10.1353/rhe.0.0075

Gardner, S. K., \& Barnes, B. J. (2007). Graduate student involvement: Socialization for the professional role. Journal of College Student Development, 48(4), 369-387. doi:10.1353/csd.2007.0036

Gardner, S. K., \& Gopaul, B. (2012). The part-time doctoral student experience. International Journal of Doctoral Studies, 7, 63-78.

Gardner, S. K., \& Mendoza, P. (2010). On Becoming a Scholar. Sterling: Stylus.

Girves, J. E., \& Wemmerus, V. (1998). Developing models of graduate student degree progress. The Journal of Higher Education, 59, 163-189. 
FACILITATING MASTER'S STUDENT SUCCESS

Glazer, J. (1986). The master's degree: Tradition, diversity, innovation. ASHE-ERIC Report No. 6. Washington DC.

Glazer-Raymo, J. (2005). Professionalizing graduate education: The master's degree in the marketplace. ASHE Higher Education Report, 31(4), 1-137.

Golde, C. M. (1998). Beginning graduate school: Explaining first-year doctoral attrition. New Directions for Higher Education, 101, 55-64.

Golde, C. M. (2000). Should I stay or should I go? Student descriptions of the doctoral attrition process. The Review of Higher Education, 23(2), 199-227.

Golde, C. M. (2005). The role of the department and discipline in doctoral student attrition: Lessons from four departments. The Journal of Higher Education, 76(7), 669-700.

Golde, C. M. (2010). Entering different worlds: Socialization into disciplinary communities. In S. K. Gardner \& P. Mendoza (Eds.), On Becoming a Scholar (pp. 79-96). Sterling: Stylus.

Golde, C. M., \& Dore, T. M. (2001). At cross purposes: What the experiences of today's doctoral students reveal about doctoral education.

Grites, G., \& Gordon, V. N. (2000). Developmental advising revised. NACADA Journal, 20(1), 12-15.

Habley, W. R. (1981). Academic advisement: The critical link in student retention. NASPA Journal, 18(4), 36-44. 
Harper, S. R., \& Hurtado, S. (2007). Nine themes in campus racial climates and implications for institutional transformation. New Directions for Student Services, 120, 7-24. doi:10.1002/ss.254

Hemwell, M. K., \& Trachte, K. C. (1999). Learning at the core: Toward a new understanding of academic advising. NACADA Journal, 19(1), 5-11.

Henderson, L. A., \& Stassen, M. L. A. (2007). The University of Massachusetts Amherst Graduate student advising experience: A study supported by the Dean of the Graduate School (pp. 1-75). Amherst.

HERI. (1997). 1997 College student survey (Senior survey).

Horn, T., \& Elliott, D. (2011). Graduate student advising: Focus group results report. Portland, Oregon.

Hurtado, S. (1992). The campus racial climate contexts of conflict. The Journal of Higher Education, 63(5), 539-569.

Hurtado, S., Griffin, K. A., Arellano, L., \& Cuellar, M. (2008). Assessing the value of climate assessments: Progress and future directions. Journal of Diversity in Higher Education, 1(4), 204-221. doi:10.1037/a0014009

Hurtado, S., Milem, J., Clayton-Pedersen, A., \& Allen, W. (1999). Enacting diverse learning environments: Improving the climate for racial/ethnic diversity in higher education. ASHE-ERIC Higher Education Report.

Johnson, B., \& Christensen, L. (2012). Educational research: Quantitative, qualitative, and mixed approaches (Fourth Edi.). London: SAGE. Retrieved from http://www.sagepub.com/books/Book233390\#.UL-um5M2Z8g.mendeley 
Johnson, W. B. (2002). The intentional mentor: Strategies and guidelines for the practice of mentoring. Professional Psychology: Research and Practice, 33(1), 88-96. doi:10.1037//0735-7028.33.1.88

Kearns, H., \& Gardiner, M. (2011). The care and maintenance of your adviser. Nature, 469(7331), 570-570. doi:10.1038/nj7331-570a

Kelley, B. (2008). Significant learning, significant advising. NACADA Journal, 28(1), $19-29$.

Knox, S., Schlosser, L. Z., Pruitt, N. T., \& Hill, C. E. (2006). A Qualitative Examination of Graduate Advising Relationships: The Advisor Perspective. The Counseling Psychologist, 34(4), 489-518. doi:10.1177/0011000006290249

Kuh, G. D., Kinzie, J., Schuh, J. H., Whitt, E. J., \& Associates. (2005). Student success in college : creating conditions that matter (1st ed.). San Francisco: Jossey-Bass. Retrieved from http://portlandstate.worldcat.org/title/student-success-in-collegecreating-conditions-that-matter/oclc/57168231\&referer=brief_results

Lovitts, B. E. (2001). Leaving the ivory tower: The causes and consequences of departure from doctoral study. Lanham Md.: Rowman \& Littlefield Publishers. Retrieved from http://portlandstate.worldcat.org/title/leaving-the-ivory-tower-thecauses-and-consequences-of-departure-from-doctoralstudy/oclc/45393394\&referer=brief_results

Lovitts, B. E. (2004). Research on the structure and process of graduate education. In D. H. Wulff, A. E. Austin, \& \& Associates (Eds.), Paths to the Professoriate (pp. 115136). San Francisco: Jossey-Bass. 
Lovitts, B. E., \& Nelson, C. (2000). The hidden crisis in graduate education: Attrition from Ph.D. programs Academe, Vol. 86, No. 6 (Nov. - Dec., 2000), pp. 44-50. Academe, 86(6), 44-50. Retrieved from http://www.jstor.org/stable/pdfplus/40251951.pdf?acceptTC=true\#.UPRafXHGd0.mendeley

Lowenstein, M. (2005). If Advising is teaching, What do advisors teach ? NACADA Journal, 25(2), 65-74.

McGuire, P. P. (1998). Advising graduate students commission. Academic Advising News. Retrieved from www.nacada.ksu.edu/Commissions/C06/resources.htm NACADA. (n.d.). NACADA: National Academic Advising Association. Retrieved December 6, 2012, from http://www.nacada.ksu.edu/

National Center for Education Statistics. (2010). Participation in Education: Graduate and Professional Education. Washington, DC.

National Center for Education Statistics. (2011). Trends in student financing of graduate and first-professional education: Selected years 1995-96 to 2007-08. National Center for Education Statistics. Retrieved from http://nces.ed.gov/pubsearch/pubsinfo.asp?pubid=2011217

Nelson, C., \& Lovitts, B. E. (2001). Ten ways to keep graduate students from quitting. The Chronicle Review.

Nerad, M., \& Miller, D. S. (1996). Increasing student retention in graduate and professional programs. New Directions for Institutional Research, 92, 61-76. doi:10.1002/ir.37019969207 
FACILITATING MASTER'S STUDENT SUCCESS

Nettles, M., \& Millet, C. M. (2006). Three magic letters: Getting to Ph. D. Baltimore: Johns Hopkins University Press. Retrieved from http://portlandstate.worldcat.org/title/three-magic-letters-getting-to-phd/oclc/58451693\&referer=brief_results

Nyquist, J. D., \& Woodford, B. J. (2000). Re-envisioning the Ph.D.: What concerns do we have? (pp. 1-26). Seattle.

Pascarella, E., \& Terenzini, P. T. (2005). How college affects students. (3rd ed.). San Francisco: Jossey-Bass. Retrieved from http://portlandstate.worldcat.org/title/howcollege-affects-students-vol-2-a-third-decade-ofresearch/oclc/58839703\&referer=brief_results

Patton, S. (2012, December 9). Some say it's time to put a warning label on graduate school. The Chronicle of Higher Education. Washington. Retrieved from http://chronicle.com/article/Some-Say-Its-Time-to-Put-a/136217/

Polson, C. J. (2003). Adult graduate students challenge institutions to change. New Directions for Student Services, 102, 59-68.

Portland State University. (2011). PSU Bulletin. Retrieved from www.pdx.edu/oaa/psubulletin

Rendon, L. I., Jalomo, R. E., \& Nora, A. (2000). Theoretical considerations in the study of minority student retention in higher education. Reworking the student departure puzzle (pp. 127-156). Nashville: Vanderbilt University.

Rindskopf, D., \& Rose, T. (1988). Some theory and application of confirmatory secondorder factor analysis. Multivariate Behavioral Research, 23, 51-67. 
Rosen, B. C., \& Bates, A. P. (1967). The structure of socialization in graduate school. Sociological Inquiry, 37(1), 71-84.

Sallee, M. W. (2010). The individual and the institution: Socialization and gender. In Susan K. Gardner \& P. Mendoza (Eds.), On Becoming a Scholar (pp. 79-96). Sterling: Stylus.

Sallee, M. W. (2011). Performing masculinity: Considering gender in doctoral student socialization. The Journal of Higher Education, 82(2), 187-216. doi:10.1353/jhe.2011.0007

Sax, L. J., Astin, A. W., Arredondo, M., \& Korn, W. S. (1996). The American College Teacher: National norms for the 1995-1996 HERI faculty survey. Los Angeles. Retrieved from http://www.heri.ucla.edu/PDFs/pubs/FAC/Norms/Monographs/TheAmericanColleg eTeacher1995To1996.pdf

Schlossberg, N. K. (1989). Improving higher education environments for adults. Improving higher education environments for adults. (pp. 21-23; 198-201). San Francisco: Jossey-Bass.

Schlosser, L. Z., \& Gelso, C. J. (2001). Measuring the working alliance in advisoradvisee relationships in graduate school. Journal of Counseling Psychology, 48(2), $157-167$.

Schlosser, L. Z., Knox, S., Moskovitz, A. R., \& Hill, C. E. (2003). A qualitative examination of graduate advising relationships: The advisee perspective. Journal of Counseling Psychology, 50(2), 178-188. doi:10.1037/0022-0167.50.2.178 
Schlosser, L. Z., Lyons, H. Z., Talleyrand, R. M., Kim, B. S. K., \& Johnson, W. B. (2010a). Advisor-advisee relationships in graduate training programs. Journal of Career Development, 38(1), 3-18. doi:10.1177/0894845309358887

Schlosser, L. Z., Lyons, H. Z., Talleyrand, R. M., Kim, B. S. K., \& Johnson, W. B. (2010b). A multiculturally infused model of graduate advising relationships. Journal of Career Development, 38(1), 44-61. doi:10.1177/0894845309359286

Schlosser, L. Z., Talleyrand, R. M., Lyons, H. Z., Kim, B. S. K., \& Johnson, W. B. (2010). Multicultural issues in graduate advising relationships. Journal of Career Development, 38(1), 19-43. doi:10.1177/0894845309359285

Schwartz, H. L., \& Holloway, E. L. (2012). Partners in learning: A grounded theory study of relational practice between master's students and professo. Mentoring \& Tutoring: Partnership in Learning, 20(1), 115-135. doi:10.1080/13611267.2012.655454

Smith, C. L., \& Allen, J. M. (2006). Essential functions of academic advising: What students want and get. NACADA Journal, 26(1), 56-66.

Snyder, T. D., \& Dillow, S. (2011). Digest of education statistics: 2010 (NCES No. 2011015). Washington, DC.

Snyder, T. D., \& Dillow, S. (2012). Digest of education statistics 2011 (NCES 2012-001). Washington DC.

Snyder, T. D., Dillow, S., \& Hoffman, C. M. (2009). Digest of educational statistics: 2008 (NCES No. 2009-20). Washington DC. 
Solorzano, D., Ceja, M., \& Yosso, T. (2000). Critical race theory, racial microaggressions, and campus racial climate: The experiences of African American college students. Journal of Negro Education, 69(1/2), 60-73.

Stewart, D. W. (2010). "Important, if True": Graduate education will drive America's future prosperity. Change, 36-44.

Tenenbaum, H. R., Crosby, F. J., \& Gliner, M. D. (2001). Mentoring relationships in graduate school. Journal of Vocational Behavior, 59(3), 326-341. doi:10.1006/jvbe.2001.1804

Tinto, V. (1993). Leaving college: Rethinking the causes and cures of student attrition Chicago: University of Chicago Press.

Waldeck, J. H., Orrego, V. O., Plax, T. G., \& Kearney, P. (1997). Graduate student/faculty mentoring relationships: Who gets mentored, how it happens, and to what end. Communication Quarterly, 45(3), 93-109.

Weidman, J. C., \& Stein, E. L. (2003). Socialization of doctoral students to academic norms. Research in Higher Education, 44(6), 641.

Weidman, J. C., Twale, D. J., \& Stein, E. L. (2001). Socialization of graduate and professional students in higher education : A perilous passage. New York: John Wiley \& Sons. Retrieved from http://portlandstate.worldcat.org/title/socializationof-graduate-and-professional-students-in-higher-education-a-perilouspassage/oclc/47360330?referer=di\&ht=edition

Wendler, C., Bridgeman, B., Cline, F., MIllett, C., Rock, J., Bell, N. E., \& McAllister, P. (2010). The Path Forward: The future of graduate education in the United States. 
FACILITATING MASTER'S STUDENT SUCCESS

American journal of transplantation : official journal of the American Society of

Transplantation and the American Society of Transplant Surgeons. Princeton, NJ. doi:10.1111/j.1600-6143.2012.04324.x

Wendler, C., Bridgeman, B., Markle, R., Cline, F., Bell, N. E., McAllister, P., \& Kent, J. (2012). The Pathways through graduate school into careers. Princeton.

Winston, R. B., \& Sandor, J. A. (1984). Developmental academic advising: What do students want? NACADA Journal, 4(1), 5-13.

Zhao, C., Golde, C. M., \& McCormick, A. C. (2007). More than a signature: how advisor choice and advisor behaviour affect doctoral student satisfaction. Journal of Further and Higher Education, 31(3), 263-281. doi:10.1080/03098770701424983 


\section{Appendix A: Graduate Student Advising Survey: Master's Student Version}

Instructions: Please answer the following questions about your experiences as a Master's student at [university].

1. What year did you begin your Master's program?

(2012-Before 2006)

2. What year do you intend to finish your Master's program?

(2012-After 2019)

3. How many credits have you completed in your program (include those you are taking this term)?

(Graduate Credits

4. Do you consider yourself a full-time or part-time student?

(Full-time, Part-time)

5. Are you currently working on your thesis or culminating project, or will you be taking your comprehensive exam this term?

(Yes, thesis; Yes, culminating project; Yes, comprehensive exam; No, I have not reached that phase of my program; No, my program does not require a thesis, culminating project, or comprehensive exam; Other (please specify____

6. Did your program have an orientation?

(Yes, I attended; Yes, but I did not attend; No; Don’t know)

6. a. (If yes, I attended, then display question) How helpful was your program orientation?

(Not helpful 1-Very helpful 6)

7. A faculty adviser is usually assigned to you when you begin your graduate program. $\mathrm{He} / \mathrm{she}$ can help you create a program of study, approve coursework, and sign official paperwork. This person may or may not be your mentor. Do you have a faculty adviser?

(Yes, No) (If No, then skip to \#12)

8. On average, how many times per term do you meet with your faculty adviser? (I have not been in contact with my adviser; Less than once per term; Once per term; Twice per term; 3 times per term; 4 times per term, 5 times per term; 6 or more times per term) 
8. a. (If I have not been in contact with my adviser, then skip pattern and display question). Why have your not met with your adviser?

9. How do you most often access your faculty adviser?

(In person, Phone, Email, Other___

10. Please select one response for each question regarding your faculty adviser.

10. a. Is your adviser the same gender as you? (Yes, No)

10. b. Is your adviser the same race/ethnicity as you? (Yes, No)

11. Please answer the questions below by thinking about your satisfaction with your advising experiences.

11.a. Your faculty adviser's accessibility. (Not Satisfied 1-Very Satisfied 6)

11. b. The amount of time you spend with your adviser. (Not Satisfied 1-Very Satisfied 6)

12. There is another faculty member in my department that I wish was my adviser.

(Strongly Disagree 1- Strongly Agree 6)

13. I am satisfied with how faculty advisers are assigned in my department/program.

(Not Satisfied 1-Very Satisfied 6, N/A)

14. Graduate students may have a faculty mentor whom they rely upon for advice, support, and encouragement. This mentor may be their faculty adviser or another faculty member. Do you have a mentor?

(If you have multiple mentors, please respond to the following questions regarding your primary mentor.)

(Yes, (same as adviser); Yes, (not same as adviser); No)

(If Yes (same as adviser), then skip to \# 19; If No, then skip to \# 19)

15. Is your mentor?

(A faculty member in your department; A faculty member outside your department; A staff member in your department; A staff member outside your department; Other

16. On average, how many times per term do you meet with your mentor?

(Less than once per term; Once per term; Twice per term; 3 times per term; 4 times per term, 5 times per term; 6 or more times per term)

17. How do you most often access your mentor?

(In person, Phone, Email, Other

18. Please select one response for each question regarding your mentor.

18. a. Is your mentor the same gender as you? (Yes, No)

18. b. Is your mentor the same race/ethnicity as you? (Yes, No) 
19. How many different faculty/staff members do you rely upon for advice/guidance about program requirements, academics, or career matters?

(None, One, Two, Three, Four, Five, Six or more)

20. Please select your primary source for information at [university] about program requirements, academics, or career matters.

(Faculty adviser (not mentor); Faculty adviser/mentor; Mentor (not adviser); Faculty member in my department (not adviser or mentor); Faculty member outside my department; Students in my program; Department Secretary; Staff member in my department (not department secretary); Staff member outside my department; Program orientation; Office of Graduate Studies; Bulletin (University catalog); Department website; Department handbook (printed); university website; Other

21. Thinking about your primary source of information, please indicate your level of satisfaction with the advising you receive on the following functions.

21. a. Ability to give you accurate information about program requirements.

(Not Satisfied 1-Very Satisfied 6, N/A)

21. b. Assisting you with understanding policies and procedures ("how things work").

(Not Satisfied 1-Very Satisfied 6, N/A)

21. c. Helping you create a program of study (educational plan).

(Not Satisfied 1-Very Satisfied 6, N/A)

21. d. Giving you good feedback on your academic work.

(Not Satisfied 1-Very Satisfied 6, N/A)

21. e. Collaborating with you (i.e., conducting research together, writing together, or copresenting).

(Not Satisfied 1-Very Satisfied 6, N/A)

21. f. Helping you network in your field (i.e., introducing you to colleagues at the university or at a conference, etc.)

(Not Satisfied 1-Very Satisfied 6, N/A)

21.g. When needed, referring you to campus services for academic support (i.e., writing center, learning center, disability resource center).

(Not Satisfied 1-Very Satisfied 6, N/A)

21.h. When needed, referring you to campus services for non-academic support (i.e., childcare, financial aid, student health and counseling center).

(Not Satisfied 1-Very Satisfied 6, N/A)

21. i. Helping you identify funding (i.e., graduate assistantships, fellowships, scholarships, and/or providing letters of recommendation).

(Not Satisfied 1-Very Satisfied 6, N/A)

21. j. (If (\#5 Yes, thesis), then display) Encouraging you to make progress on your thesis.

(Not Satisfied 1-Very Satisfied 6, N/A)

21. k. Knowing you as an individual.

(Not Satisfied 1-Very Satisfied 6, N/A) 
21. 1. Caring about your academic progress.

(Not Satisfied 1-Very Satisfied 6, N/A)

22. I believe I have been accurately advised.

(Yes, No)

22. b. (If No, then display) If no, what consequences resulted from the advising inaccuracy? Please check all that apply.

(I had to delay my graduation in order to take one or more additional classes; I took one or more classes that I later discovered I didn't need to graduate; I petitioned for an exception to an academic requirement; I was placed in a course for which I was unprepared; Other

23. Overall, I am satisfied with the quality of the advising I receive.

(Not Satisfied 1-Very Satisfied 6)

24. (If \#14 (Yes, (same as adviser); Yes, (not same as adviser), then display). Overall, I am satisfied with the quality of the mentoring I receive.

(Not Satisfied 1-Very Satisfied 6)

25. Please provide feedback on student relationships in your program.

25. a. Students collaborate with one another.

(Strongly Disagree 1- Strongly Agree 6)

25. b. Students share resources and information.

(Strongly Disagree 1- Strongly Agree 6)

25. c. Students compete for faculty time.

(Strongly Disagree 1- Strongly Agree 6)

25. d. Experienced students mentor new students.

(Strongly Disagree 1- Strongly Agree 6)

25. e. I am friends with students in my program.

(Strongly Disagree 1- Strongly Agree 6)

25. f. I feel like I "fit" in my program.

(Strongly Disagree 1- Strongly Agree 6)

26.During your master's program, did you participate in any of the following activities? Please check all that apply.

26. a. Attend a conference.

(Alone, With adviser, With mentor (not adviser); With other faculty in department; With Peers; N/A)

26. b. Present at a conference.

(Alone, With adviser, With mentor (not adviser); With other faculty in department; With Peers; N/A)

26. c. Write an article, chapter, conference paper.

(Alone, With adviser, With mentor (not adviser); With other faculty in department; With Peers; N/A) 
26. d. Publish an article, chapter, conference paper.

(Alone, With adviser, With mentor (not adviser); With other faculty in department; With Peers; N/A)

27. I am part of a cohort program (I take the same classes with the same students in the same order). (Yes, No)

27. a. (If Yes, then display) Approximately, how many students (including you) are in your cohort?

(Students

28. Please select your level of agreement with the following statements regarding your department.

28. a. Faculty are accessible.

(Strongly Disagree 1- Strongly Agree 6)

28. b. I experience an inclusive and respectful learning environment.

(Strongly Disagree 1- Strongly Agree 6)

28. c. Social events are planned to bring faculty and students together.

(Strongly Disagree 1- Strongly Agree 6)

28. d. I feel like I belong in my department.

(Strongly Disagree 1- Strongly Agree 6)

29. Indicate your agreement with each of the following statements.

29. a. I have been singled out in my program or treated disrespectfully because of my gender.

(Strongly Disagree 1- Strongly Agree 6)

29. b. I have been singled out in my program or treated disrespectfully because of my race/ethnicity.

(Strongly Disagree 1- Strongly Agree 6)

29. c. Faculty treat students the same regardless of gender.

(Strongly Disagree 1- Strongly Agree 6)

29. d. Faculty treat students the same regardless of race/ethnicity.

(Strongly Disagree 1- Strongly Agree 6)

30. I have observed discriminatory words, behaviors, or gestures directed toward students who are:

30. a. Ethnic/racial minorities

(Strongly Disagree 1- Strongly Agree 6)

30. b. Female

(Strongly Disagree 1- Strongly Agree 6)

30. c. Male

(Strongly Disagree 1- Strongly Agree 6)

30. d. International students

(Strongly Disagree 1- Strongly Agree 6)

30. e. LGBTQ: Lesbian, Gay, Bisexual, Transgender, Queer 
(Strongly Disagree 1- Strongly Agree 6)

30. f. People with disabilities

(Strongly Disagree 1- Strongly Agree 6)

30. g. Veterans

(Strongly Disagree 1- Strongly Agree 6)

31. Please indicate how many hours each week you spend working:

31. a. Job (unrelated to your program)

$(0,1-5,6-10,11-15,16-20,21-25,26-30,31-35,36-40,40+)$

31. b. Job (related to your program, but not as a graduate assistant)

(0, 1-5, 6-10, 11-15, 16-20, 21-25, 26-30, 31-35, 36-40, 40+)

31. c. Graduate Assistant (GA, TA, AA)

$(0,1-5,6-10,11-15,16-20,21-25,26-30,31-35,36-40,40+)$

31. d. Intern for credit

(0, 1-5, 6-10, 11-15, 16-20, 21-25, 26-30, 31-35, 36-40, 40+)

31. e. Service-learning or community-based learning for class

$(0,1-5,6-10,11-15,16-20,21-25,26-30,31-35,36-40,40+)$

32. Are you employed by your academic department?

(Yes, No)

32.a. (If yes, the display) Please indicate your position within the department.

(Graduate assistant; Adjunct faculty; Staff member; Other

32. b. (If Graduate Assistant, then display) Did you attend the Graduate Assistant (GA)

Orientation?

(Yes; No; I have never heard of this)

32. c. (If Yes, then display) How helpful was the GA Orientation?

(Not Helpful 1- Very Helpful 6)

32. d. (If \#32 yes, then display) Is your supervisor your:

(Faculty adviser; Faculty adviser/mentor; Mentor (not adviser); Faculty member in your department (not adviser/mentor); Staff member; Other

32. e. (If Faculty adviser, or Faculty adviser/mentor, then display) I have a stronger

advising relationship because I work for my faculty adviser.

(Strongly Disagree 1- Strongly Agree 6)

33. Please select the number of hours each week you spend on the activities below.

33.a. Taking Classes.

$(0,1-3,4-6,7-9,10-12,13-15,16-18,19-21,22-24,25+)$

33. b. Reading or preparing for classes.

$(0,1-3,4-6,7-9,10-12,13-15,16-18,19-21,22-24,25+)$

33. c. Writing papers for class or writing thesis/culminating project.

$(0,1-3,4-6,7-9,10-12,13-15,16-18,19-21,22-24,25+)$

33. d. Meeting with peers to work on class assignments.

$(0,1-3,4-6,7-9,10-12,13-15,16-18,19-21,22-24,25+)$ 
34. Have you accessed the following services on campus? Please check all that apply. (Yes, No, I have never hear of this service/place)

34. a. Career Center

(If yes, display) When you accessed the Career Center, how helpful was it?

34. b. Computer Lab

(If yes, display) When you accessed the Computer Lab, how helpful was it?

34. c. Disability Resource Center

(If yes, display) When you accessed the Disability Resource Center, how helpful was it?

34. d. Learning Center

(If yes, display) When you accessed the Learning Center, how helpful was it?

34. e. Library

(If yes, display) When you accessed the Library, how helpful was it?

34. f. Multicultural Center (MCC)

(If yes, display) When you accessed the Multicultural Center (MCC), how helpful was it?

34. g. Native American Student \& Community Center

(If yes, display) When you accessed the Native American Student \& Community Center, how helpful was it?

34. h. Office of Graduate Studies

(If yes, display) When you accessed the Office of Graduate Studies, how helpful was it?

34. i. Organization of International Students (OIS)

(If yes, display) When you accessed the Organization of International Students, how

helpful was it?

34. j. Queer Resource Center

(If yes, display) When you accessed the Queer Resource Center, how helpful was it?

34. k. Student Health and Counseling (SHAC)

(If yes, display) When you accessed the Student Health and Counseling (SHAC), how helpful was it?

34. 1. Student Legal Services

(If yes, display) When you accessed the Student Legal Services, how helpful was it?

34. m. Veteran's Services

(If yes, display) When you accessed the Veteran's Services, how helpful was it?

34. n. Women's Resource Center

(If yes, display) When you accessed the Women's Resource Center, how helpful was it?

34. o. Writing Center

(If yes, display) When you accessed the Writing Center, how helpful was it?

35. I am confident that I made the right decision in choosing to attend [university].

(Strongly Disagree 1- Strongly Agree 6)

36. I know what requirements I must fulfill in order to earn my degree.

(Strongly Disagree 1- Strongly Agree 6)

37. In my program, I am learning the skills and knowledge I need to work in my field.

(Strongly Disagree 1- Strongly Agree 6) 
38. My graduate degree will help me advance professionally.

(Strongly Disagree 1- Strongly Agree 6)

39. Overall, I am satisfied with my educational experience at [university].

(Strongly Disagree 1- Strongly Agree 6)

40. Highest educational level of your parent(s)/guardian(s)

Parent Number One

(High School degree or less, no college; Some college, no degree; Associate (2 year)

degree; Baccalaureate (e.g., BS or BA) degree; Post Baccalaureate education (not a

master's degree); Master's degree; Doctorate degree)

40. a. Parent Number Two

(Not applicable, I have only one parent; High School degree or less, no college; Some college, no degree; Associate (2 year) degree; Baccalaureate (e.g., BS or BA) degree;

Post Baccalaureate education (not a master's degree); Master's degree; Doctorate degree)

41. With which category do you most identify?

(Asian/Pacific Islander; Black/African American; Indigenous/Native American;

Latino(a)/Hispanic; Middle Eastern; White; Multiracial; I prefer not to answer)

42. Are you an international student?

(Yes, No)

43. With which gender do you identify?

(Man; Woman; Transgender; Other___; I prefer not to answer this question.)

44. Do you identify as (LGBTQ)? Please check all that apply.

(Lesbian; Gay; Bisexual; Transgender; Queer; Other ; No, I do not identify as

LGBTQ; I prefer not to answer)

45. Please select your current relationship status:

(I am single; I am in a committed relationship; I am in a domestic partnership; I am married; I am separated or divorced; I am widowed; I prefer not to answer this question.)

46. Please select all that apply. Are you currently caring for:

(Child/Children (under the age of 18) living in your home; Child/Children (under the age of 18) not living in your home; Aging parents; Family member requiring medical care)

47. Please check all that apply.

(I have a bachelor's degree from [university]; I have a previous graduate degree from [university]; I have a previous graduate degree from another college/university).

48. What are your plans for Fall 2012? 
(I will have graduated; I will be continuing in my program; I will be taking a break from my graduate program; I will be leaving my program and I do not plan to finish; I will be transferring to a different program at [university]; I will be transferring to a different school; Other (Please specify)

49. What would improve your advising experience?

(Essay text box)

50. Please use the space below to comment about any aspect of your experience with graduate advising at [university]:

(Essay text box)

51. When you click the arrows below, your survey will be submitted. 


\section{Appendix B: Advising Survey Letters}

Dear First Name Last Name:

Academic advising is important to the success of graduate students, and I want to hear about your experiences with advising at [university]. I am inviting you to complete a survey that will tell us in the Office of Graduate Studies what you think about academic advising at [university]. Your answers to these questions are crucial to our continued efforts to improve graduate student experiences at [university], and I hope you will take the 15 minutes required to complete the survey. As an incentive, I am offering a chance to win a $\$ 50$ Gift Certificate from the [university] Bookstore; the winner will be chosen from all students who complete and submit the survey. Please follow this link to complete the survey: Take the Survey (Survey link).

Please be assured that the answers you provide will be kept confidential to the extent permitted by law. Any information that is obtained in connection with this study that can be linked to you or identify you will be confidential. Special precautions have been established to protect the confidentiality of your responses by using an electronic system that will separate your survey responses from any personally identifiable information that could link your responses to you. We will match your responses to information you have already provided to [university] (such as age, GPA, enrollment status), but we would like to reassure you that all information you provide will remain confidential. The foreseeable risks to you as a participant in this project are minimal and the primary one is a potential loss of confidentiality. Also, there are no direct benefits. The answers you provide will be summarized along with the responses of other students so that your individual responses will never be identified in any report. Your answers to the questions are crucial to our continued efforts to improve graduate student experiences at [university].

Although your participation is entirely voluntary, I hope you will complete the survey. Your willingness or unwillingness to participate will not affect decisions involving course grades or other evaluations of your coursework, or your employment or relationship with [university]. You may choose not to participate and can skip any question or withdraw at any time, but if you do not complete and submit the survey you will not be eligible for the gift certificate drawing.

If you have questions about your rights as a participant in this research project, please contact the Chair of the Human Subjects Research Review Committee, Office of Research and Sponsored Projects, [contact information]. If you have questions about the study itself, please contact [researcher \& email].

Thank you for telling us what we are doing well with academic advising and where we need to improve. You can take the survey now through this link: Take the Survey (Survey link). 
Sincerely,

Name

Interim Dean Graduate Studies

University

\section{First Follow-Up Email}

\section{Dear First Name Last Name:}

A short time ago, I invited you to answer some questions related to graduate academic advising and your experiences at [university]. Your answers to these questions are crucial to our continued efforts to improve graduate student experiences at [university], and I hope you will take the 15 minutes required to complete the survey. As an incentive, I am offering a chance to win a $\$ 50$ Gift Certificate from the [university] Bookstore; the winner will be chosen from all students who complete and submit the survey. Please follow this link to complete the survey: Take the Survey (Survey link).

Please be assured that the answers you provide will be kept confidential to the extent permitted by law. Special precautions have been established to protect the confidentiality of your responses. Any information that is obtained in connection with this study that can be linked to you or identify you will be confidential. The answers you provide will be summarized along with the responses of other students so that your individual responses will never be identified in any report. The foreseeable risks to you as a participant in this project are minimal; and there are no direct benefits. However, your participation is extremely valued.

Although your participation is entirely voluntary, I hope you will complete the survey. Your willingness or unwillingness to participate will not affect decisions involving course grades or other evaluations of your coursework, or your employment or relationship with [university]. You may choose not to participate and can skip any question or withdraw at any time, but if you do not complete and submit the survey you will not be eligible for the gift certificate drawing.

If you have questions about your rights as a participant in this research project, please contact the Chair of the Human Subjects Research Review Committee, Office of Research and Sponsored Projects [contact information]. If you have questions about the study itself, please contact [researcher \& email].

Thank you for telling us what we are doing well with academic advising and where we 
need to improve. You can take the survey now through this link: Take the Survey (Survey link).

Sincerely,

Name

Interim Dean Graduate Studies

University

\section{Second Follow-up Email}

Dear First Name:

I know this is a busy time of the year, but your opinion as [university] graduate student matters to me and other decision makers at [university]. Although many students have responded to my initial requests, it is crucial that we have equal representation from the diverse perspectives that characterize graduate students at [university].

Your answers to the survey questions are crucial to our continued efforts to improve the student experience at [university], and I hope you will take the 15 minutes required to answer the questions. As an incentive, I am offering a chance to win a $\$ 50 \mathrm{Gift}$ Certificate from the [university] Bookstore. In order to be eligible to win, you will need to complete and submit the survey by the closing date June 3, 2012, 5:00 PDT. There is still time to let your opinions be heard by selecting this link: Take the Survey (Survey link).

Please be assured that the answers you provide will be kept confidential to the extent permitted by law. Special precautions have been established to protect the confidentiality of your responses. Any information that is obtained in connection with this study that can be linked to you or identify you will be confidential. The answers you provide will be summarized along with the responses of other students so that your individual responses will never be identified in any report. The foreseeable risks to you as a participant in this project are minimal; and there are no direct benefits. However, your participation is extremely valued.

Although your participation is entirely voluntary, I hope you will complete the survey. Your willingness or unwillingness to participate will not affect decisions involving course grades or other evaluations of your coursework, or your employment or relationship with [university]. You may choose not to participate and can skip any question or withdraw at any time, but if you do not complete and submit the survey you will not be eligible for the gift certificate drawing.

If you have any questions about your rights as a participant in this research project, please contact the Chair of the Human Subjects Research Review Committee, Office of 
Research and Sponsored Projects [contact information]. If you have questions about the study itself, please contact [researcher \& email].

You can take the survey through this link: Take the Survey (Survey link).

Thank you for your time.

Sincerely,

Name

Interim Dean of Graduate Studies

University 
Appendix C: Results of regression analyses with student characteristics predicting student satisfaction with advising

Results of regression analysis with student characteristics predicting student satisfaction with accurate information

\begin{tabular}{|l|l|l|l|l|}
\hline Model & B & Std. Error & Beta & Sig. \\
\hline Constant $)$ & 3.70 & 0.24 & & 0.00 \\
\hline Female & -0.04 & 0.11 & -0.01 & 0.71 \\
\hline Minority & 0.20 & 0.13 & 0.06 & 0.14 \\
\hline Age & 0.01 & 0.01 & 0.06 & 0.14 \\
\hline Part-time & 0.14 & 0.12 & 0.05 & 0.25 \\
\hline Cohort* & -0.28 & 0.10 & -0.11 & 0.01 \\
\hline Thesis & 0.04 & 0.14 & 0.01 & 0.77 \\
\hline Mentored* & 0.27 & 0.11 & 0.10 & 0.01 \\
\hline Multiple Faculty** & 0.34 & 0.11 & 0.13 & 0.00 \\
\hline Meeting Often** & 0.39 & 0.11 & 0.15 & 0.00 \\
\hline
\end{tabular}

$\mathrm{R}^{2}=0.08, \mathrm{~F}=6.16, \mathrm{p}<0.001$ 
Results of regression analysis with student characteristics predicting student satisfaction with help with policies and procedures

\begin{tabular}{|l|l|l|l|l|}
\hline Model & B & Std. Error & Beta & Sig. \\
\hline (Constant) & 3.12 & 0.25 & & 0.00 \\
\hline Female & 0.13 & 0.11 & 0.04 & 0.26 \\
\hline Minority & 0.10 & 0.14 & 0.03 & 0.49 \\
\hline Age & 0.01 & 0.01 & 0.05 & 0.16 \\
\hline Part-time* & 0.26 & 0.13 & 0.08 & 0.04 \\
\hline Cohort & -0.05 & 0.11 & -0.02 & 0.64 \\
\hline Thesis & 0.03 & 0.14 & 0.01 & 0.82 \\
\hline Mentored* & 0.31 & 0.11 & 0.11 & 0.01 \\
\hline Multiple Faculty** & 0.53 & 0.12 & 0.18 & 0.00 \\
\hline Meeting Often** & 0.34 & 0.12 & 0.12 & 0.00 \\
\hline
\end{tabular}

$\mathrm{R}^{2}=0.08, \mathrm{~F}=6.56, \mathrm{p}<0.001$ 
FACILITATING MASTER'S STUDENT SUCCESS

Results of regression analysis with student characteristics predicting student satisfaction with educational plan

\begin{tabular}{|l|l|l|l|l|}
\hline Model & B & Std. Error & Beta & Sig. \\
\hline (Constant) & 3.04 & 0.30 & & 0.00 \\
\hline Female & 0.09 & 0.14 & 0.03 & 0.51 \\
\hline Minority & 0.25 & 0.17 & 0.06 & 0.15 \\
\hline Age & 0.00 & 0.01 & 0.01 & 0.81 \\
\hline Part-time & 0.08 & 0.15 & 0.02 & 0.60 \\
\hline Cohort & 0.01 & 0.13 & 0.00 & 0.92 \\
\hline Thesis & -0.03 & 0.17 & -0.01 & 0.87 \\
\hline Mentored** & 0.57 & 0.14 & 0.18 & 0.00 \\
\hline Multiple Faculty* & 0.38 & 0.14 & 0.11 & 0.01 \\
\hline Meeting Often** & 0.60 & 0.14 & 0.18 & 0.00 \\
\hline
\end{tabular}

$\mathrm{R}^{2}=0.11, \mathrm{~F}=8.40, \mathrm{p}<0.001$ 
FACILITATING MASTER'S STUDENT SUCCESS

Results of regression analysis with student characteristics predicting student satisfaction with adviser's accessibility

\begin{tabular}{|l|l|l|l|l|}
\hline Model & B & Std. Error & Beta & Sig. \\
\hline (Constant) & 3.30 & 0.33 & & 0.00 \\
\hline Female & -0.27 & 0.15 & -0.07 & 0.07 \\
\hline Minority & 0.11 & 0.19 & 0.02 & 0.55 \\
\hline Age & 0.01 & 0.01 & 0.05 & 0.16 \\
\hline Part-time & 0.05 & 0.17 & 0.01 & 0.76 \\
\hline Cohort & -0.04 & 0.14 & -0.01 & 0.76 \\
\hline Thesis & 0.23 & 0.19 & 0.05 & 0.23 \\
\hline Mentored* & 0.33 & 0.15 & 0.09 & 0.02 \\
\hline Multiple Faculty & 0.15 & 0.15 & 0.04 & 0.32 \\
\hline Meeting Often** & 1.32 & 0.15 & 0.34 & 0.00 \\
\hline
\end{tabular}

$\mathrm{R}^{2}=0.17, \mathrm{~F}=14.24, \mathrm{p}<0.001$ 
FACILITATING MASTER'S STUDENT SUCCESS

Results of regression analysis with student characteristics predicting student satisfaction with amount of time you spend with your adviser

\begin{tabular}{|l|l|l|l|l|}
\hline Model & B & Std. Error & Beta & Sig. \\
\hline (Constant) & 2.59 & 0.33 & & 0.00 \\
\hline Female & -0.19 & 0.15 & -0.05 & 0.20 \\
\hline Minority & 0.32 & 0.19 & 0.06 & 0.09 \\
\hline Age & 0.01 & 0.01 & 0.06 & 0.10 \\
\hline Part-time & 0.04 & 0.17 & 0.01 & 0.82 \\
\hline Cohort & -0.11 & 0.14 & -0.03 & 0.43 \\
\hline Thesis & 0.35 & 0.19 & 0.07 & 0.06 \\
\hline Mentored** & 0.42 & 0.15 & 0.11 & 0.00 \\
\hline Multiple Faculty & 0.24 & 0.15 & 0.06 & 0.12 \\
\hline Meeting Often** & 1.53 & 0.15 & 0.38 & 0.00 \\
\hline
\end{tabular}

$\mathrm{R}^{2}=0.23, \mathrm{~F}=20.55, \mathrm{p}<0.001$ 
FACILITATING MASTER'S STUDENT SUCCESS

Results of regression analysis with student characteristics predicting student wish for another adviser

\begin{tabular}{|l|l|l|l|l|}
\hline Model & B & Std. Error & Beta & Sig. \\
\hline (Constant) & 4.05 & 0.32 & & 0.00 \\
\hline Female & -0.02 & 0.14 & 0.00 & 0.90 \\
\hline Minority & -0.16 & 0.18 & -0.03 & 0.37 \\
\hline Age* & -0.02 & 0.01 & -0.09 & 0.02 \\
\hline Part-time & 0.04 & 0.16 & 0.01 & 0.82 \\
\hline Cohort & 0.23 & 0.14 & 0.07 & 0.09 \\
\hline Thesis* & -0.38 & 0.18 & -0.08 & 0.04 \\
\hline Mentored & -0.11 & 0.14 & -0.03 & 0.44 \\
\hline Multiple Faculty & 0.14 & 0.15 & 0.04 & 0.35 \\
\hline Meeting Often** & -0.93 & 0.15 & -0.26 & 0.00 \\
\hline
\end{tabular}

$\mathrm{R}^{2}=0.10, \mathrm{~F}=7.91, \mathrm{p}<0.001$ 
FACILITATING MASTER'S STUDENT SUCCESS

Results of regression analysis with student characteristics predicting student satisfaction with how advisers are assigned

\begin{tabular}{|l|l|l|l|l|}
\hline Model & B & Std. Error & Beta & Sig. \\
\hline (Constant) & 2.63 & 0.34 & & 0.00 \\
\hline Female & -0.05 & 0.16 & -0.01 & 0.75 \\
\hline Minority & -0.03 & 0.20 & -0.01 & 0.88 \\
\hline Age* & 0.02 & 0.01 & 0.10 & 0.01 \\
\hline Part-time & 0.06 & 0.17 & 0.01 & 0.72 \\
\hline Cohort & -0.04 & 0.15 & -0.01 & 0.81 \\
\hline Thesis & 0.22 & 0.20 & 0.04 & 0.26 \\
\hline Mentored & -0.05 & 0.15 & -0.01 & 0.75 \\
\hline Multiple Faculty & 0.30 & 0.16 & 0.07 & 0.06 \\
\hline Meeting Often** & 0.95 & 0.16 & 0.24 & 0.00 \\
\hline
\end{tabular}

$\mathrm{R}^{2}=0.08, \mathrm{~F}=6.53, \mathrm{p}<0.001$ 
FACILITATING MASTER'S STUDENT SUCCESS

Results of regression analysis with student characteristics predicting student satisfaction good feedback

\begin{tabular}{|l|l|l|l|l|}
\hline Model & B & Std. Error & Beta & Sig. \\
\hline (Constant) & 2.06 & 0.36 & & 0.00 \\
\hline Female & -0.11 & 0.16 & -0.03 & 0.47 \\
\hline Minority & -0.04 & 0.21 & -0.01 & 0.83 \\
\hline Age & 0.01 & 0.01 & 0.06 & 0.18 \\
\hline Part-time & 0.25 & 0.18 & 0.06 & 0.16 \\
\hline Cohort & 0.00 & 0.15 & 0.00 & 0.98 \\
\hline Thesis & 0.33 & 0.20 & 0.07 & 0.10 \\
\hline Mentored** & 1.00 & 0.16 & 0.28 & 0.00 \\
\hline Multiple Faculty** & 0.56 & 0.17 & 0.15 & 0.00 \\
\hline Meeting Often** & 0.75 & 0.17 & 0.20 & 0.00 \\
\hline
\end{tabular}

$\mathrm{R}^{2}=0.23, \mathrm{~F}=15.23, \mathrm{p}<0.001$ 
FACILITATING MASTER'S STUDENT SUCCESS

Results of regression analysis with student characteristics predicting student satisfaction with faculty collaboration

\begin{tabular}{|l|l|l|l|l|}
\hline Model & B & Std. Error & Beta & Sig. \\
\hline (Constant) & 2.06 & 0.42 & & 0.00 \\
\hline Female & 0.17 & 0.18 & 0.04 & 0.35 \\
\hline Minority & 0.18 & 0.22 & 0.04 & 0.41 \\
\hline Age & 0.01 & 0.01 & 0.05 & 0.26 \\
\hline Part-time & -0.27 & 0.21 & -0.06 & 0.19 \\
\hline Cohort & 0.08 & 0.17 & 0.02 & 0.63 \\
\hline Thesis & 0.43 & 0.22 & 0.09 & 0.06 \\
\hline Mentored** & 1.03 & 0.18 & 0.29 & 0.00 \\
\hline Multiple Faculty & 0.15 & 0.18 & 0.04 & 0.41 \\
\hline Meeting Often & 0.33 & 0.19 & 0.09 & 0.08 \\
\hline
\end{tabular}

$\mathrm{R}^{2}=0.16, \mathrm{~F}=8.72, \mathrm{p}<0.001$ 
FACILITATING MASTER'S STUDENT SUCCESS

Results of regression analysis with student characteristics predicting student satisfaction with faculty help with networking

\begin{tabular}{|l|l|l|l|l|}
\hline Model & B & Std. Error & Beta & Sig. \\
\hline Constant $)$ & 2.26 & 0.39 & & 0.00 \\
\hline Female & 0.03 & 0.17 & 0.01 & 0.86 \\
\hline Minority & 0.21 & 0.21 & 0.04 & 0.32 \\
\hline Age & 0.01 & 0.01 & 0.03 & 0.57 \\
\hline Part-time & -0.10 & 0.19 & -0.02 & 0.59 \\
\hline Cohort & 0.00 & 0.16 & 0.00 & 0.98 \\
\hline Thesis & 0.12 & 0.21 & 0.03 & 0.58 \\
\hline Mentored** & 0.91 & 0.17 & 0.26 & 0.00 \\
\hline Multiple Faculty & 0.28 & 0.17 & 0.07 & 0.11 \\
\hline Meeting Often* & 0.48 & 0.18 & 0.13 & 0.01 \\
\hline
\end{tabular}

$\mathrm{R}^{2}=0.14, \mathrm{~F}=8.42, \mathrm{p}<0.001$ 
Results of regression analysis with student characteristics predicting student satisfaction with faculty help with referral to academic support

\begin{tabular}{|l|l|l|l|l|}
\hline Model & B & Std. Error & Beta & Sig. \\
\hline (Constant) & 2.47 & 0.42 & & 0.00 \\
\hline Female & 0.06 & 0.18 & 0.02 & 0.76 \\
\hline Minority & $0.45^{*}$ & 0.21 & 0.11 & 0.03 \\
\hline Age & 0.01 & 0.01 & 0.04 & 0.48 \\
\hline Part-time & 0.24 & 0.21 & 0.06 & 0.25 \\
\hline Cohort & -0.21 & 0.17 & -0.06 & 0.23 \\
\hline Thesis & -0.07 & 0.24 & -0.01 & 0.78 \\
\hline Mentored & $0.77^{* *}$ & 0.18 & 0.24 & 0.00 \\
\hline Multiple Faculty & $0.57^{* *}$ & 0.19 & 0.17 & 0.00 \\
\hline Meeting Often & $0.37^{*}$ & 0.19 & 0.11 & 0.05 \\
\hline
\end{tabular}

$\mathrm{R}^{2}=0.14, \mathrm{~F}=6.34, \mathrm{p}<0.001$ 
Results of regression analysis with student characteristics predicting student satisfaction with faculty help with referral to non-academic support

\begin{tabular}{|l|l|l|l|l|}
\hline Model & B & Std. Error & Beta & Sig. \\
\hline (Constant) & 1.98 & 0.44 & & 0.00 \\
\hline Female & -0.01 & 0.20 & 0.00 & 0.96 \\
\hline Minority & 0.37 & 0.23 & 0.09 & 0.10 \\
\hline Age & 0.01 & 0.01 & 0.06 & 0.27 \\
\hline Part-time & 0.07 & 0.22 & 0.02 & 0.75 \\
\hline Cohort & 0.02 & 0.19 & 0.00 & 0.94 \\
\hline Thesis & 0.12 & 0.26 & 0.03 & 0.64 \\
\hline Mentored** & 0.65 & 0.20 & 0.20 & 0.00 \\
\hline Multiple Faculty** & 0.62 & 0.20 & 0.18 & 0.00 \\
\hline Meeting Often* & 0.38 & 0.19 & 0.12 & 0.05 \\
\hline
\end{tabular}

$\mathrm{R}^{2}=0.15, \mathrm{~F}=5.74, \mathrm{p}<0.001$ 
Results of regression analysis with student characteristics predicting student satisfaction with faculty help with identifying funding

\begin{tabular}{|l|l|l|l|l|}
\hline Model & B & Std. Error & Beta & Sig. \\
\hline (Constant) & 2.09 & 0.39 & & 0.00 \\
\hline Female & 0.06 & 0.17 & 0.02 & 0.72 \\
\hline Minority & 0.26 & 0.21 & 0.05 & 0.22 \\
\hline Age & 0.01 & 0.01 & 0.04 & 0.42 \\
\hline Part-time & 0.12 & 0.19 & 0.03 & 0.54 \\
\hline Cohort & 0.02 & 0.16 & 0.01 & 0.88 \\
\hline Thesis* & 0.53 & 0.21 & 0.12 & 0.01 \\
\hline Mentored** & 0.88 & 0.17 & 0.25 & 0.00 \\
\hline Multiple Faculty & 0.29 & 0.17 & 0.08 & 0.10 \\
\hline Meeting Often** & 0.62 & 0.18 & 0.17 & 0.00 \\
\hline
\end{tabular}

$\mathrm{R}^{2}=0.17, \mathrm{~F}=10.09, \mathrm{p}<0.001$ 
Results of regression analysis with student characteristics predicting student satisfaction with faculty encouragement on thesis

\begin{tabular}{|l|l|l|l|l|}
\hline Model & B & Std. Error & Beta & Sig. \\
\hline Constant $)$ & 3.30 & 0.86 & & 0.00 \\
\hline Female & -0.10 & 0.29 & -0.03 & 0.73 \\
\hline Minority & 0.28 & 0.39 & 0.07 & 0.47 \\
\hline Age & 0.00 & 0.02 & -0.01 & 0.89 \\
\hline Part-time & -0.23 & 0.36 & -0.07 & 0.51 \\
\hline Cohort & 0.20 & 0.29 & 0.06 & 0.50 \\
\hline Mentored & $1.37 *$ & 0.34 & 0.40 & 0.00 \\
\hline Multiple Faculty & -0.28 & 0.37 & -0.07 & 0.44 \\
\hline Meeting Often & 0.60 & 0.49 & 0.12 & 0.23 \\
\hline
\end{tabular}

$\mathrm{R}^{2}=0.19, \mathrm{~F}=3.0, \mathrm{p}<0.05$ 
Results of regression analysis with student characteristics predicting student satisfaction with faculty knowing student as an individual

\begin{tabular}{|l|l|l|l|l|}
\hline Model & B & Std. Error & Beta & Sig. \\
\hline (Constant) & 2.36 & 0.34 & & 0.00 \\
\hline Female & -0.07 & 0.15 & -0.02 & 0.66 \\
\hline Minority & 0.17 & 0.19 & 0.03 & 0.37 \\
\hline Age & 0.02 & 0.01 & 0.08 & 0.06 \\
\hline Part-time & -0.06 & 0.17 & -0.01 & 0.72 \\
\hline Cohort & 0.17 & 0.14 & 0.05 & 0.24 \\
\hline Thesis & 0.16 & 0.19 & 0.03 & 0.41 \\
\hline Mentored** & 0.99 & 0.15 & 0.28 & 0.00 \\
\hline Multiple Faculty* & 0.42 & 0.15 & 0.11 & 0.01 \\
\hline Meeting Often** & 0.57 & 0.16 & 0.15 & 0.00 \\
\hline
\end{tabular}

$\mathrm{R}^{2}=0.19, \mathrm{~F}=13.91, \mathrm{p}<0.001$ 
FACILITATING MASTER'S STUDENT SUCCESS

Results of regression analysis with student characteristics predicting student satisfaction with faculty care about student academic progress

\begin{tabular}{|l|l|l|l|l|}
\hline Model & B & Std. Error & Beta & Sig. \\
\hline (Constant) & 2.60 & 0.34 & & 0.00 \\
\hline Female & -0.07 & 0.15 & -0.02 & 0.64 \\
\hline Minority & 0.12 & 0.19 & 0.02 & 0.53 \\
\hline Age & 0.01 & 0.01 & 0.05 & 0.21 \\
\hline Part-time & -0.05 & 0.17 & -0.01 & 0.78 \\
\hline Cohort & 0.18 & 0.14 & 0.05 & 0.20 \\
\hline Thesis & 0.06 & 0.19 & 0.01 & 0.75 \\
\hline Mentored** & 0.99 & 0.15 & 0.28 & 0.00 \\
\hline Multiple Faculty** & 0.56 & 0.15 & 0.15 & 0.00 \\
\hline Meeting Often** & 0.65 & 0.16 & 0.17 & 0.00 \\
\hline
\end{tabular}

$\mathrm{R}^{2}=0.21, \mathrm{~F}=15.77, \mathrm{p}<0.001$ 